\title{
GRID-SCALE ENERGY STORAGE: A PROPOSED CONTROL ALGORITHM FOR SODIUM SULFUR BATTERIES
}

\author{
A Thesis \\ Presented to \\ the Faculty of California Polytechnic State University, \\ San Luis Obispo
}

In Partial Fulfillment

of the Requirements for the Degree

Master of Science in Electrical Engineering

by

Daniel Spaizman

July 2014 
(C) 2014

Daniel Spaizman

ALL RIGHTS RESERVED

Page | ii 


\section{COMMITTEE MEMBERSHIP}

TITLE:

Grid-Scale Energy Storage: A Proposed Control Algorithm for Sodium-Sulfur Batteries
AUTHOR:
Daniel Spaizman
DATE SUBMITTED: July 2014
COMMITTE CHAIR: Dale Dolan, PhD
Assistant Professor of Electrical Engineering

COMMITTEE MEMBER: Taufik, PhD

Professor of Electrical Engineering

COMMITTEE MEMBER: Ali Shaban, $\mathrm{PhD}$

Professor of Electrical Engineering 


\begin{abstract}
Grid-Scale Energy Storage: A Proposed Control Algorithm for Sodium-Sulfur Batteries Daniel Spaizman

With carbon dioxide levels in our atmosphere reaching record highs and 2020 quickly approaching, California is expected to pave the way for the United States in terms of replacing fossil fuel generation facilities with various renewable energy power plants. It is well documented that the inherent variability and limited duty cycle of renewables has hindered their growth. Energy storage technologies represent the bridge that can help us cross the divide from where we stand to where we must stand in the next 6 years. Utility companies value services such as peak shaving, voltage support, and frequency regulation, all of which energy storage technologies can provide. Commercial and residential clients' of the utility will begin to install their own storage systems once properly incentivized. In this paper, a control algorithm for Sodium Sulfur batteries is proposed with hopes that the aforementioned services will be provided to the utilities while system owners realize profit.
\end{abstract}




\section{ACKNOWLEDGMENTS}

I would first like to thank my parents, grandparents and friends. The unyielding support that I have had has allowed me to experience the success and quality of life I desire. They are always in my thoughts and are my motivation to use my education to better the world we live in.

Next, I would like to acknowledge Jon Eric Thalman and the rest of PG\&E for supporting me throughout this process. The opportunity to work on a real-life problem and develop potential solutions is exactly what I was hoping to get out of my thesis project. Having access to their Vacaville-Dixon and Yerba Buena Sodium Sulfur Battery facilities has elevated my knowledge of energy storage systems further than I could have imagined before this project began.

Lastly, I would like to thank my thesis committee. Dr. Dolan, Dr. Taufik, and Dr. Shaban have taught me so much this year about power systems and electronics. As a desire to spend my career in the renewable energy sector, having this knowledge is invaluable. Their patience, selflessness, and commitment have not gone without notice. 


\section{TABLE OF CONTENTS}

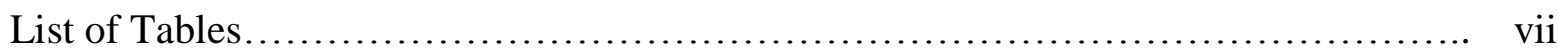

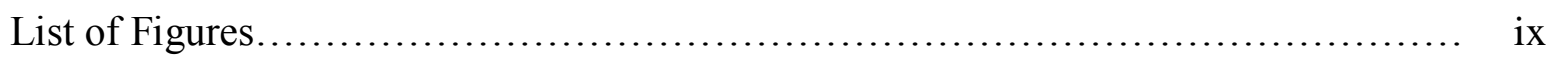

List of Abbreviations and Acronyms.......................................... xi

Chapter 1 - The Electric Grid............................................... 1

Section 1.1: Load Shifting and Peak Shaving............................. 3

Section 1.2: Voltage Support........................................ 4

Section 1.3: Integration of Variable Energy Resources..................... 6

Section 1.4: Frequency Regulation.................................... 7

Section 1.5: Smart Grid Interaction..................................... 10

Section 1.6: Requirements for Energy Storage............................. 10

Section 1.7: Types of Energy Storage................................. 13

Pumped-Storage Hydro......................................... 14

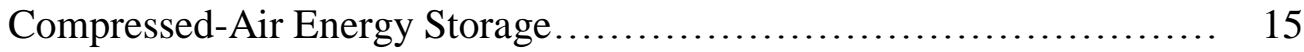

Flywheels.................................................... 17

Sodium Sulfur Batteries......................................... 18

Supercapacitors.............................................. 20

Molten Salt................................................. 22

Section 1.8: Analysis of Presented Storage Systems........................ 23

Chapter 2 - Literature Review ............................................. 31

Section 2.1: Vaca-Dixon Testing Strategies and Results.................... 31

Section 2.2: Meisei University Testing and Results........................ 42

Chapter 3 - Simulation and Implementation of Charging and Discharging Algorithm.... 56

Section 3.1: Initial Algorithm Development............................ 56

Section 3.2: Data and Analysis of First Algorithm......................... 58

Section 3.3: Assessing Performance of First Algorithm..................... 69

Section 3.4: Suggestions for an Improved Algorithm....................... 79

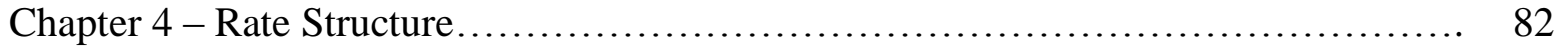

Section 4.1: Rate Structures for Commercial Clients........................ 82

Section 4.2: Rate Structures for Residential Clients......................... 85

Chapter 5 - Conclusion................................................ 89

References.......................................................... 92

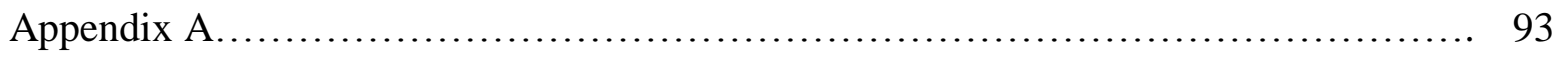




\section{LIST OF TABLES}

Table

Page

2.1.1 Vaca-Dixon 2 MW Efficiencies with Idle Time......... 32

2.1.2 Vaca-Dixon 1.75 MW Efficiencies with Idle Time..... 32

2.1.3 Vaca-Dixon 1.5 MW Efficiencies with Idle Time...... 34

2.1.4 Vaca-Dixon 1.25 MW Efficiencies with Idle Time...... 35

2.1.5 Vaca-Dixon Minimum SOCs for Trial with Idle Time... 36

2.1.6 Vaca-Dixon 2 MW Efficiencies no Idle Time.......... 37

2.1.7 Vaca-Dixon 1.75 MW Efficiencies no Idle Time........ 37

2.1.8 Vaca-Dixon 1.5 MW Efficiencies no Idle Time......... 38

2.1.9 Vaca-Dixon 1.25 MW Efficiencies no Idle Time........ 38

2.1.10 Vaca-Dixon 1 MW Efficiencies no Idle Time.......... 38

2.1.11 Vaca-Dixon 0.75 MW Efficiencies no Idle Time....... 38

2.1.12 Vaca-Dixon 0.5 MW Efficiencies no Idle Time........ 38

2.1.13 Vaca-Dixon Minimum SOCs for Trial no Idle Time... 39

2.1.14 Vaca-Dixon Efficiency Difference $\ldots \ldots \ldots \ldots \ldots \ldots \ldots . . \ldots$

2.2.1 Meisei University Weights for Equation 2.2.2........ 47

2.2.2 Meisei University Temperature Coefficients.......... 48

3.2.1 Season Dates and Temperature Sensitivities........... 60

3.2.2 Weight Coefficients Used in Algorithm.............. 61

$\begin{array}{lll}\text { 3.3.1 Simple and Load-Following Discharge Profile Profits. } & \text { S7 }\end{array}$

4.1.1 Commercial Time of Production Schedule ............. 84

4.1.2 Commercial Tier Rate Structure................... 85

4.2.1 Residential Time of Use Schedule................... 85 
4.2 .2

Residential Tier Rate Structure.......................

Page | viii 


\section{LIST OF FIGURES}

Figure Page

1.1.1 Basic Structure of the Electric System................. 1

1.4.1 Frequency Response in the Electric System............ 9

1.4.2 Services Provided in the Electric System................ 9

1.7.1 Pumped-Storage Hydro System.................... 15

1.7.2 Compressed Air Energy System.................... 16

1.7.3 Flywheel Storage System......................... 18

1.7.4 Sodium Sulfur Battery Energy Storage System.......... 20

1.7.5 Supercapacitor Energy Storage Pack................. 21

1.7.6 Molten Salt Storage System...................... 23

1.8.1 Power or Energy Application Classification............. 24

1.8.2 Storage Systems: Energy and Volume Density.......... 25

1.8.3 Storage Systems: Discharge Time and Rated Power..... 26

1.8.4 Storage Systems: Capital Cost per Energy and Power..... 27

1.8.5 Storage Systems: Capital Cost and Lifetime............ 28

1.8.6 Storage Systems: Primary Application and Challenges... 29

2.1.1 Vaca-Dixon 2 MW Efficiencies with Idle Time.......... 33

2.1.2 Vaca-Dixon 1.75 MW Efficiencies with Idle Time....... 34

2.1.3 Vaca-Dixon 1.5 MW Efficiencies with Idle Time........ 35

2.1.4 Vaca-Dixon 1.25 MW Efficiencies with Idle Time....... 36

2.1.5 Vaca-Dixon Efficiencies no Idle Time.................. 40

2.1.6 Vaca-Dixon 6 Hour Discharge no Idle Time............ 41 
2.2.1 Meisei University Power Curves from Sample Data..... 43

2.2.2 Meisei University Energy and Efficiency Curves........ 44

2.2.3 Meisei University Air Temp and Power Correlation..... 45

2.2.4 Meisei University Power Demand vs Temperature...... 48

2.2.5 Meisei University Load Following Algorithm Flowchart. $\quad 49$

2.2.6 Meisei University Predicted Power and Error............ 51

2.2.7 Meisei University Light Load Power Curves............ 52

2.2.8 Meisei University Heavy Load Power Curves............ 53

2.2.9 Meisei University Algorithm Performance.............. 55

3.2.1 Finding Temperature Sensitivity for San Jose, CA..... 59

3.2.2 Temperature Sensitivity for San Jose, CA................... 60

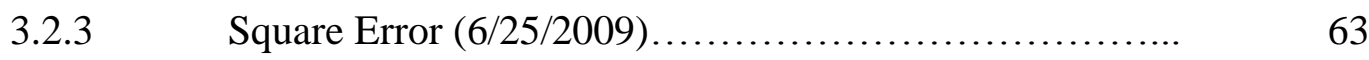

3.2.4 Square Error $(6 / 27 / 2009) \ldots \ldots \ldots \ldots \ldots \ldots \ldots \ldots \ldots \ldots \ldots \ldots \ldots$

3.2.5 Proposed Control Algorithm Flowchart................. 68

3.3.1 Simple 7 Hour Discharge Profile.................... 70

3.3.2 Simple 7 Hour Discharge Profile with Area............. 71

S.3.3 Simple 14 Hour Discharge Profile................... 72

3.3.4 Simple 14 Hour Discharge Profile with Area............ 73

3.3.5 Simple 7 Hour Discharge Profile (1/23/2010) ........... 74

3.3.6 Simple 14 Hour Discharge Profile (1/23/2010) .......... 75

3.3.7 Load Following Profile (1/23/2010) Hitachi............. 77

3.3.8 Load Following Profile (6/24/2014) Transformer........ 78

4.1.1 Solar Power Integrated with Battery Storage Technology $\quad 84$ 


\section{LIST OF ABBREVIATIONS AND ACRONYMS}

Contracted Term

$\mathrm{kW}$

MW

GW

ISO

PSH

CAES

$\mathrm{NaS}$

Li-ion

$\Delta \mathrm{U}_{\text {gravitational }}$

$\mathrm{R}$

BESS

SOC

PPA
Full Term

Kilowatt

Megawatt

Gigawatt

Independent System Operator

Pumped-Storage Hydro

Compressed-Air Energy Storage

Gravitational Potential Energy

Ideal Gas Constant

Battery Energy Storage System

State Of Charge

Power Purchasing Agreement
Definition [units]

$1 \times 10^{3}$ watts

$1 \times 10^{6}$ watts

$1 \times 10^{9}$ watts
Sodium-Sulfur

Lithium-Ion

[joules]

$8.31\left[\frac{\text { joules }}{\mathrm{mol} \mathrm{x} \mathrm{K}}\right]$
Percentage of Rated Energy Remaining

Contract between producer and consumer for transfer of power 


\section{Chapter 1 -- The Electric Grid}

As consumers of energy, most of us give little thought as to how energy is provided to us. We all know that we pay energy bills to our utility company, but beside that, the rest is a mystery. In this section of this paper, the process, from beginning to end, of how energy is generated and provided to end users is described. From that point, a discussion of shortcomings of this process is presented and an investigation of methods which address those same problems is conducted.

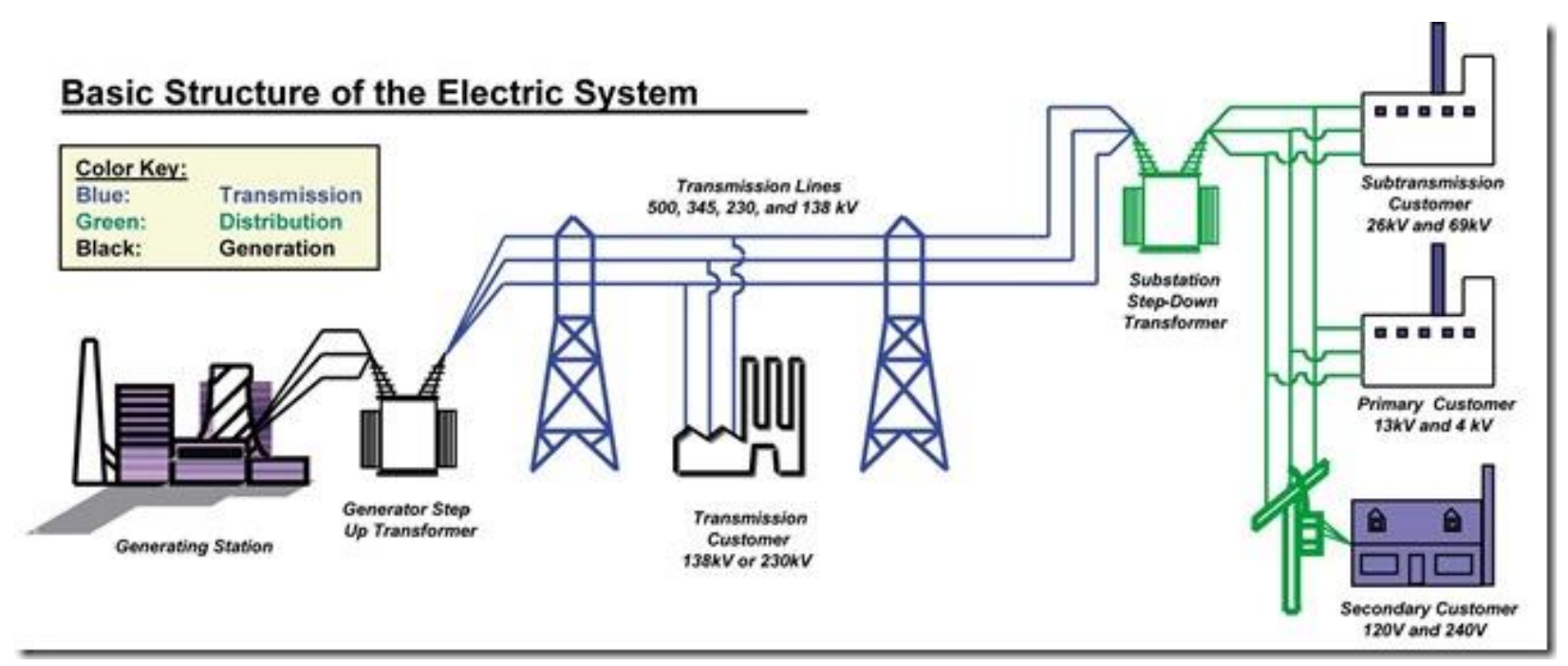

Figure 1.1.1: Basic Structure of the Electric System.

Energy cannot be created nor destroyed, so to produce electrical energy, we must convert another form of energy into electrical energy. This is the process that occurs at a power plant or a generating station as seen on the far left in Figure 1.1.1 [1]. Common power plant input sources are coal, oil, natural gas, solar radiation, and wind. Most non-renewable power plants use combustion in order to create heat energy. The resulting heat energy spins a turbine creating mechanical energy. Finally, this mechanical energy is used to spin the rotor of a generator which outputs electrical energy. Outside of the generation facility, the electrical energy travels through 
transformers to step up the voltage (and step down the current), which reduces line losses by the following:

$$
\mathrm{P}_{\text {Line }}=3 \mathrm{I}^{2} \mathrm{R}_{\text {Line }}[\mathrm{W}]
$$

where $\mathrm{I}$ is the rms line current and $\mathrm{R}_{\mathrm{Line}}$ is the internal resistance of the line. This phase where power is transmitted at high-voltage levels (hundreds of kilovolts) is called transmission. Customers that require transmission voltage levels are called transformer customers and are represented in the middle of Figure 1.1.1. After being transmitted over long distances, transmission lines feed step-down transformers (which lower the voltage and raise the current) and join a network of shorter lines called distribution lines. The step-down transformer can be seen in the right-hand portion of Figure 1.1.1. The line voltage at this point in our energy transmission process ranges from around a few hundred to one-thousand volts. Companies with warehouses are an example of a customer who would consume power at the upper end of this voltage range. On the other hand, homes have few appliances that require voltage levels above $120-240 \mathrm{~V}_{\text {rms }}$. The challenge in this process is minimizing the mismatch in energy demanded and energy produced.

Energy demand changes on a second to second basis. Every time we flip a switch, the local load is different than it was right before. It is in the utilities best interest to try and purchase the same amount of energy that is to be used by consumers so that energy does not go to waste. In order to do this, daily demand from previous years is analyzed to predict how much energy will be needed in an advance. Unfortunately, these predictions are not perfect, which leads to a few possible situations. In the case where there is not enough energy to meet actual 
demand, utilities either ask power plants which are already on-line to ramp up production, or they turn to peaker plants and ask them to start providing power to the grid. Ramping up production at plants that are typical power providers is the cheaper option, but the machinery is much more efficient when running at rated load rather than increasing and decreasing load. Peaker plants are generally natural gas turbine plants designed to provide huge amounts of power. The problem with peaker plants is that they are extremely inefficient compared to the plants that provide power to the grid on a daily basis. This is because they are meant to get online quickly and meet demand. As we can see, each scenario has its weakness. Now, it is critical to analyze the case where there is more energy than demand. Ideally, electrical energy that has been produced, yet unconsumed, should be stored until it is needed at a later time. Energy storage technology does exist in today's world, but not on a very large scale. Because of the numerous benefits that can be realized from implementing grid-scale energy storage, it seems the expansion of this technology is near. The aforementioned benefits that are focused on are: load shifting and peak shaving, voltage support, integration of variable energy resources, frequency regulation, and demand management with smart grid technology interaction.

\section{Section 1.1: Load Shifting and Peak Shaving}

Load shifting and peak shaving are potentially the most beneficial aspect of energy storage. As mentioned earlier, when generated energy does not match energy demanded, problems arise. Those problems can take the form of stress on generation machinery or inefficient energy usage. By storing energy when an excess is generated and providing energy when there is a shortage, power providers can produce at a constant output without the fear of mismatching demand. This reallocation of demand is where the title "load shifting" comes from. Typically, load during nighttime hours is only a fraction of what it is during the day. This makes 
nighttime an ideal time to charge. On the other hand, load is greatest in the mornings and late afternoons. This is where energy storage can help power the grid and reduce energy needed from power plants to provide appropriate supply to consumers, hence the name "peak shaving." When dealing with copious amounts of energy, maintaining high efficiency is crucial, economically and environmentally. Efficiency of the system is reduced when there is a high load factor. Load factor is defined as:

$$
\text { Load factor }=\frac{\text { Peak Demand }}{\text { Average Demand }} \text { [unitless] }
$$

Load factor is important because it gives an idea of how far a given group of consumers is from using a constant amount of energy. The farther this number is from one, the more likely the help of peaker plants will be needed to satisfy demand. Ideally, this number would be one and the forecasted average demand would equal the actual average demand, maximizing the electric system efficiency.

\section{Section 1.2: Voltage Support}

One of the benefits provided by energy storage systems on a grid-scale is voltage support. In introductory circuit classes, it is taught that wires are perfect conductors, meaning there is no resistance in the wire, hence no voltage lost or power absorbed by the line. In reality, conductors do have a non-zero resistance. That value is given by:

$$
\mathrm{R}_{\text {Line }}=\frac{\rho \mathrm{l}}{\mathrm{A}_{\text {Line }}}[\mathrm{Ohms}]
$$


where $\rho$ is the resistivity of the material in ohm-meters, 1 is the length of the line in meters, and $\mathrm{A}_{\text {Line }}$ is the cross-sectional area of the line in meters squared. In addition to this resistance, aluminum conductors (most popular lines to transmit energy in the grid) have both inductance and capacitance which change based on the strand and bundle configuration. These together form a line reactance. The total impedance of the line is:

$$
\mathrm{Z}_{\text {Line }}=\mathrm{R}_{\text {Line }}+\mathrm{j} \mathrm{X}_{\text {Line }}=\left|\mathrm{Z}_{\text {Line }}\right|<\left[\tan ^{-1}\left(\mathrm{X}_{\text {Line }} / \mathrm{R}_{\text {Line }}\right)\right]^{\circ}
$$

Because this internal impedance in the line exists, there is a voltage drop along the line:

$$
\mathrm{V}_{\text {Line }}=\mathrm{I}_{\mathrm{L}} \mathrm{Z}_{\text {Line }}
$$

where $\mathrm{I}_{\mathrm{L}}$ is the current in the line. This indicates that a given node is not actually an equipotential and line voltage decreases with distance from the source. Customers who receive service at the end of a distribution line, therefore, are provided with voltages lower than the typical $120 \mathrm{~V}_{\mathrm{rms}}$ when the load breaks a certain threshold. A possible consequence of this is inadequate power quality. Consumers may experience difficulty powering their load because the line voltage is lower than the rated load voltage. Inadequate power quality means unhappy customers, reflecting poorly on the power provider. Placing an additional voltage source on the line can solve this problem. Grid-scale energy storage makes adding a voltage source possible. Specifically, sources which can be placed directly next to the line for quick response time make ideal candidates. One such source is a battery, which can combat the line voltage fluctuations that are a function of the load. Regardless of the source, it makes sense to charge when demand 
is low, since line voltage rises above its rating, and discharge when there is a large load, since line voltage drops. This would, ideally, keep the line at (nearly) a constant voltage at all times.

\section{Section 1.3: Integration of Variable Energy Resources}

Some grid-scale storage solutions, such as batteries are classified as uninterruptible power sources. This means, even when generated power is insufficient to match demand, power can still be provided continuously by way of a reliable additional source. In addition to being uninterruptable, the output of a battery can be programmed at the will of the operator. This is an extremely valuable trait when it comes to integrating variable energy resources into the grid. One of the biggest areas of concern in our world today is limiting greenhouse gas emissions and preventing severe climate change. In attempts to do so, much emphasis has been placed on introducing clean energy generation in place of coal, petroleum and natural gas power. In the recent past, photovoltaics (PV) and wind power have emerged as the most prominent and promising forms of renewable energy. One of the, if not the, biggest concern with them is their inability to generate constant power. Unfortunately, this is an inherent property of these methods, as they utilize solar radiation, which is only available for a portion of the day, and wind, which does not flow at a steady rate. That being said, if the potential of these clean sources is to be realized, this variability must be addressed. Energy storage systems possess the necessary qualities to enable the full integration of variable energy sources due to their ability to charge without needing steady current flow and discharge at a rate determined by the operator. This solution, of sending excess energy generated by renewable sources into grid-scale storage, 
reduces losses associated with inverter clipping ${ }^{1}$ and prevents a shortage of energy production during diffuse sky or low wind-speed conditions.

\section{Section 1.4: Frequency Regulation}

Similar to line voltage, grid frequency changes as a function of generation and load. In some parts of Japan, as well as here in America, the grid operates at $60 \mathrm{~Hz}$ frequency. Around the globe, other electric systems run at $50 \mathrm{~Hz}$. Maintaining this frequency is crucial for power reliability and system safety. When the frequency of the grid deviates more than the measured threshold, likelihood of damaging electrical equipment increases greatly. For this reason, system frequency is monitored by control systems that are designed to make the appropriate changes to maintain the proper number of voltage cycles per second. Generally these changes include altering the number of available generators or fluctuating the load. Response time is an important parameter to consider when attempting to increase or decrease system frequency. As mentioned before, either supply or load can be altered to achieve the desired end. Generators are machines that include stators and rotors, meaning that inertia becomes a factor in start-up or shut-down time. Because the generators capability to move online or offline is limited by inertia, they have a large response time (compared other potential frequency correcting options), making them a second choice in terms of solutions [2]. A faster way of responding to a change in frequency is load fluctuation. If the load is too large, frequency drops and control circuits respond by shedding load. Until frequency is regulated, the load can remain at that reduced level, while waiting for additional generators to come online. As the additional power is added to the grid, the load can then be returned to its nominal level.

\footnotetext{
${ }^{1}$ Inverter clipping is the process of purposely overloading the inverters (DC : AC ratio $>1$ ) so that constant output is achieved for a greater portion of the day. As stated in name, power is clipped (wasted) to get this output, rather than storing it for later use).
} 
The one obvious problem with this method is: reducing load equates to less power provided to customers. Leaving consumers with inadequate power reflects poorly on utilities, leaving them looking for a better solutions than shedding load in an attempt to regulate frequency. If we look to grid-scale storage as a possible solution to frequency regulation, we find that pumped storage hydro is relatively slow to come online, flywheels have the same inertia problem, and supercapacitors are not energy dense. Batteries, on the other hand, respond as quickly as supercapacitors and have an energy density on the order of pumped storage hydro. Batteries do not possess the inherent restriction of moving mechanical parts, removing the inertial aspect which changes response time. Because of this, batteries represent a suitable replacement power source, which can either greatly reduce or eliminate the method of load shedding. Figure 1.4.1 shows a visual of the stages of grid frequency correction. In a report by Oak Ridge National Laboratory, intended for the United States Department of Energy, voltage and frequency regulation was classified as an ancillary service. Ancillary services are "functions performed by the equipment and people that generate, control, and transmit electricity in support of the basic services of generating capacity, energy supply, and power delivery" [3]. Figure 1.4.2 provides a broad outlook on where ancillary services fit into the power market. 

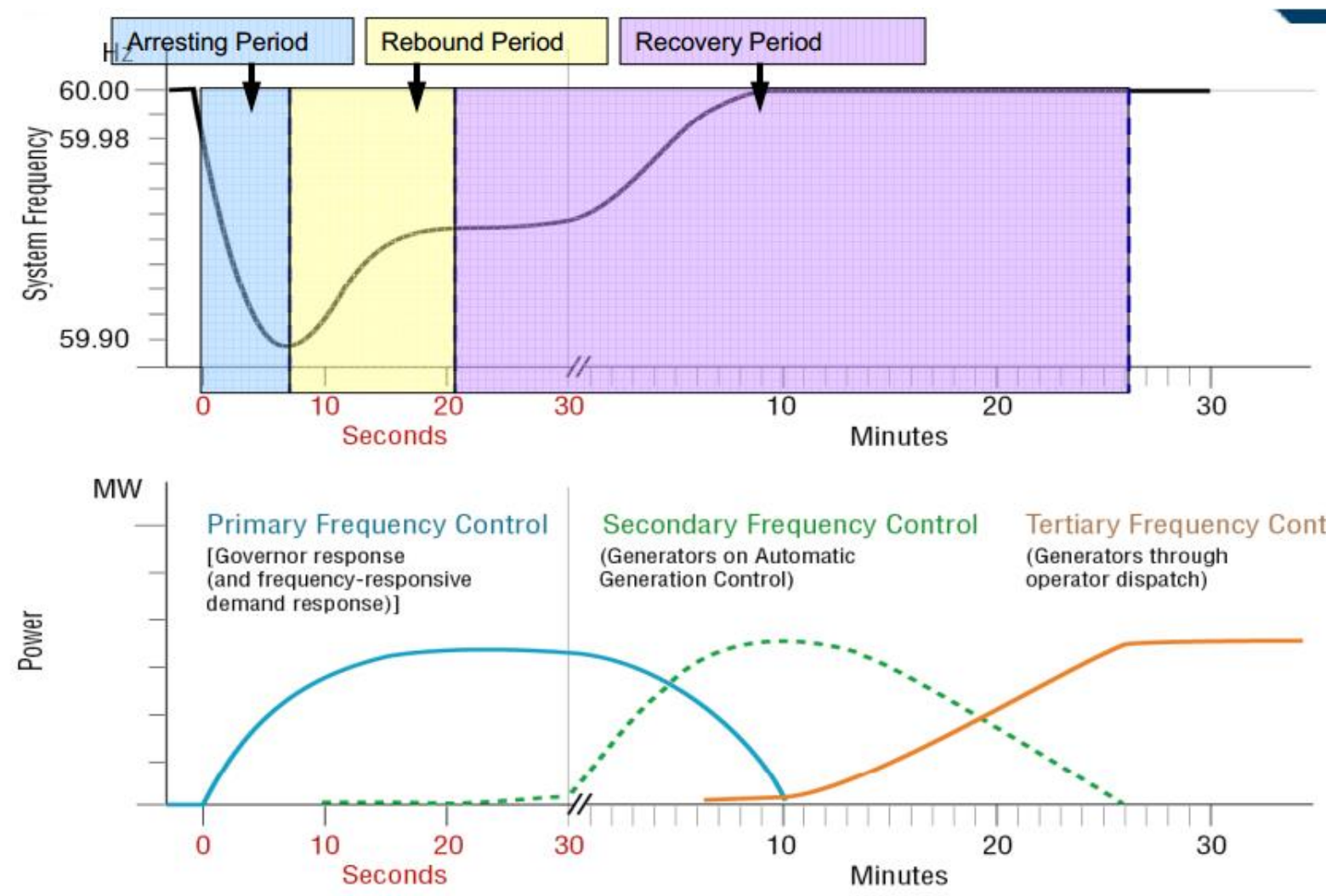

Figure 1.4.1: Frequency Response in the Electric System.

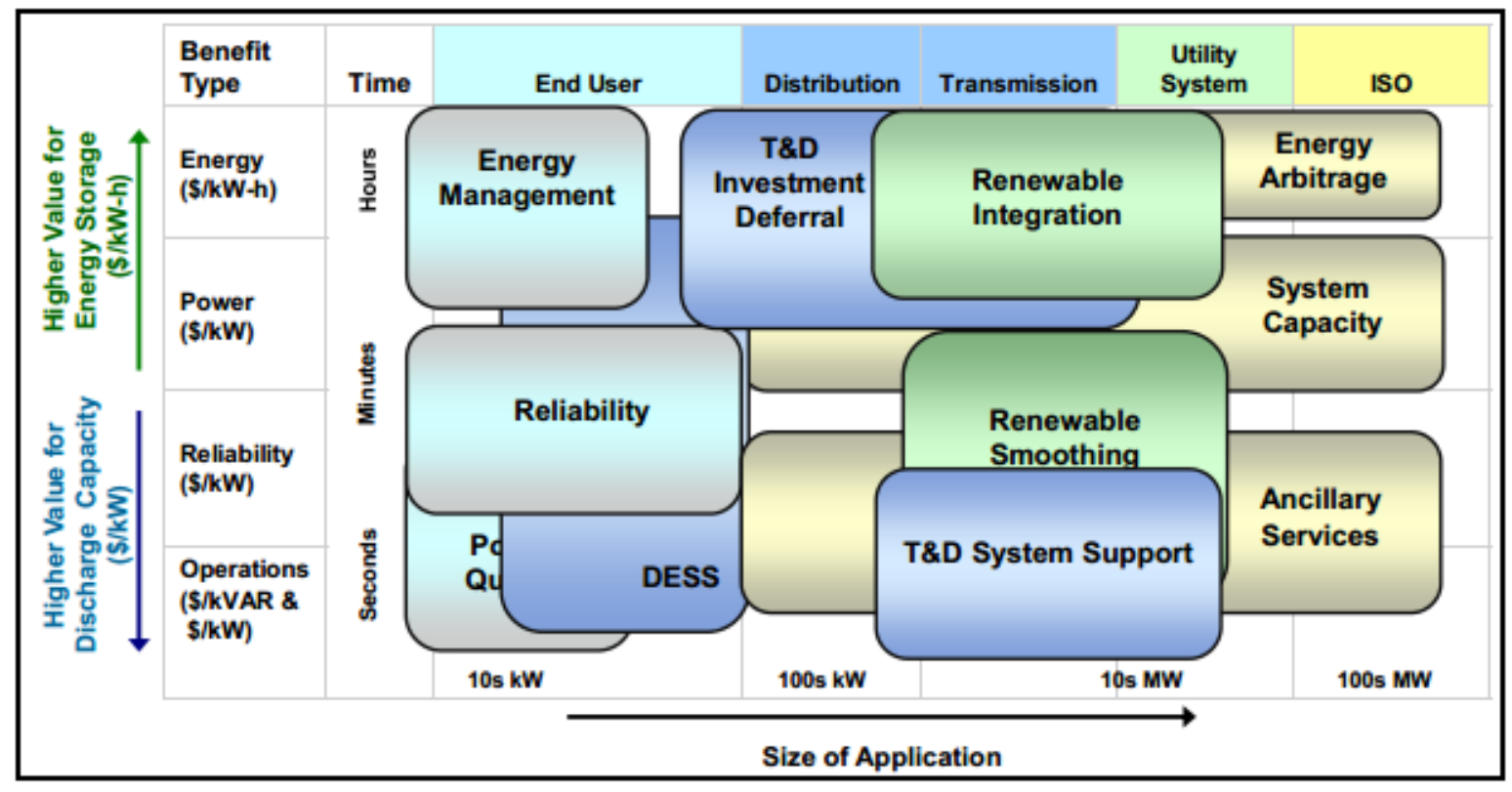

Figure 1.4.2: Services Provided in the Electric System. 


\section{Section 1.5: Smart Grid Interaction}

Since smart appliances hit the market, power hungry devices (freezers, refrigerators, washing machines and dryers) have had monitoring systems built into them in order to control their power draw as time varies. This is different than non-"smart" appliances in that power draw is not only determined by the function of the appliance itself, but by the activity, at a given time, in the electric grid. As discussed in the frequency regulation portion of this section, load shedding is employed when the grid is under too great of stress. With the support from batteries in situations where voltage or frequency shifts occur, load shedding should be reduced, but this does not mean that smart grid technology should become obsolete. In fact, the integration of grid-scale energy would be incomplete without it. In order for the storage systems to efficiently deliver energy and provide the desired services, smart grid technology must be heavily relied upon. When local load exceeds supply, control circuits will relay the message to the storage, where the system can begin to feed the grid lines. When the system reaches its minimum SOC, the system will alert the controls to cause an open between the grid and system, until a later time which the system can be charged. Conversely, when an excess of energy has been generated, the same control circuits can control power flow into the storage system to be held for later use. The more communication between appliances, users, and utilities, the more energy can be saved, and as a result, pollution and money as well.

\section{Section 1.6: Requirements for Energy Storage}

The goal of implementing grid-scale energy is to improve the electric system with the intent to reduce green-house gas emissions and increase financial efficiency. If the shortcomings of the electric grid are to be corrected, grid-scale energy systems should possess certain 
traits. The most desirable characteristics include: high energy density, high power density, high cycle efficiency, high cycling capability, long operating lifetime, low capital cost, and low marginal cost. Energy density is defined as:

$$
\text { Energy Density }=\frac{\text { Energy Stored in Element }}{\text { Volume of Element }}=\left[\frac{\text { Joules }}{\text { Liter }}\right]
$$

This is similar to, but different from, specific energy. Specific energy is defined as:

$$
\text { Specific Energy }=\frac{\text { Energy Stored in Element }}{\text { Mass of Element }}=\left[\frac{\text { Joules }}{\mathrm{kg}}\right]
$$

In many situations, both characteristics are important to consider when deciding what energy storage solution to choose. For example, in electric vehicles, it is ideal to have energy sources which are very light and have a large storage capacity in a small volume. For grid-scale energy storage, the specific energy is not as important, since the energy source will be stationary. On the contrary, the volume (and therefore energy density) of the storage element is extremely important. Land is a very expensive commodity and to maximize electric energy conversion efficiency, the element need be as close to the existing distribution lines as possible. The most impactful storage solutions will be ones with large amounts of energy per unit volume. As with energy density, power density, given by:

$$
\text { Power Density }=\frac{\text { Energy Stored in Element } / \text { Time }}{\text { Volume of Element }}=\left[\frac{\text { Watts }}{\text { Liter }}\right]
$$


is more important than specific power, which is defined as:

$$
\text { Specific Power }=\frac{\text { Energy Stored in Element/Time }}{\text { Mass of Element }}=\left[\frac{\text { Watts }}{\mathrm{kg}}\right]
$$

The next desirable traits are high cycle efficiency and high cycling capability. Because storage systems would, ideally, be used at a moment's notice (depending on load, line voltage, and line frequency), and therefore extremely often, both the efficiency of this power transfer and the number of cycles in the element's lifetime become significant. Cycle efficiency is defined as:

$$
\text { Cycle Efficiency }=\frac{\text { Energy Out of System }}{\text { Energy Into System }} \text { [unitless] }
$$

In words, this means: cycle efficiency is equal to the total amount of energy that comes out of the system during discharge divided by the total amount of energy sent into the system during charge. Clearly, to be a suitable addition to the grid, the storage method must be able to return a certain percentage of the energy sent to it, otherwise the issue of wasting generated energy is not truly addressed. The number of cycles which a storage system can be used (cycling capability) is the total number of instances which power can be sent to fully charge and discharge the element while meeting grid specifications. All elements have some finite lifetime before requiring upgrades to the system or overall replacement; the higher the number of cycles before upgrades, the more valuable the solution. In addition to the number of cycles before upgrade being an important aspect of the storage solution, the operating lifetime as a whole is another contributing characteristic to consider. Operating lifetime is said to be the amount of time which the facility 
is in service. Unlike the cycling capability, operating lifetime does not only account for service time before upgrade, but service time after upgrade as well. At a certain point, financially, it will not make sense to continue to maintain a facility any longer. The longer period of time before this point is reached, the more suitable the solution. Cost is one of, if not the most, important factor in implementing the appropriate storage systems. In order for a system to be desirable, it should have both a low capital and marginal cost. Capital cost is the sum of money required to build and start-up a new facility. Marginal cost is defined as follows:

$$
\text { Marginal cost }=\frac{\text { change in cost }}{\text { change in quantity }}\left[\frac{\$}{k W h}\right]
$$

In this case, the quantity that is mentioned in equation 1.6.6 is the energy provided from the storage system. To clarify, there is a cost associated with operating the storage system because it has inherent inefficiency. When there is a target amount of energy needed to satisfy load, cycle efficiencies less than one indicate the need to generate more than the target amount. The more efficient the system, the less additional energy needed to meet the target. The less additional energy generated, the less it costs to store and later provide energy back to the grid. While marginal cost is extremely important to consider, capital cost is what, generally, deters investors. This is because large capital costs extend the time period until that cost is paid off and the facility becomes profitable.

\section{Section 1.7: Types of Energy Storage}

There are various energy storage solutions that possess some of the desired qualities presented in Section 1.7. These solutions fall into three categories: mechanical systems, 
electrochemical systems, and thermal systems. Examples of mechanical storage systems include pumped-storage hydro (PSH) and compressed air energy storage (CAES). The basis of these solutions lies in mechanical concepts such as gravitational potential energy or fluid dynamics. Out of the three categories, the most number of storage solutions exist within the electrochemical branch. All batteries, including Lead-acid, Lithium-ion (Li-ion), and Sodium Sulfur (NaS), fall under the electrochemical systems category. In addition to batteries, supercapacitors reside in this category as well. Lastly, an example of a storage system that belongs to the thermal solutions branch is molten salt heat storage.

Each of these solutions has the potential to act as a suitable grid-scale energy storage system, but each has its downfalls. To determine the best fit energy storage solution, an examination of all storage systems should be done. In this section the benefits and drawbacks of all types of systems will be presented to help classify which systems are most sensible in given scenarios. Starting with our mechanical systems, a breakdown of PSH is first.

\section{Pumped-Storage Hydro}

How it works: Pumped-Storage Hydro systems work by relocating water from a lower elevation to a higher elevation with pumps during off-peak, low priced times (typically during the night). During the day, when there is a mismatch between power supply and demand, water is released back to the lower elevation through a turbine which generates electricity to support the grid. This technique relies upon the potential energy gained by the water, when relocated, to drive the turbine. The gain in potential energy is given by the mass $\mathrm{m}$, times gravity $\mathrm{g}$, times the height $\mathrm{h}$ :

$$
\text { Change in Potential Energy }=\Delta \mathrm{U}_{\text {gravitational }}=\operatorname{mg} \Delta \mathrm{h}[\text { Joules }]
$$




\section{Benefits}

- Stores energy over long period of time

- Stores large amounts of energy

- $\quad$ Supports renewable energy

\section{Drawbacks}

- Land intensive

- Lower round-trip efficiency compared to other systems $(\sim 75 \%)$

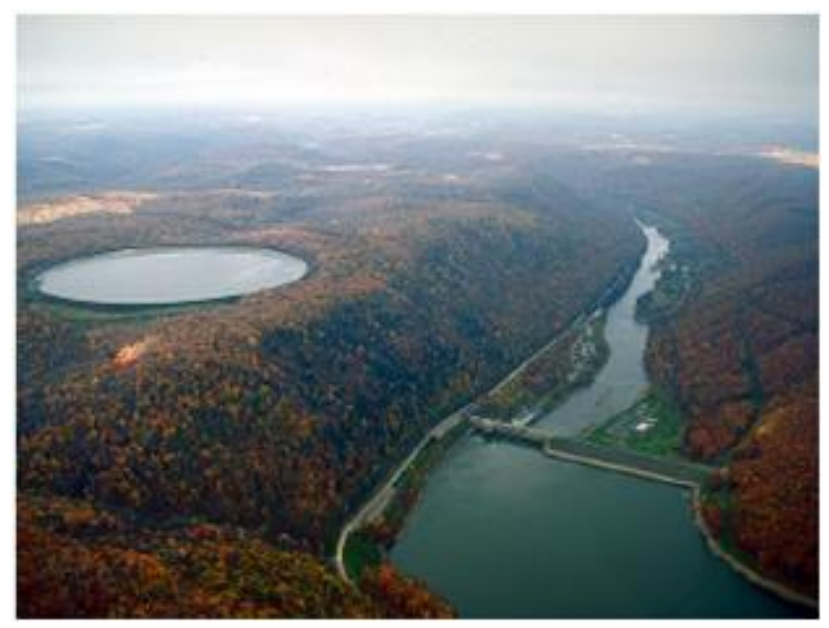

Figure 1.7.1: Pumped-Storage Hydro System.

Because of its ability to store massive amounts of energy over a long period of time, which maximizes energy arbitrage, PSH is a very established solution, in terms of grid-scale energy storage. In total, there are more than $123 \mathrm{GW}$ of PSH installed around the globe, which makes up nearly $97 \%$ of all grid-scale storage [4].

\section{Compressed-Air Energy Storage}

How it works: Compressed-Air Energy Storage does not, on its own, supply power to the grid. Instead, this method works in conjunction with combustion-based power plants, such as natural gas or coal-fired facilities. During off-peak hours, air is compressed and then stored underground. When power supply does not meet demand and additional power is needed, this 
compressed air is fed into the combustion chamber which drives the turbine. Because the air is compressed, less energy (at a high price, since this occurs during peak hours) is required to heat the air. We can confirm that compressed air has a higher temperature than air which is not compressed (assuming the air is stored in a constant volume) with the ideal gas law:

$$
\mathrm{PV}=\mathrm{nRT}\left[\text { pascal } \mathrm{m}^{3}\right. \text { ] }
$$

Since V, the volume in meters cubed in which the air is stored, $n$, the number of moles of air, and $\mathrm{R}$, the universal gas constant in joules per mole kelvin are non-changing values, air pressure and air temperature are directly related.

\section{Benefits}

Drawbacks

- Low capital cost compared to PSH

- Very low efficiency ( 45-60\%)

- High output power

- No VER integration

- Long lifetime

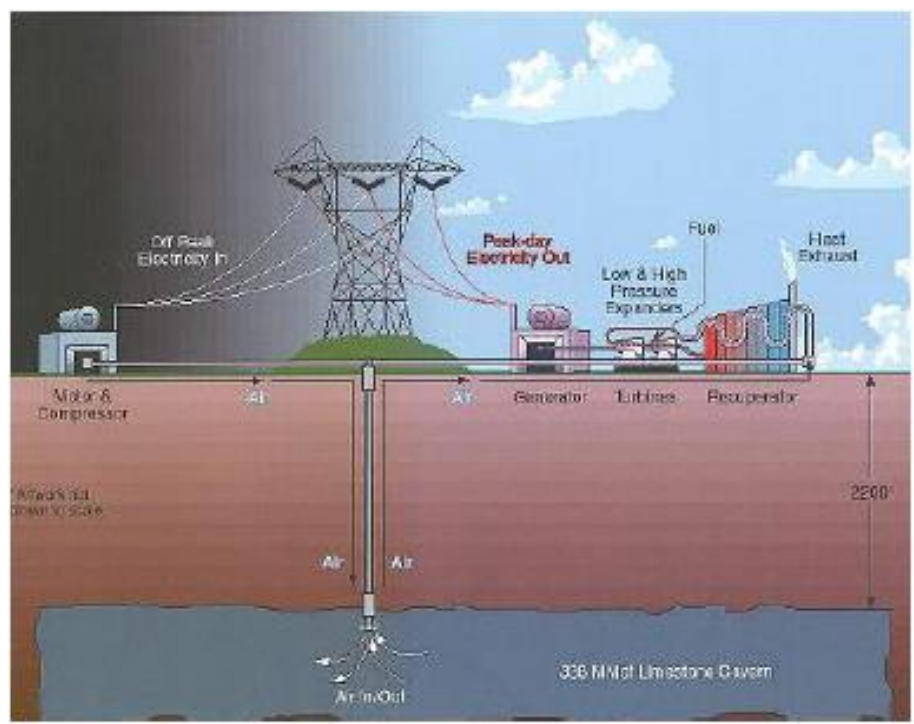

Figure 1.7.2: Compressed Air Energy System. 
Since CAES is used with traditional power plants, it has the same features, some of which are desired. Globally, there are over 440 MW (as of 2011) of CAES systems installed [4]. Unfortunately, because of its low efficiency and inability to be integrated with renewable energy sources such as wind and solar, it seems that an increase in compressed air systems being deployed is unlikely.

\section{Flywheels}

How it works: Like the other two mechanical solutions discussed, a flywheel system requires energy to be input during off-peak, low cost times. Rather than making use of the concept of potential energy, as PSH does, flywheels rely on kinetic energy. The initial energy going into the system is used to put the flywheels in motion. During peak hours, the wheels' energy is sent back to a generator which feeds the grid. The energy stored in the flywheel's rotational motion is:

$$
\mathrm{E}_{\text {flywheel }}=\frac{1}{2} \mathrm{I} \omega^{2}[\text { Joules }]
$$

where I is the moment of inertia of the wheel in kilogram meters squared and $\omega$ is the angular velocity in radians per second.

\section{Benefits}

\section{Drawbacks}

- High power output

- Small system size

- Very high efficiency ( $90 \%)$
- Provides power for short duration

- Heavy-duty materials call for very high capital cost 


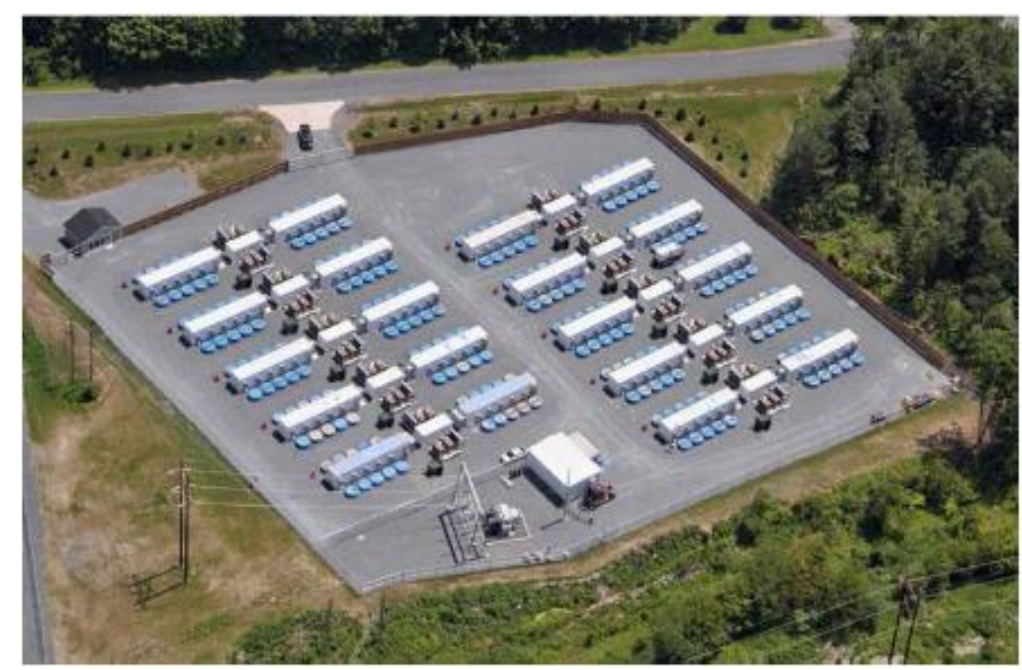

Figure 1.7.3: Flywheel Storage System.

The largest flywheel systems around the world are on the order of $20 \mathrm{MW}$, which is sizeable for grid-scale energy storage. Despite this fact, flywheels only account for a total of less than $100 \mathrm{MW}$, globally, as of 2011 [4]. Because of the fact that flywheels discharge so quickly, they are unlikely to be used for load shifting, which is, what is expected to be, the most profitable service that energy storage can provide. Though load shifting cannot be done, flywheels have high output power, making them good for both voltage and frequency support.

\section{Sodium Sulfur Batteries}

How it works: Just like most batteries that we encounter on a daily basis, NaS batteries have an anode, a cathode, and an electrolyte which separates the two. The anode in a NaS battery is Sulfur (S), while the cathode is Sodium $(\mathrm{Na})$. Unlike batteries such as lead-acid or lithium-ion (Li-ion), the two electrodes are molten. In addition, the electrolyte is a special material named a Beta-Alumina Solid Electrolyte (BASE), which only conducts Sodium ions near 300 degrees Celsius ( 600 Fahrenheit) [5]. When the two electrodes are connected through the terminals of 
the battery, a DC current will flow, delivering power to the desired system. This power can be calculated with the following formula:

$$
\mathrm{P}=\mathrm{IV} \text { [Watts] }
$$

where $\mathrm{V}$ is the rated voltage in volts of the battery and $\mathrm{I}$ is the current leaving the positive electrode in amps. Since this type of system is to be used to provide power to the grid, this current is then fed through a grid-tied inverter to create an AC signal matching that of the current flowing through the grid. During times when the battery is idle, the cells are heated to keep them warm.

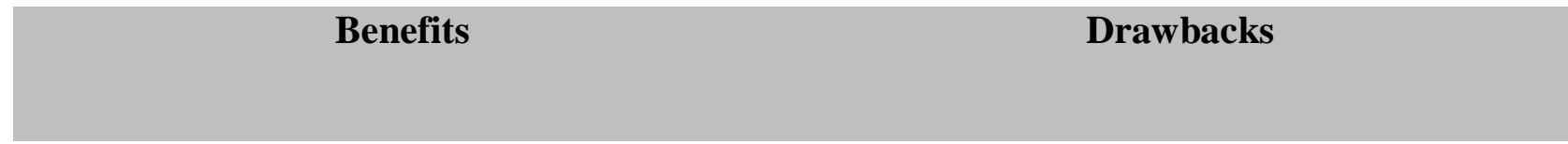

- High energy density

- Local support since batteries don't require much land

- Efficient compared to other storage technologies

- Supports renewable energy
- High temperature required for operation

- Potential fire hazard 


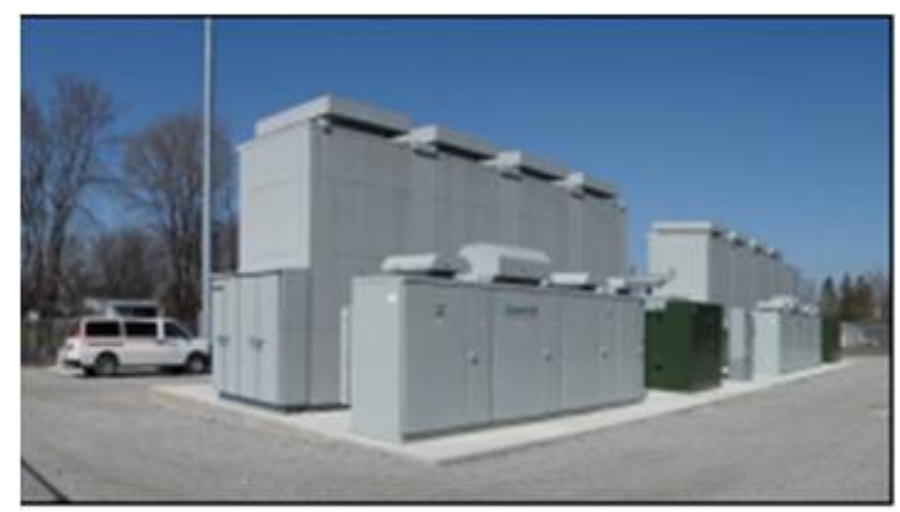

Figure 1.7.4: Sodium Sulfur Battery Energy Storage System.

The rated power and energy of common NaS systems is about $2 \mathrm{MW}$ and $14 \mathrm{MWh}$. The systems themselves are comprised of smaller cells which make up modules connected in series. Globally, more than $316 \mathrm{MW}$ of NaS energy storage systems were installed as of 2012 [4]. This makes up more than $50 \%$ of all grid-scale battery storage, yet only $.25 \%$ of all grid-scale energy storage at the time. Because Sodium Sulfur batteries are so versatile, in that they are energy dense, compact, and efficient, they present a very viable option for grid storage.

\section{Supercapacitors}

How it works: Supercapacitors, also known as ultracapacitors, work exactly as traditional capacitors, just with a much higher rated capacitance. The difference between the two lies in the makeup of the capacitor itself. A traditional capacitor is made with parallel conducting plates with either air or a dielectric in the middle, while a supercapacitor is made with layered carbon electrodes which have a high specific surface area, allowing for greater capacitance. This is evidenced by:

$$
\mathrm{C}=\frac{\epsilon \mathrm{A}}{\mathrm{d}}[\text { Farads }]
$$


where $\varepsilon$ is the dielectric constant, A is the surface area of the electrode in meters squared, and $\mathrm{d}$ is the distance between the electrodes in meters. The amount of energy that a given supercapacitor can store is:

$$
\mathrm{E}=\frac{1}{2} \mathrm{CV}^{2}[\text { Joules }]
$$

Clearly, by increasing the capacitance of the device, we linearly increase the amount of energy which it can store. $\mathrm{V}$ is the voltage across the capacitor in volts.

\section{Benefits}

Drawbacks

- High power density

- Very low energy density

- Compact system

- Low capital cost per cycle compared to other energy storage systems

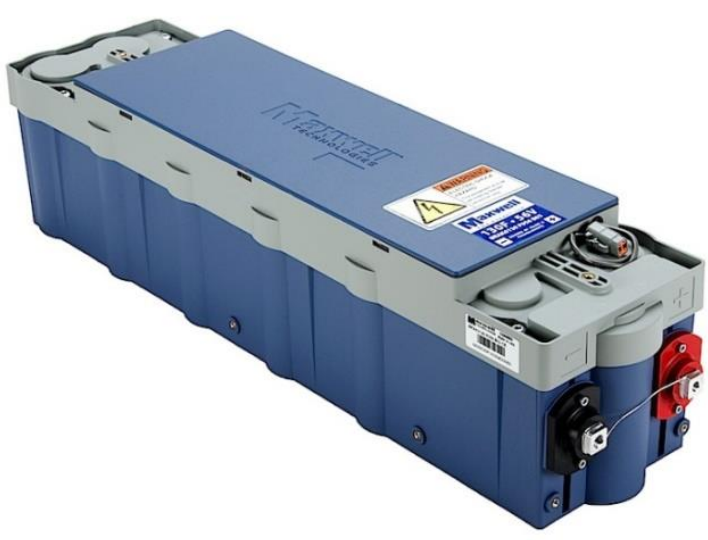

Figure 1.7.5: Supercapacitor Energy Storage Pack. 
Most commonly, supercapacitor energy storage systems are rated on the order of a megawatt. Though this power rating is suitable for grid-scale application, the discharge time of the apparatus is typically less a minute. Clearly, if rapid charging and discharging is needed, as may be the case with frequency regulation and voltage support, supercapacitors may be a worthwhile notion. In terms of peak shaving or load management, this system is not the most reliable solution.

\section{Molten Salt}

How it works: Most often, molten salt storage is found on site of a generation facility, such as that of a concentrated solar power plant. Concentrated solar (CS) differs from photovoltaic solar (PV) in that light is reflected, using mirrors, onto a target which gets very hot. This heat can then be used in a variety of ways, one of them being to store it within a molten salt system. By storing the heat generated from the sun, it can be used at a later time, such as night or during diffuse sky conditions (instances in which PV fails to provide constant power). The tanks in which the hot salt compound resides are insulated well enough to maintain a specific energy level for nearly a week.

\footnotetext{
Benefits

- Long storage time

- Very high temperature required for operation

- High efficiency system

- More land intensive than other options

- Low capital cost

- Supports renewable energy
} 


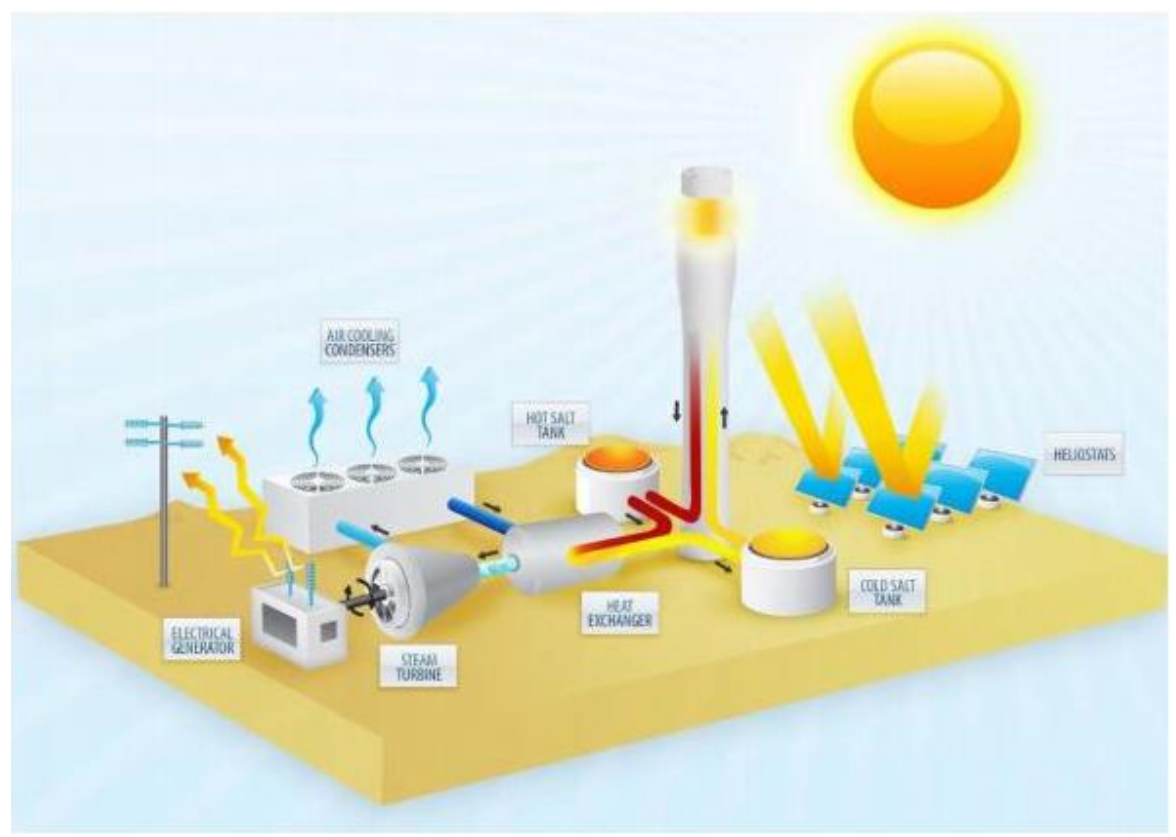

Figure 1.7.6: Molten Salt Storage System.

The reason that these storage systems are usually paired with concentrated solar is that to keep the salts molten, the must be heated to more than 500 degrees Fahrenheit. By concentrating the sun with mirrors onto a focal point, these temperatures can easily be achieved. Clearly, long storage time, high efficiency and low capital cost are very desirable traits within a storage system, which explains why concentrated solar plants are employing molten salts on scales anywhere from $1 \mathrm{MW}$ to $20 \mathrm{MW}$.

\section{Section 1.8: Analysis of Presented Storage Systems}

Now that we have determined the strengths and weaknesses of the various systems available for grid-scale storage, it is necessary to determine what services can be provided by the said strengths. Generally, we can sort the systems into categories of Power Application or 
Energy Application. The figure below, provided by ElectricityStorage. org $^{2}$, indicates whether or not a particular system should be used for power support or energy support.

\begin{tabular}{|c|c|c|c|c|}
\hline $\begin{array}{c}\text { Storage } \\
\text { Technologies }\end{array}$ & $\begin{array}{c}\text { Main Advantages } \\
\text { (relative) }\end{array}$ & $\begin{array}{c}\text { Disadvantages } \\
\text { (Relative) }\end{array}$ & $\begin{array}{c}\text { Power } \\
\text { Application }\end{array}$ & $\begin{array}{l}\text { Energy } \\
\text { Application }\end{array}$ \\
\hline $\begin{array}{l}\text { Pumped } \\
\text { Storage }\end{array}$ & $\begin{array}{l}\text { High Capacity, Low } \\
\text { Cost }\end{array}$ & $\begin{array}{l}\text { Special Site } \\
\text { Requirement }\end{array}$ & & \\
\hline CAES & $\begin{array}{l}\text { High Capacity, Low } \\
\text { Cost }\end{array}$ & $\begin{array}{l}\text { Special Site } \\
\text { Requirement, } \\
\text { Need Gas Fuel }\end{array}$ & & \\
\hline $\begin{array}{l}\text { Flow Batteries: } \\
\text { PSB } \\
\text { VRB } \\
\mathrm{ZnBr}\end{array}$ & $\begin{array}{l}\text { High Capacity, } \\
\text { Independent Power } \\
\text { and Energy Ratings }\end{array}$ & Low Energy Density & & \\
\hline Metal-Air & $\begin{array}{l}\text { Very High Energy } \\
\text { Density }\end{array}$ & $\begin{array}{l}\text { Electric Charging is } \\
\text { Difficult }\end{array}$ & & \\
\hline Nas & $\begin{array}{l}\text { High Power \& Energy } \\
\text { Densities, } \\
\text { High Efficiency }\end{array}$ & $\begin{array}{l}\text { Production Cost, } \\
\text { Safety Concerns } \\
\text { (addressed in } \\
\text { design) }\end{array}$ & & \\
\hline Li-ion & $\begin{array}{l}\text { High Power \& Energy } \\
\text { Densities, High } \\
\text { Efficiency }\end{array}$ & $\begin{array}{l}\text { High Production } \\
\text { Cost, } \\
\text { Requires Special } \\
\text { Charging Circuit }\end{array}$ & & \\
\hline $\mathrm{Ni}-\mathrm{Cd}$ & $\begin{array}{l}\text { High Power \& Energy } \\
\text { Densities, Efficiency }\end{array}$ & & & \\
\hline $\begin{array}{l}\text { Other Advanced } \\
\text { Batteries }\end{array}$ & $\begin{array}{l}\text { High Power \& Energy } \\
\text { Densities, } \\
\text { High Efficiency }\end{array}$ & $\begin{array}{l}\text { High Production } \\
\text { Cost }\end{array}$ & & \\
\hline Lead-Acid & Low Capital Cost & $\begin{array}{l}\text { Limited Cycle Life } \\
\text { when Deeply } \\
\text { Discharged }\end{array}$ & & \\
\hline Flywheels & High Power & Low Energy density & & \\
\hline SMES, DSMES & High Power & $\begin{array}{l}\text { Low Energy Density, } \\
\text { High Production } \\
\text { Cost }\end{array}$ & & \\
\hline E.C. Capacitors & $\begin{array}{l}\text { Long Cycle Life, } \\
\text { High Efficiency }\end{array}$ & Low Energy Density & & \\
\hline
\end{tabular}

Figure 1.8.1: Power or Energy Application Classification.

The results in Figure 1.8.1 are a function of energy and power densities of the technologies in question. Figures 1.8.2 and 1.8.3 give us insight as to where the presented systems compare to each other in this realm. The most versatile energy storage solutions will possess both high energy and high power density. In Figure 1.8.2, systems in the top right corner of the plot will store the most energy per unit space and weight. Clearly, weight is not as critical when it comes to a stationary system, but having a large weight energy density means we can have more energy at a given structural weight limitation than a low weight energy density technology. Figure 1.8.3 demonstrates the discharge times and rated powers associated with

\footnotetext{
${ }^{2}$ All images in Section 1.8 are from ElectricitySorage.org
} 
various energy storage methods. The best load-leveling technologies will be able to output energy at a high rate and for a long duration of time. As mentioned earlier in this paper, $\mathrm{PSH}$ is, by far, the most common type of grid-scale system in the world. In this figure, we see it in a class of its own, with the closest competitors being NaS and CAES storage. Only a few other storage solutions on that chart, which also have long discharge durations, would be considered for energy applications. The remaining solutions play more of a role in the power application sector, which can be seen in Figure 1.8.1.

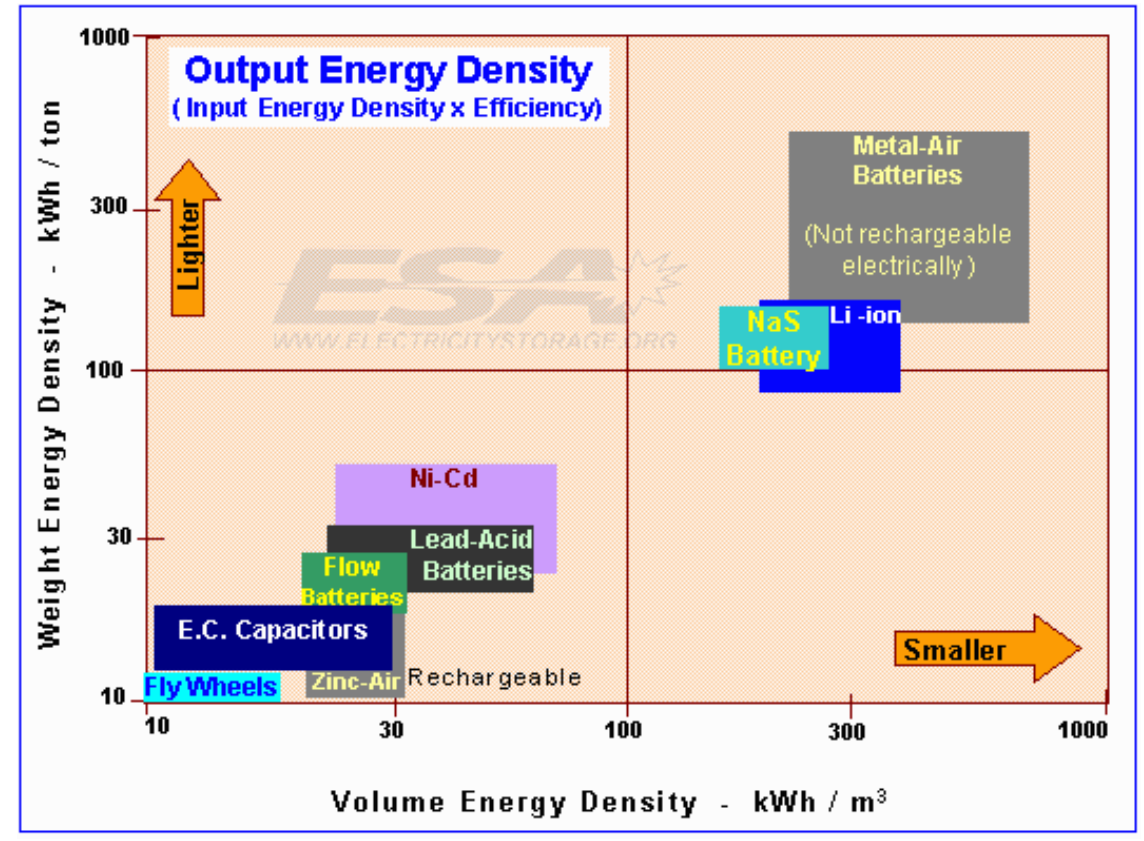

Figure 1.8.2: Storage Systems: Energy and Volume Density. 


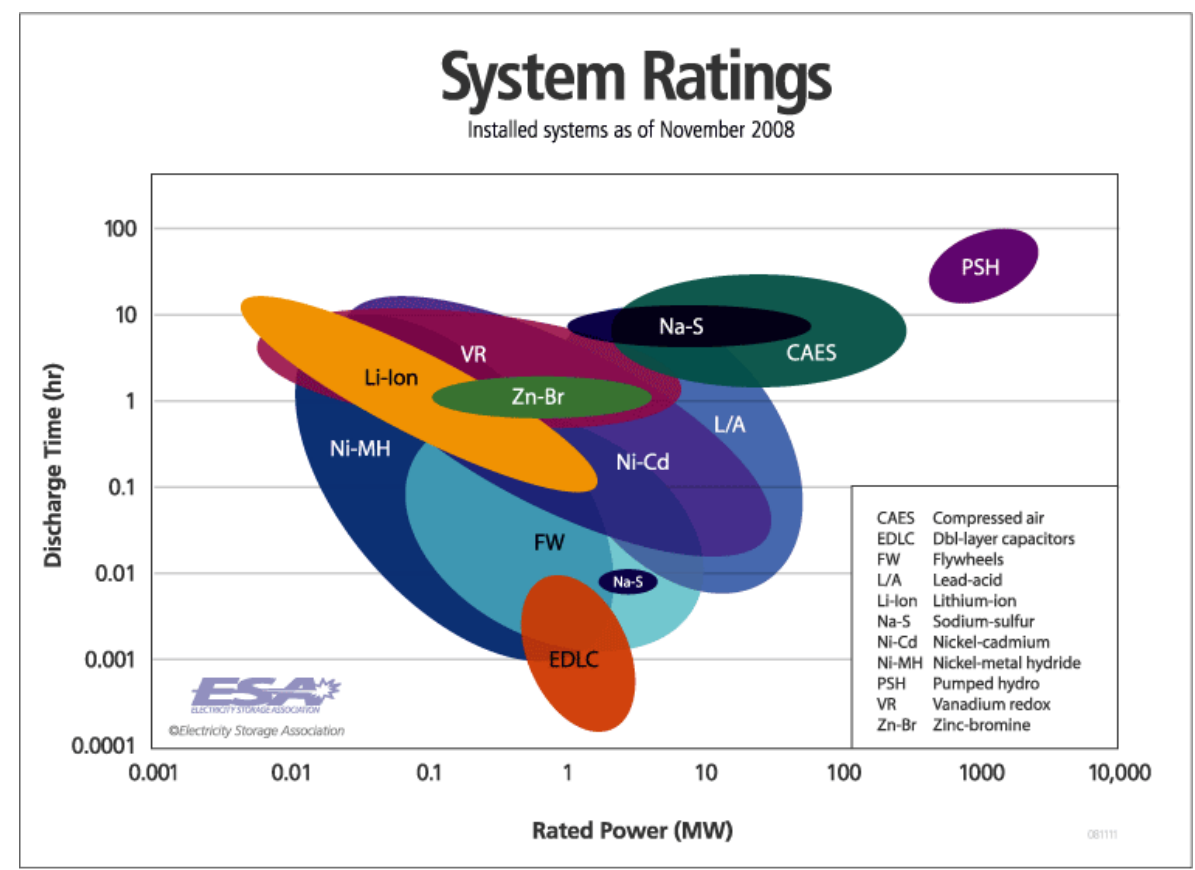

Figure 1.8.3: Storage Systems: Discharge Time and Rated Power.

In addition to determining which application a system falls into (power or energy), it is important to consider the capital cost to get those units of power and energy. Ideally we would compare total cost, which includes marginal cost - the cost to provide the next unit of energyand capital cost, but that requires operating data from each type of system and changes based on location and time of use. Figure 1.8.4 illustrates each system's capital cost in terms of energy and power to give an idea of which appears to be the most sound investment. As described earlier, certain technologies are very good in some aspects, such as high power density, like supercapacitors, but they lack in other aspects. This plot shows, financially, how much they lack. The ideal storage solutions would have low capital costs per unit energy and per unit power and would lie in the bottom-left corner of the image. 


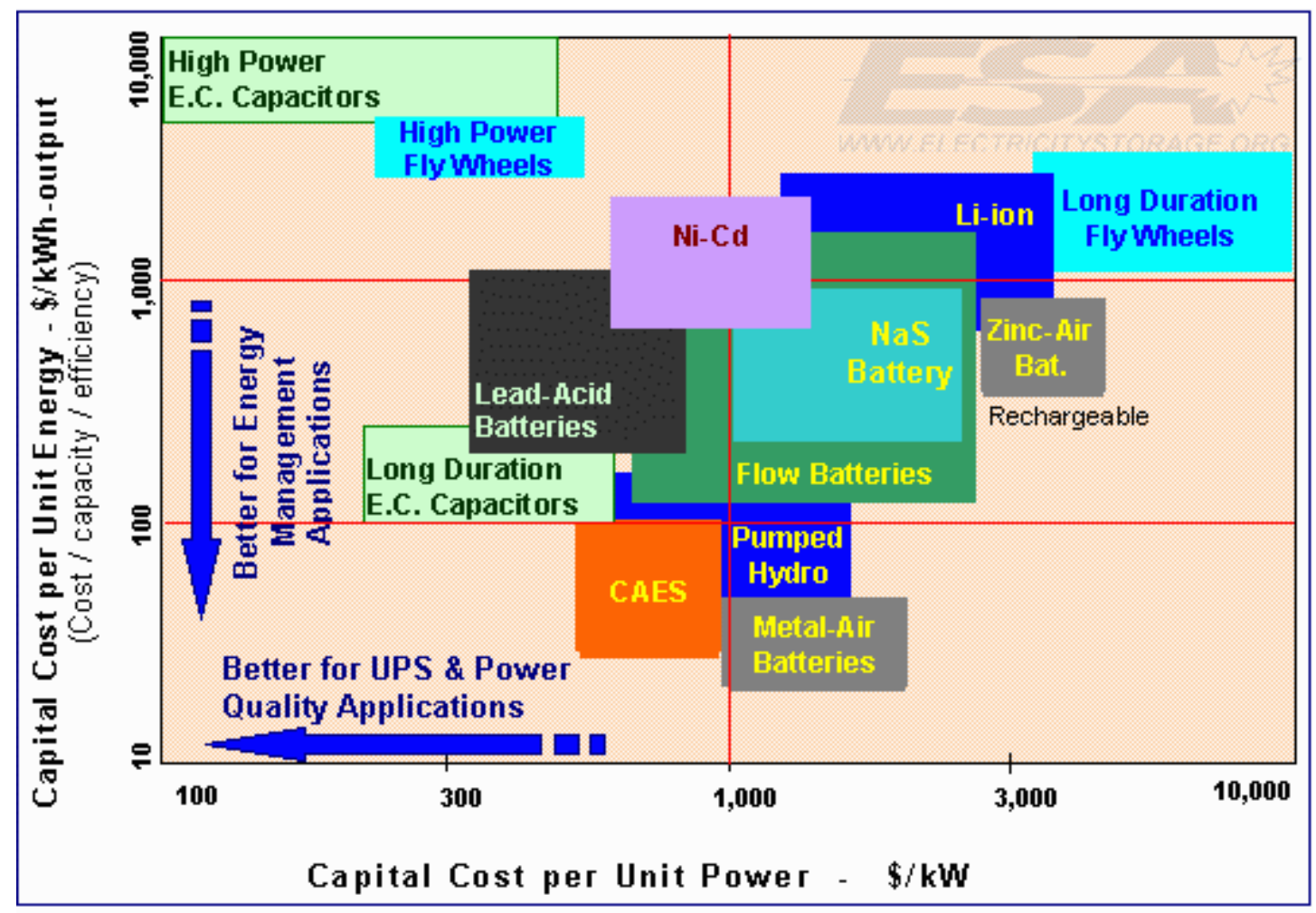

Figure 1.8.4: Storage Systems: Capital Cost per Energy and Power.

Another factor that is extremely necessary to analyze is the cyclability of the storage system in question. Even the most power and energy dense solutions will be rejected if the estimated lifetime isn't suitable. Typically, power plants have contracts with utilities for somewhere on the order of 25 years [6]. Therefore, it is reasonable to assume that grid-scale storage should have comparable capabilities. Figure 1.8.5 demarcates the cost per unit energy per cycle of various systems. In order to compete with existing power plants, storage systems must have relatively low costs per unit of energy stored, but they must also have high cyclability. Though energy storage is better in terms of energy saved and emission abated, money is what drives corporations. To be implemented on a wide-scale, cyclability must go way up, as is the case with PSH, to drive cost per unit energy per cycle down. 


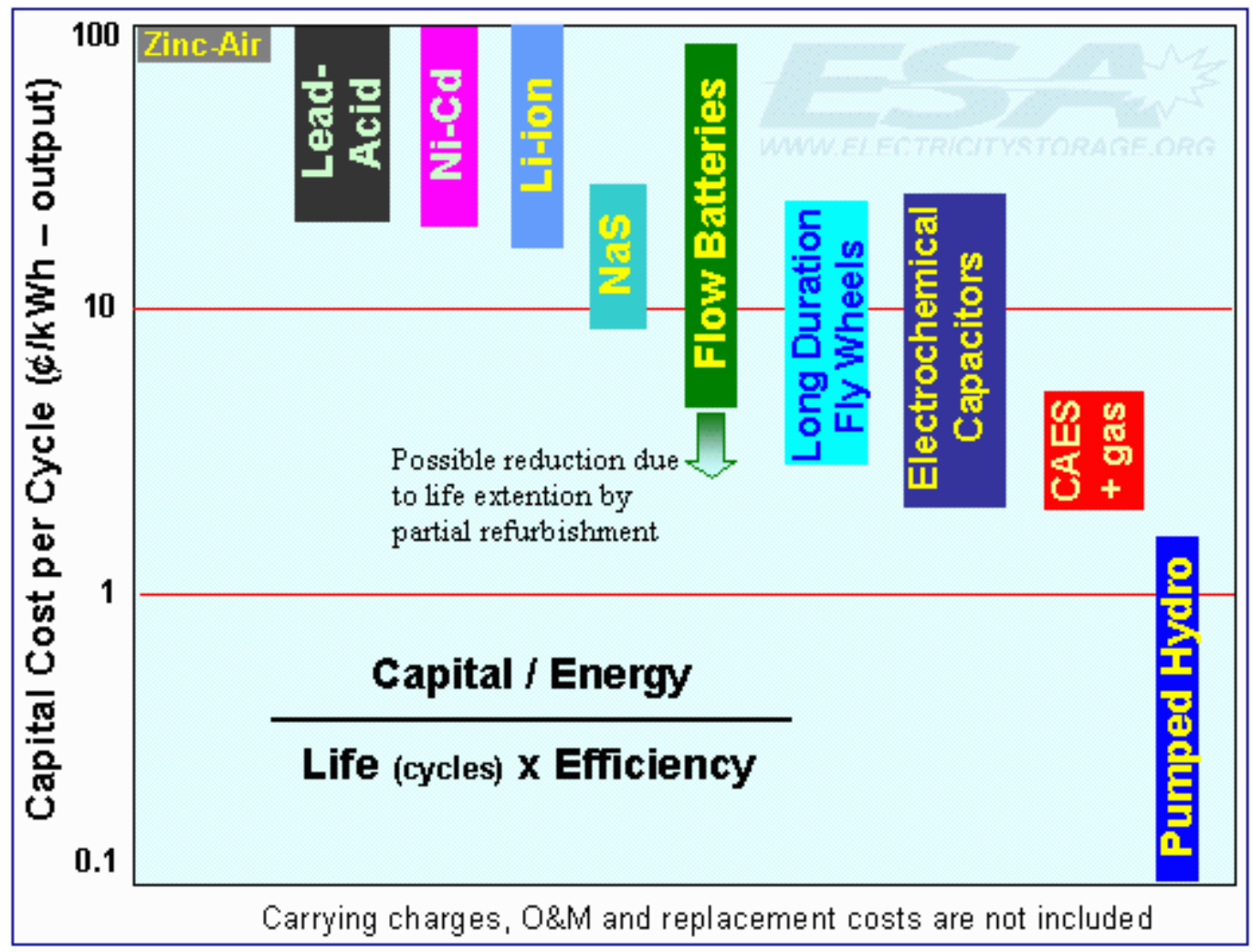

Figure 1.8.5: Storage Systems: Capital Cost and Lifetime.

To this point, the various services available from grid-scale energy storage have been discussed, as well as the strengths and weaknesses of potential solutions. At this point, the connection must be made between the strengths and the services which result from those strengths. Figure 1.8.6 does this in a very succinct way. The major services seen in the figure are, as focused on in Sections 1.1 through 1.4, load leveling (or peak shaving), voltage support, and frequency support. 


\begin{tabular}{|c|c|c|c|}
\hline Technology & Primary Application & What we know currently & Challenges \\
\hline Fly wheels & $\begin{array}{l}\text { - Load leveling } \\
\text { - Frequency regulation } \\
\text { - Peak shaving and off } \\
\text { peak storage } \\
\text { - Transient stability }\end{array}$ & $\begin{array}{l}\text { - Modular technology } \\
\text { - Proven growth potential to } \\
\text { utility scale } \\
\text { - Long cycle life } \\
\text { - High peak power without } \\
\text { overheating concerns } \\
\text { - Rapid response } \\
\text { - High round trip energy } \\
\text { efficiency }\end{array}$ & $\begin{array}{l}\text { - Rotor tensile strength } \\
\text { limitations } \\
\text { - Limited energy storage time } \\
\text { due to high frictional losses }\end{array}$ \\
\hline $\begin{array}{l}\text { Advanced Lead- } \\
\text { Acid }\end{array}$ & $\begin{array}{l}\text { - Load leveling and } \\
\text { regulation } \\
\text { - Grid stabilization }\end{array}$ & $\begin{array}{l}\text { - Mature battery technology } \\
\text { - Low cost } \\
\text { - High recycled content } \\
\text { - Good battery life } \\
\text { - }\end{array}$ & $\begin{array}{l}\text { - Limited depth of discharge } \\
\text { - Low energy density } \\
\text { - Large footprint } \\
\text { - Electrode corrosion limits } \\
\text { useful life }\end{array}$ \\
\hline NaS & $\begin{array}{l}\text { - Power quality } \\
\text { - Congestion relief } \\
\text { - Renewable source } \\
\text { integration }\end{array}$ & $\begin{array}{l}\text { - High energy density } \\
\text { - Long discharge cycles } \\
\text { - Fast response } \\
\text { - Long life } \\
\text { - Good scaling potential }\end{array}$ & $\begin{array}{l}\text { - Operating Temperature } \\
\text { required between } 250^{\circ} \text { and } \\
300^{\circ} \mathrm{C} \\
\text { - Liquid containment issues } \\
\text { (corrosion and brittle glass } \\
\text { seals) }\end{array}$ \\
\hline Li-ion & $\begin{array}{l}\text { - Power quality } \\
\text { - Frequency regulation }\end{array}$ & $\begin{array}{l}\text { - High energy densities } \\
\text { - Good cycle life } \\
\text { - High charge/discharge } \\
\text { efficiency }\end{array}$ & $\begin{array}{l}\text { - High production cost - } \\
\text { scalability } \\
\text { - Extremely sensitive to over } \\
\text { temperature, overcharge and } \\
\text { internal pressure buildup } \\
\text { - Intoleranoe to deep discharges }\end{array}$ \\
\hline Flow Batteries & $\begin{array}{l}\text { - Ramping } \\
\text { - Peak Shaving } \\
\text { - Time Shifting } \\
\text { - Frequency regulation } \\
\text { - Power quality } \\
\text { - }\end{array}$ & $\begin{array}{l}\text { - Ability to perform high } \\
\text { number of discharge cycles } \\
\text { - Lower charge/discharge } \\
\text { efficiencies } \\
\text { - Very long life }\end{array}$ & $\begin{array}{l}\text { - Developing technology, not } \\
\text { mature for commercial scale } \\
\text { development } \\
\text { - Complicated design } \\
\text { - Lower energy density }\end{array}$ \\
\hline SMES & $\begin{array}{l}\text { - Power quality } \\
\text { - Frequency regulation }\end{array}$ & $\begin{array}{l}\text { Highest round-trip efficiency } \\
\text { from discharge }\end{array}$ & $\begin{array}{l}\text { - Low energy density } \\
\text { - Material and manufacturing } \\
\text { cost prohibitive }\end{array}$ \\
\hline $\begin{array}{l}\text { Electrochemical } \\
\text { Capacitors }\end{array}$ & $\begin{array}{l}\text { - Power quality } \\
\text { - Frequency regulation }\end{array}$ & $\begin{array}{l}\text { - Very long life } \\
\text { - Highly reversible and fast } \\
\text { discharge }\end{array}$ & - Currently cost prohibitive \\
\hline $\begin{array}{l}\text { Thermochemical } \\
\text { Energy Storage }\end{array}$ & $\begin{array}{l}\text { - Load leveling and } \\
\text { regulation } \\
\text { - Grid stabilization }\end{array}$ & $\begin{array}{l}\text { Extremely high energy } \\
\text { densities }\end{array}$ & - Currently cost prohibitive \\
\hline
\end{tabular}

Figure 1.8.6: Storage Systems: Primary Application and Challenges.

Because of the numerous benefits and few drawbacks of the NaS battery storage system, this technology is beginning to be implemented on a wider scale. For instance, with money received from the federal government, Pacific Gas and Electric (PG\&E) decided to erect two of such facilities in the Bay Area, California. One of the facilities has already been through a variety of tests to determine maximum charge and discharge rates, actual capacity, and roundtrip efficiency. This site is located north of San Francisco, between Vacaville and Dixon. The second facility, located in San Jose, is the one on which our efforts will be focused. The goals of 
this project are to determine what services this battery can provide, what monetary values of those services are, and what battery controlling algorithm reduces carbon emissions the most, while removing financial inefficiency as well. In order to optimize this system, it is helpful to examine results from existing systems and their algorithm's. This will be presented in the next section of this report. 


\section{Chapter 2 -- Literature Review}

As mentioned in the overview of grid-scale energy storage, many of the Sodium-Sulfur battery systems existing today have power ratings of $2 \mathrm{MW}$ and energy ratings of $14 \mathrm{MWh}$. PG\&E's Yerba Buena facility is one of the few facilities to exceed these ratings. The system of focus, BESS in Yerba Buena, is rated at $4 \mathrm{MW}$ and has a capacity of $28 \mathrm{MWh}$. In order to get an idea of where to start, in terms of characterizing the battery's performance and applying efficiency optimizing algorithm, it is helpful to analyze data from other batteries. Doing so will give a better idea of where our battery's max efficiency zone is, rather than starting from scratch, employing charge and discharge profiles which are known to result in efficiencies lower than desirable. Two sources will be considered in the attempt to determine how to achieve maximum round-trip efficiency for the NaS system in question. Those sources include "Vaca-Dixon BESS Engineer-of-Record Report" (with operating data) by William Steeley and Robert Schainker of EPRI and a paper dubbed "Operation and Control of NAS Batteries on a University Campus" by Professor Kenji Iba, and Kouji Tanaka and Kuniaki Yabe of Tokyo Electric Power Co. Inc $[7,8,9]$.

\section{Section 2.1: Vaca-Dixon Testing Strategies and Results}

The sources will be analyzed in order of algorithm complexity, starting with the simplest. The Vaca-Dixon report ${ }^{3}$ describes the testing strategies implemented at the Vaca-Dixon facility owned by PG\&E, breaking the measurements into two separate groups. One group consists of a battery discharge followed by an idle period prior to recharge. The other group consists of a discharge followed immediately by a recharge cycle. Though various discharge rates were tested, in most trials, at the end of the discharge cycle, the SOC was near 10\% (most likely, per

\footnotetext{
${ }^{3}$ All tables and figures from Section 2.1 are from [7]
} 
NGK's - the battery manufacturer-recommendation). Because the ending SOC was fixed in some trials, the discharge time varied with the chosen discharge rates. The shortest discharge time was 3.6 hours, while the longest was 10.6 hours. The different discharge rates that were used include $2 \mathrm{MW}, 1.75 \mathrm{MW}, 1.5 \mathrm{MW}$, and 1.25 MW, while the charging rate was $2.1 \mathrm{MW}$ according to PG\&E's EPRI Vaca-Dixon Report. Because the minimum time to fully discharge and recharge the battery (round-trip cycle) was so high, only one trial per day was executed. Each discharge began at 4pm, the beginning of the afternoon/evening peak load. In each test, the $\mathrm{AC}$ round-trip and DC round-trip efficiencies were calculated in addition to the 24 hour AC round-trip efficiency. The 24 hour AC round-trip efficiency is the outcome we must pay most attention to. This is due to the fact that it includes heater losses from maintaining the high temperature of the NaS battery's cells. Including these losses in our analysis is crucial if we are to accurately find abated emissions resulting from this technology. Not to mention, the most suitable rate structure for this BESS's services will account for marginal cost, which heating the battery is part of. Table 2.1.1 shows the average of the results from testing $\underline{\text { with }}$ a resting period prior to recharge at $2 \mathrm{MW}$ discharge for different durations of time.

\begin{tabular}{|c|c|c|c|}
\hline $\begin{array}{c}\text { Discharge Duration } \\
\text { at 2 MW (Hours) }\end{array}$ & $\begin{array}{c}\text { Average AC Round- } \\
\text { Trip Efficiency (\%) }\end{array}$ & $\begin{array}{c}\text { Average DC Round- } \\
\text { Trip Efficiency (\%) }\end{array}$ & $\begin{array}{c}\text { Average 24 Hour } \\
\text { AC Round-Trip } \\
\text { Efficiency (\%) }\end{array}$ \\
\hline 3.6 & 79.2 & 90.7 & 63.4 \\
\hline 4.6 & 79.7 & 90.4 & 68.3 \\
\hline 5.6 & 80.2 & 89.8 & 71.8 \\
\hline 6.6 & 79.3 & 88.9 & 74.0 \\
\hline
\end{tabular}

Table 2.1.1: Vaca-Dixon 2 MW Efficiencies with Idle Time 


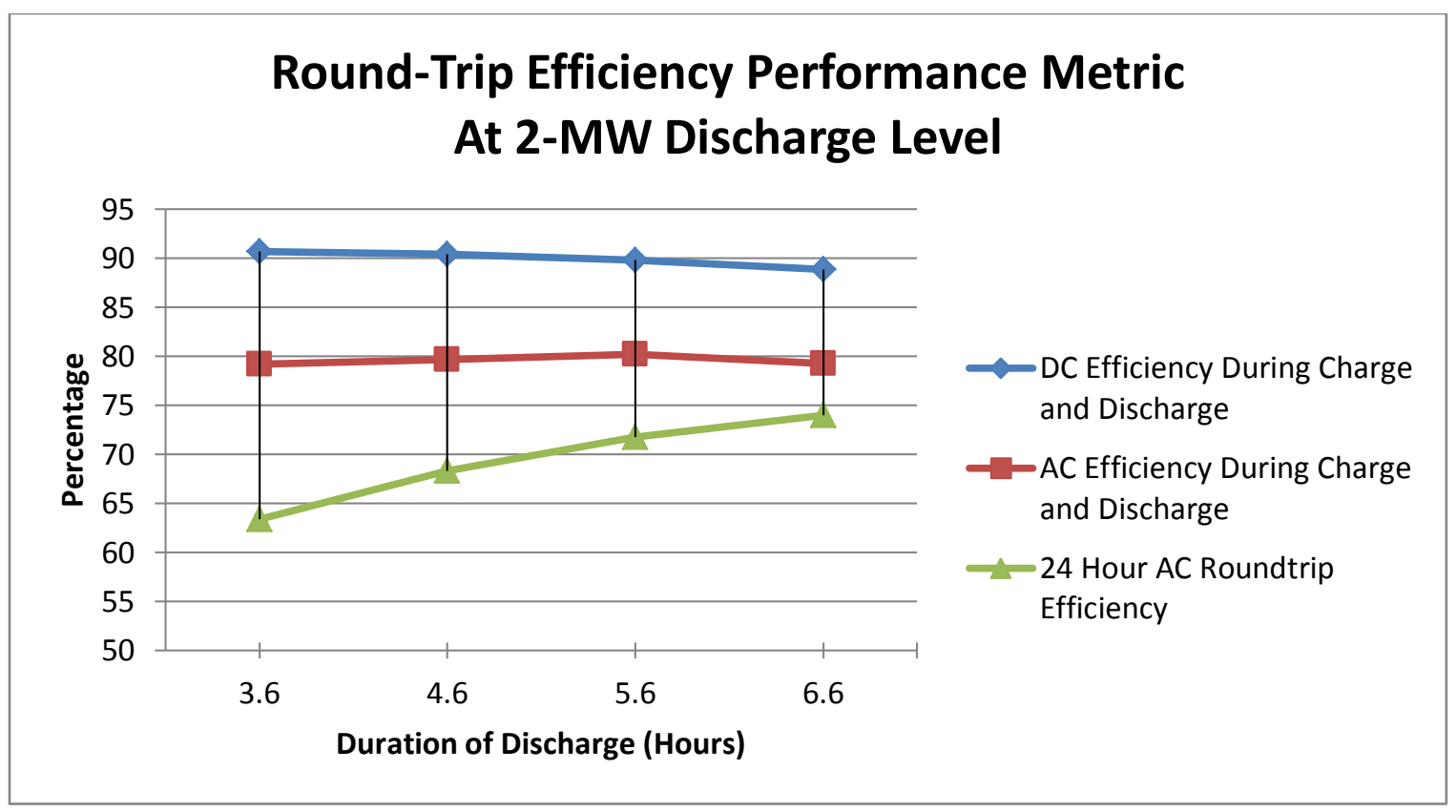

Figure 2.1.1: Vaca-Dixon 2 MW Efficiencies with Idle Time.

Table 2.1.2 shows the average of the results from testing with a resting period prior to recharge at 1.75 MW discharge for different durations of time.

\begin{tabular}{|c|c|c|c|}
\hline $\begin{array}{c}\text { Discharge Duration } \\
\text { at 1.75 MW (Hours) }\end{array}$ & $\begin{array}{c}\text { Average AC Round- } \\
\text { Trip Efficiency (\%) }\end{array}$ & $\begin{array}{c}\text { Average DC Round- } \\
\text { Trip Efficiency (\%) }\end{array}$ & $\begin{array}{c}\text { Average 24 Hour } \\
\text { AC Round-Trip } \\
\text { Efficiency (\%) }\end{array}$ \\
\hline 5.1 & 78.7 & 90.8 & 67.8 \\
\hline 5.9 & 79.0 & 89.9 & 70.4 \\
\hline 6.6 & 78.9 & 89.4 & 71.9 \\
\hline
\end{tabular}

Table 2.1.2: Vaca-Dixon 1.75 MW Efficiencies with Idle Time. 


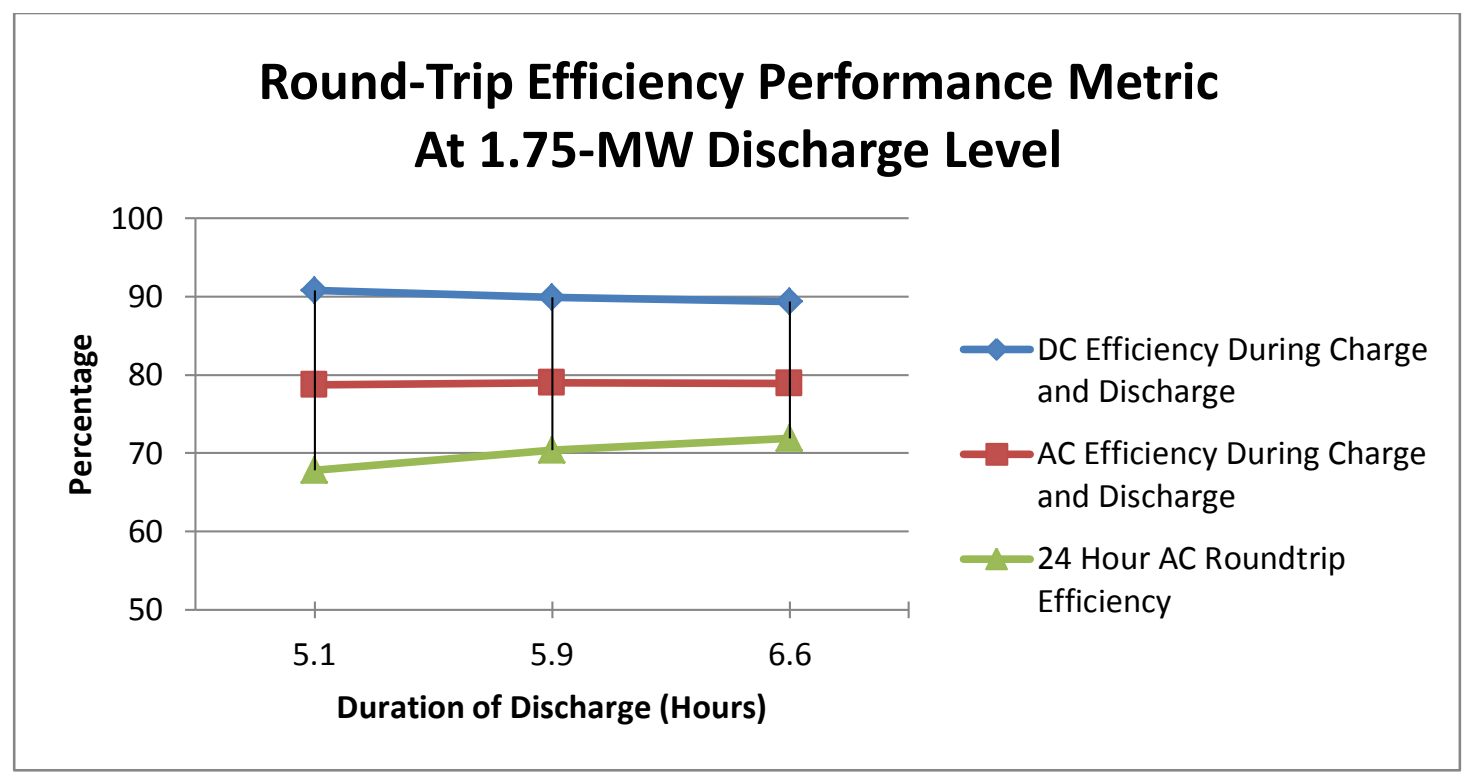

Figure 2.1.2: Vaca-Dixon 1.75 MW Efficiencies with Idle Time.

Table 2.1.3 shows the average of the results from testing with a resting period prior to recharge at 1.5 MW discharge for different durations of time.

\begin{tabular}{|c|c|c|c|}
\hline $\begin{array}{c}\text { Discharge Duration } \\
\text { at 1.5 MW (Hours) }\end{array}$ & $\begin{array}{c}\text { Average AC Round- } \\
\text { Trip Efficiency (\%) }\end{array}$ & $\begin{array}{c}\text { Average DC Round- } \\
\text { Trip Efficiency (\%) }\end{array}$ & $\begin{array}{c}\text { Average 24 Hour } \\
\text { AC Round-Trip } \\
\text { Efficiency (\%) }\end{array}$ \\
\hline 7.3 & 77.9 & 90.8 & 71.2 \\
\hline 7.8 & 78.0 & 90.4 & 72.0 \\
\hline 8.3 & 78.6 & 90.5 & 73.7 \\
\hline
\end{tabular}

Table 2.1.3: Vaca-Dixon 1.5 MW Efficiencies with Idle Time. 


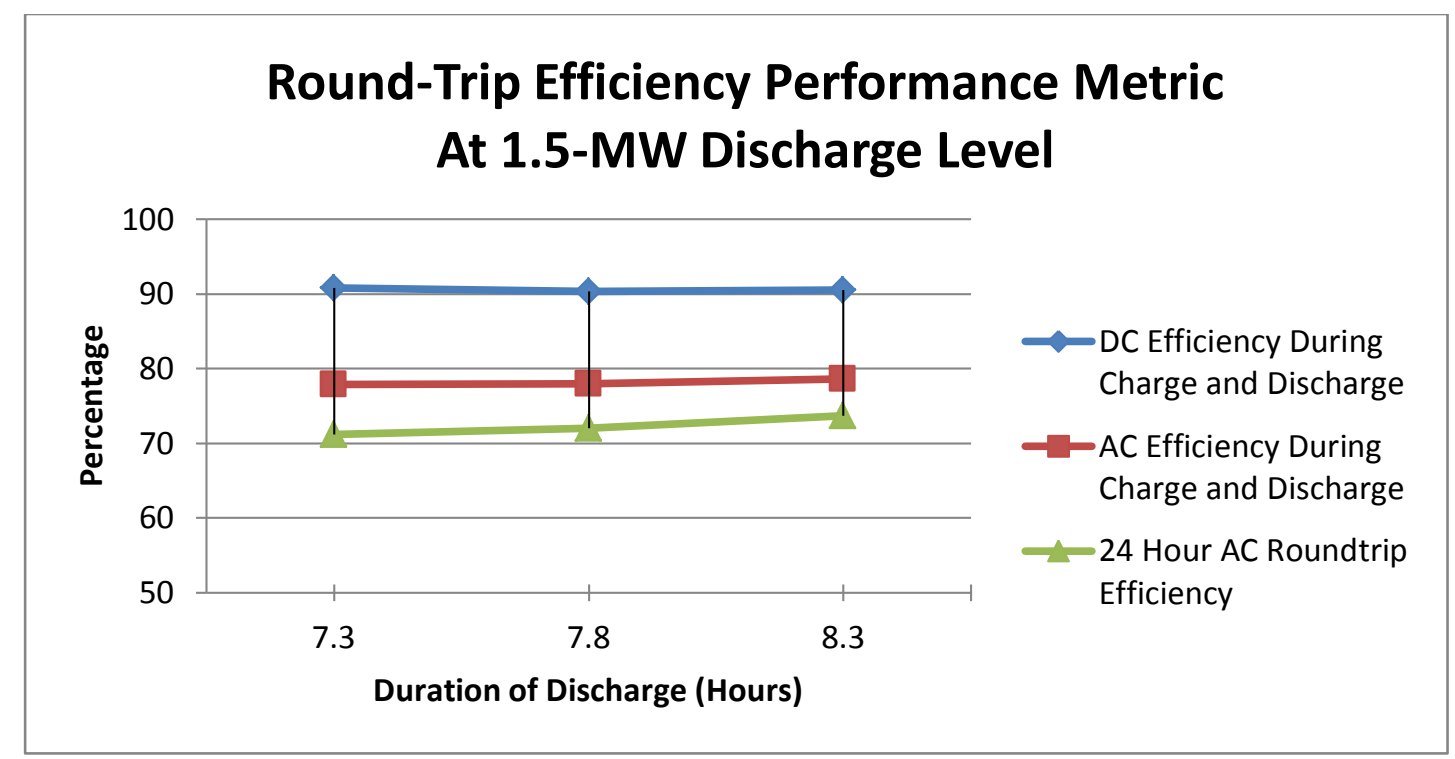

Figure 2.1.3: Vaca-Dixon 1.5 MW Efficiencies with Idle Time.

Table 2.1.4 shows the average of the results from testing with a resting period prior to recharge at $1.25 \mathrm{MW}$ discharge.

\begin{tabular}{|c|c|c|c|}
\hline $\begin{array}{c}\text { Discharge Duration } \\
\text { at 1.25 MW (Hours) }\end{array}$ & $\begin{array}{c}\text { Average AC Round- } \\
\text { Trip Efficiency (\%) }\end{array}$ & $\begin{array}{c}\text { Average DC Round- } \\
\text { Trip Efficiency (\%) }\end{array}$ & $\begin{array}{c}\text { Average 24 Hour } \\
\text { AC Round-Trip } \\
\text { Efficiency (\%) }\end{array}$ \\
\hline 10.6 & 77.1 & 91.4 & 73.8 \\
\hline
\end{tabular}

Table 2.1.4: Vaca-Dixon 1.25 MW Efficiencies with Idle Time 




Figure 2.1.4: Vaca-Dixon 1.25 MW Efficiencies with Idle Time.

From these trials, there are a few findings to note. First, we see the highest average 24 Hour AC Round-Trip Efficiency was $74.0 \%$ after 6.6 hours of discharge at $2 \mathrm{MW}$. Though this was highest, a close second and third place followed for 10.6 hours of discharge at $1.25 \mathrm{MW}$ and 8.3 hours of discharge at $1.5 \mathrm{MW}$. The only discharge rate which did not result in an average 24 Hour AC Round-Trip Efficiency close to the other three was 1.75 MW. The longest time that the BESS was discharged at this rate was 6.6 hours. Table 2.1.5 shows the minimum average SOC for the longest discharge time at each discharge rate.

\begin{tabular}{|c|c|c|c|c|}
\hline $\begin{array}{c}\text { Discharge Rate } \\
\text { (Duration) }\end{array}$ & $\begin{array}{c}2 \mathrm{MW} \\
\text { (6.6 Hours) }\end{array}$ & $\begin{array}{c}1.75 \mathrm{MW} \\
\text { (6.6 Hours) }\end{array}$ & $\begin{array}{c}1.5 \mathrm{MW} \\
\text { (8.3 Hours) }\end{array}$ & $\begin{array}{c}1.25 \mathrm{MW} \\
\text { (10.6 Hours) }\end{array}$ \\
\hline $\begin{array}{c}\text { Minimum } \\
\text { Average SOC (\%) }\end{array}$ & 10.2 & 19.9 & 14.6 & 9.8 \\
\hline
\end{tabular}

Table 2.1.5: Vaca-Dixon Minimum SOCs for Trial with Idle Time. 
Clearly, it is reasonable to suggest, as a second finding, there is a correlation between 24 Hour AC Round-Trip Efficiency and final SOC. In other words, pushing the battery to the lowest SOC allowed by manufacturer specifications, by discharging it at a given rate for a longer duration, may result in maximum efficiencies. Having come to these conclusions about discharging the BESS and then having an idle time prior to recharge, the data from the second group of measurements (discharge followed by immediate charge cycle) should be analyzed to see if the same phenomenon occurs.

In addition to using the rates presented above (2 MW, 1.75 MW, 1.5 MW, 1.25 MW), in the second group of measurements, additional discharge rates were tested. Namely, rates of 1 MW, 0.75 MW, and 0.5 MW were added. Tables 2.1.6 through 2.1.12 illustrate the average efficiencies measured for discharges lasting either 6.6 hours or 6 hours at different rates, without an idle period prior to recharge.

\begin{tabular}{|c|c|c|c|}
\hline $\begin{array}{c}\text { Discharge Duration } \\
\text { at 2 MW (Hours) }\end{array}$ & $\begin{array}{c}\text { Average AC Round- } \\
\text { Trip Efficiency (\%) }\end{array}$ & $\begin{array}{c}\text { Average DC Round- } \\
\text { Trip Efficiency (\%) }\end{array}$ & $\begin{array}{c}\text { Average 24 Hour } \\
\text { AC Round-Trip } \\
\text { Efficiency (\%) }\end{array}$ \\
\hline 6.6 & 79.3 & 88.3 & 73.2 \\
\hline
\end{tabular}

Table 2.1.6: Vaca-Dixon $2 \mathrm{MW}$ Efficiencies no Idle Time

\begin{tabular}{|c|c|c|c|}
\hline $\begin{array}{c}\text { Discharge Duration } \\
\text { at 1.75 MW (Hours) }\end{array}$ & $\begin{array}{c}\text { Average AC Round- } \\
\text { Trip Efficiency (\%) }\end{array}$ & $\begin{array}{c}\text { Average DC Round- } \\
\text { Trip Efficiency (\%) }\end{array}$ & $\begin{array}{c}\text { Average 24 Hour } \\
\text { AC Round-Trip } \\
\text { Efficiency (\%) }\end{array}$ \\
\hline 6 & 80.5 & 91.3 & 71.2 \\
\hline
\end{tabular}

Table 2.1.7: Vaca-Dixon 1.75 MW Efficiencies no Idle Time 


\begin{tabular}{|c|c|c|c|}
\hline $\begin{array}{c}\text { Discharge Duration } \\
\text { at 1.5 MW (Hours) }\end{array}$ & $\begin{array}{c}\text { Average AC Round- } \\
\text { Trip Efficiency (\%) }\end{array}$ & $\begin{array}{c}\text { Average DC Round- } \\
\text { Trip Efficiency (\%) }\end{array}$ & $\begin{array}{c}\text { Average 24 Hour } \\
\text { AC Round-Trip } \\
\text { Efficiency (\%) }\end{array}$ \\
\hline 6 & 79.9 & 92.3 & 68.5 \\
\hline
\end{tabular}

Table 2.1.8: Vaca-Dixon 1.5 MW Efficiencies no Idle Time

\begin{tabular}{|c|c|c|c|}
\hline $\begin{array}{c}\text { Discharge Duration } \\
\text { at 1.25 MW (Hours) }\end{array}$ & $\begin{array}{c}\text { Average AC Round- } \\
\text { Trip Efficiency (\%) }\end{array}$ & $\begin{array}{c}\text { Average DC Round- } \\
\text { Trip Efficiency (\%) }\end{array}$ & $\begin{array}{c}\text { Average 24 Hour } \\
\text { AC Round-Trip } \\
\text { Efficiency (\%) }\end{array}$ \\
\hline 6 & 78.1 & 92.9 & 64.3 \\
\hline
\end{tabular}

Table 2.1.9: Vaca-Dixon 1.25 MW Efficiencies no Idle Time

\begin{tabular}{|c|c|c|c|}
\hline $\begin{array}{c}\text { Discharge Duration } \\
\text { at 1 MW (Hours) }\end{array}$ & $\begin{array}{c}\text { Average AC Round- } \\
\text { Trip Efficiency (\%) }\end{array}$ & $\begin{array}{c}\text { Average DC Round- } \\
\text { Trip Efficiency (\%) }\end{array}$ & $\begin{array}{c}\text { Average 24 Hour } \\
\text { AC Round-Trip } \\
\text { Efficiency (\%) }\end{array}$ \\
\hline 6 & 76.1 & 93.8 & 59.1 \\
\hline
\end{tabular}

Table 2.1.10: Vaca-Dixon 1 MW Efficiencies no Idle Time

\begin{tabular}{|c|c|c|c|}
\hline $\begin{array}{c}\text { Discharge Duration } \\
\text { at 0.75 MW (Hours) }\end{array}$ & $\begin{array}{c}\text { Average AC Round- } \\
\text { Trip Efficiency (\%) }\end{array}$ & $\begin{array}{c}\text { Average DC Round- } \\
\text { Trip Efficiency (\%) }\end{array}$ & $\begin{array}{c}\text { Average 24 Hour } \\
\text { AC Round-Trip } \\
\text { Efficiency (\%) }\end{array}$ \\
\hline 6 & 71.7 & 96.1 & 51.0 \\
\hline
\end{tabular}

Table 2.1.11: Vaca-Dixon 0.75 MW Efficiencies no Idle Time.

\begin{tabular}{|c|c|c|c|}
\hline $\begin{array}{c}\text { Discharge Duration } \\
\text { at 0.5 MW (Hours) }\end{array}$ & $\begin{array}{c}\text { Average AC Round- } \\
\text { Trip Efficiency (\%) }\end{array}$ & $\begin{array}{c}\text { Average DC Round- } \\
\text { Trip Efficiency (\%) }\end{array}$ & $\begin{array}{c}\text { Average 24 Hour } \\
\text { AC Round-Trip } \\
\text { Efficiency (\%) }\end{array}$ \\
\hline 6 & 63.5 & 95.8 & 38.4 \\
\hline
\end{tabular}

Table 2.1.12: Vaca-Dixon 0.5 MW Efficiencies no Idle Time

The second finding noted following the first group of measurements was the correlation between 24 hour AC round-trip efficiency and final state of charge. To determine whether this 
correlation is present in the second group of measurements, Table 2.1.13 and Figure 2.1.5 are presented below. Table 2.1.13 allows us to see the minimum average SOCs for each of the different discharge rates, while the figure provides efficiency data.

\begin{tabular}{|c|c|c|c|c|}
\hline $\begin{array}{c}\text { Discharge Rate } \\
\text { (Duration) }\end{array}$ & $\begin{array}{c}2 \mathrm{MW} \\
(6.6 \mathrm{Hours})\end{array}$ & $\begin{array}{c}1.75 \mathrm{MW} \\
\text { (6 Hours) }\end{array}$ & $\begin{array}{c}1.5 \mathrm{MW} \\
\text { (6 Hours) }\end{array}$ & $\begin{array}{c}1.25 \mathrm{MW} \\
\text { (6 Hours) }\end{array}$ \\
\hline $\begin{array}{c}\text { Minimum } \\
\text { Average SOC (\%) }\end{array}$ & 10.4 & 29.9 & 40.7 & 51.0 \\
\hline $\begin{array}{c}\text { Discharge Rate } \\
\text { (Duration) }\end{array}$ & $\mathbf{1 ~ M W}$ & $\mathbf{0 . 7 5} \mathrm{MW}$ & $\mathbf{0 . 5} \mathrm{MW}$ & \\
\hline $\begin{array}{c}\text { Minimum } \\
\text { (6 Hours) }\end{array}$ & $(6 \mathrm{Hours})$ & 80.6 & \\
\hline
\end{tabular}

Table 2.1.13: Vaca-Dixon Minimum SOCs for Trial no Idle Time.

The Vaca-Dixon report presents the plot below, Figure 2.1.5, after detailing their findings from the second group of testing. This figure shows us, visually, that the higher the discharge rate, the higher the average 24 hour AC round-trip efficiency. Like its 24 hour counterpart, the average AC efficiency during charge and discharge also rose with discharge rate. Lastly, DC efficiency during charge and discharge suffered as power rose. 


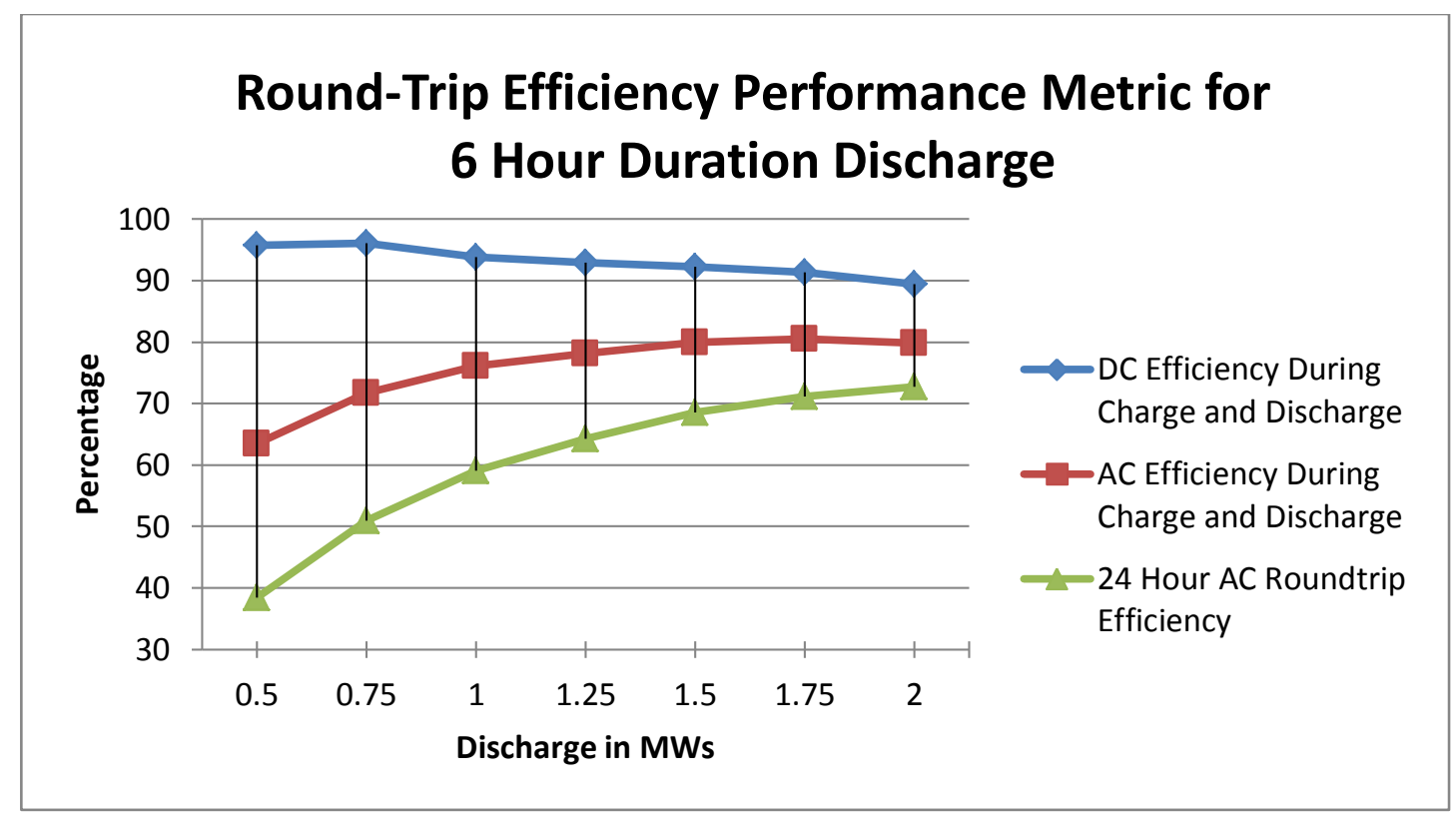

Figure 2.1.5: Vaca-Dixon Efficiencies with no Idle Time.

Ideally, we would be able to determine the delta in efficiency for each discharge rate from the first group of results and the second, but unfortunately the same length of discharge was not used in the group 2 testing. Thankfully, one rate of discharge had the same length of discharge for each testing group. That rate was $2 \mathrm{MW}$, the rated power of the BESS. Though the efficiencies for each testing group were very similar, group 1, adding an idle time prior to recharge, provided a higher average 24 hour AC round-trip value.

\begin{tabular}{|c|c|}
\hline $\begin{array}{c}\text { Discharge Rate } \\
\text { (Duration) }\end{array}$ & $\mathbf{2}$ MW \\
& (6.6 Hours) \\
\hline Efficiency $_{\text {Idle Time }}-$ Efficiency $_{\text {No Idle Time }}(\%)$ & $74.0-73.2=0.8 \%$ \\
\hline
\end{tabular}

Table 2.1.14: Vaca-Dixon Efficiency Difference 
Since we cannot directly compare the deltas in efficiency, we can attempt to confirm a trend found in the first testing group. This trend was: the lower the final SOC, the higher the average 24 hour round-trip efficiency. Mathematically,

$$
24 \text { Hour AC Round Trip Efficiency } \propto \frac{1}{\text { Final SOC Value }}
$$

Figure 2.1.6, shows us, similar to group one testing, group two also maintains higher average 24 hour round-trip efficiencies with lower final SOCs. It just so happens, in this case, this directly correlates to higher discharge rate, since all discharges were done for the same duration. As the BESS facility we are going to study (Yerba Buena) is of the same origin as the one which this data came from, these results are very important for determining where to begin testing at Yerba Buena.

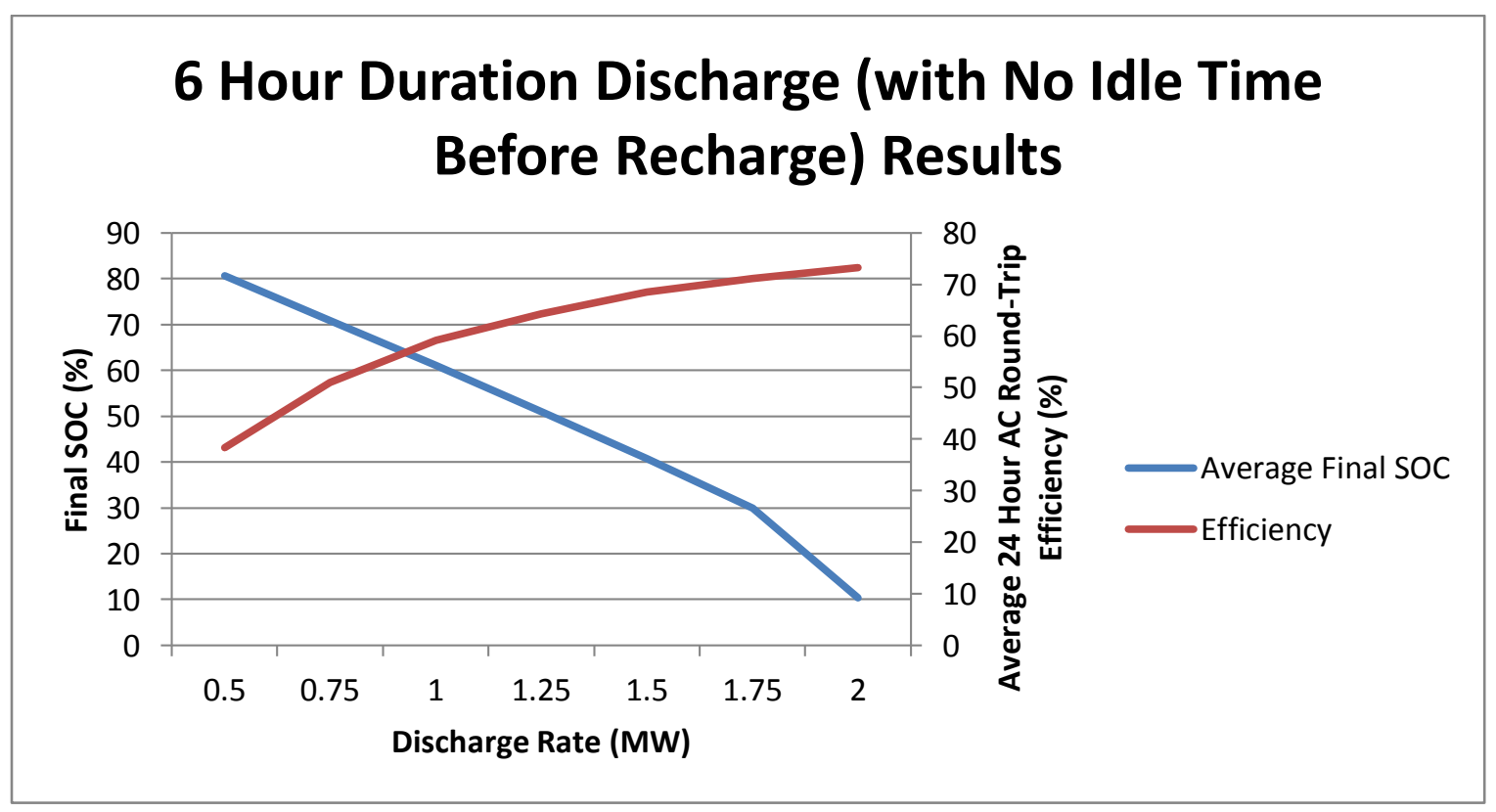

Figure 2.1.6: Vaca-Dixon 6 Hour Discharge no Idle Time. 


\section{Section 2.2: Meisei University Testing and Results}

As mentioned in the thesis overview, $316 \mathrm{MW}$ of $\mathrm{NaS}$ batteries were deployed around the globe, dating back to 2012. One system, in particular, is to be examined, due to the size similarity between it and our Yerba Buena BESS. This system resides on the campus of Meisei University in Japan, and has since it was erected in 2002. One professor set out to collect data and study the benefits presented by the 1 MW Meisei BESS. That person is Dr. Kenji Iba. Dr. Iba authored multiple papers on the NaS facility. Those published in $2006^{4}$ and in $2008^{5}$ will be the focus of our analysis.

The Meisei BESS was established in the year 2002. In the paper Iba published in 2006, the system is said to have a $1 \mathrm{MW}$ power rating, a system voltage of $6.6 \mathrm{kV}$, and an $\mathrm{AC}$ energy rating of $8 \mathrm{MWh}[8]$. According to Iba, this battery can run on two modes, a pre-determined discharge and charge pattern, or a load-following algorithm. The load-following algorithm is the one of interest in these papers, as automation presents greater promise to maximize the usefulness of the system, or provide the most services. Figure 2.2.1 shows the total power demand, the discharge power of the battery, and the net power demand after the battery has been engaged (discharged) for a sample of operating data from June 2004. The goal of engaging the battery is to level the net power load the university requires. As we can see, throughout most of the day, the blue curve, which represents the net load (or total power actually received from the grid), is flat. This practice of engaging, or discharging, the battery to achieve a flat demand is

\footnotetext{
${ }^{4}$ [8] Iba, K.; Ideta, R.; Suzuki, K., "Analysis and Operational Records of NAS Battery," Universities Power Engineering Conference, 2006. UPEC '06. Proceedings of the 41st International, vol.2, no., pp.491,495, 6-8 Sept. 2006

${ }^{5}$ [9] Iba, Kenji, Kouji Tanaka, and Kuniaki Yabe. Operation and Control of NaS Batteries on a University Campus. Tech. Tokyo Electric Power Co., July 2008. Web. 22 Oct. 2013.
} 
called load leveling. Because the system appears to level fairly well, the driving algorithm which the system uses should be investigated further.

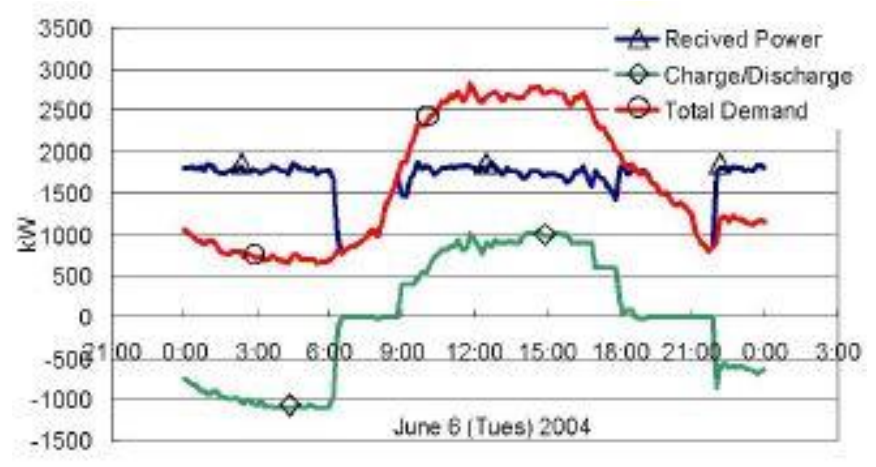

Figure 2.2.1: Meisei University Power Curves from Sample Data.

As stated above, the driving algorithm of the BESS located on the Meisei campus seems to accurately follow campus load. Figure 2.2.2 shows us the efficiency curves associated with the NaS battery operation over the course of two weeks. The campus is closed each and every Sunday, which is why the energy and efficiency curves fall to 0 . The only curve which rises on Sundays is the energy curve of the heater. This is due to the fact the idle system must be kept warm to avoid system damages. The author defines the efficiency as follows:

$$
\text { efficiency }=\frac{\text { discharge energy }[\mathrm{kWh}]}{\text { charge energy }+ \text { heater energy }[\mathrm{kWh}]}
$$

This definition of efficiency is identical to the 24 hour AC round-trip efficiency that was presented in the PG\&E Vaca-Dixon report, which means that we can confidently compare efficiencies achieved by the Meisei system with those in the Vaca-Dixon report. As shown in Figure 2.2.2, efficiencies of $80 \%$ were recorded. The highest 24 hour AC round-trip efficiencies seen at the Vaca-Dixon facility were $74 \%$ or so. Interestingly enough, without analyzing the 
load-following algorithm, we see this system is more efficient than the Vaca-Dixon BESS even standard charge and discharge profile at a constant rate, which one would think would be more efficient, due to reduced strain on the system.

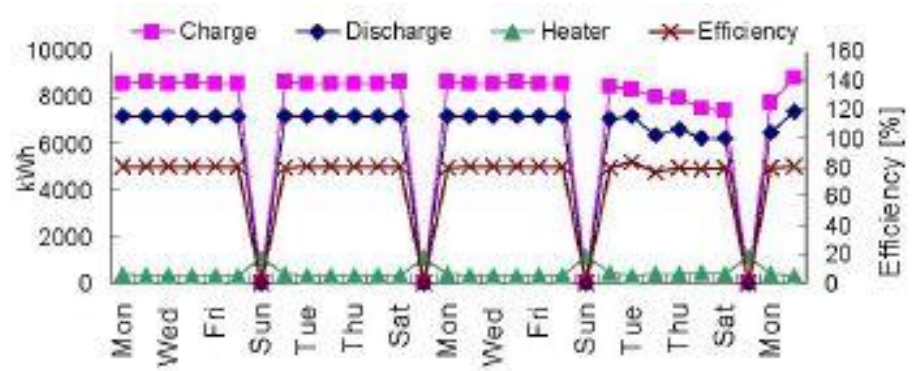

Figure 2.2.2: Meisei University Energy and Efficiency Curves.

In order to accurately track power demand on campus, Dr. Iba started by trying to predict the power demand on a given day; by doing so, he can make an educated guess as to when support from the battery will be needed, and how much. Knowing that the BESS does not discharge at a high enough rate to cover the total demand of the campus at most points of the day, the best the system can do is attempt to reduce the power required from the grid to a level amount; doing so results in less strain on the grid, hence, higher efficiency of transmission and a reduced impact on the environment, in terms of carbon dioxide emissions. Dr. Iba refers to this level amount as a power threshold—dubbed $\mathrm{P}_{0}$ in his papers — which, if power demand exceeds, engages the battery circuit for discharge.

Dr. Iba, in his search to determine what parameters contribute to power demand on campus, investigated air temperature as a potential culprit. Figure 2.2.3 shows more than one year of air temperature (degrees Celsius) and peak demand (kilowatts) data. The most noticeable section of data provided in this plot is from around 2005/1/31, or mid-to-late January 2005. The average air temperature over the last few weeks of that month appears to be between 5 and 10 
degrees Celsius, which corresponds Fahrenheit temperatures of about 40 and 50 degrees, respectively. Inversely, the peak power during this same period is elevated from the average peak demand of the data set. Logically, this makes sense, as cooler temperatures usually result in the employment of heating mechanisms. In addition to peak power being elevated during lower ambient temperatures, we see that high air temperatures result in increased peak demand as well. For example, the largest peak demand shown in the figure below is found in August of 2005, or near 2005/8/8. The ambient temperature at that time is about 35 degrees Celsius (95 degrees Fahrenheit), increasing university power demand to nearly 3 MW, 3 times the BESS's rated power. Similarly, throughout the data set, any time the air temperature rises above the average air temperature, the peak demand rises as well. Clearly, this is a result of hot weather pushing consumers - the university in this case - to employ cooling mechanisms, which use about the same energy as heating mechanisms.

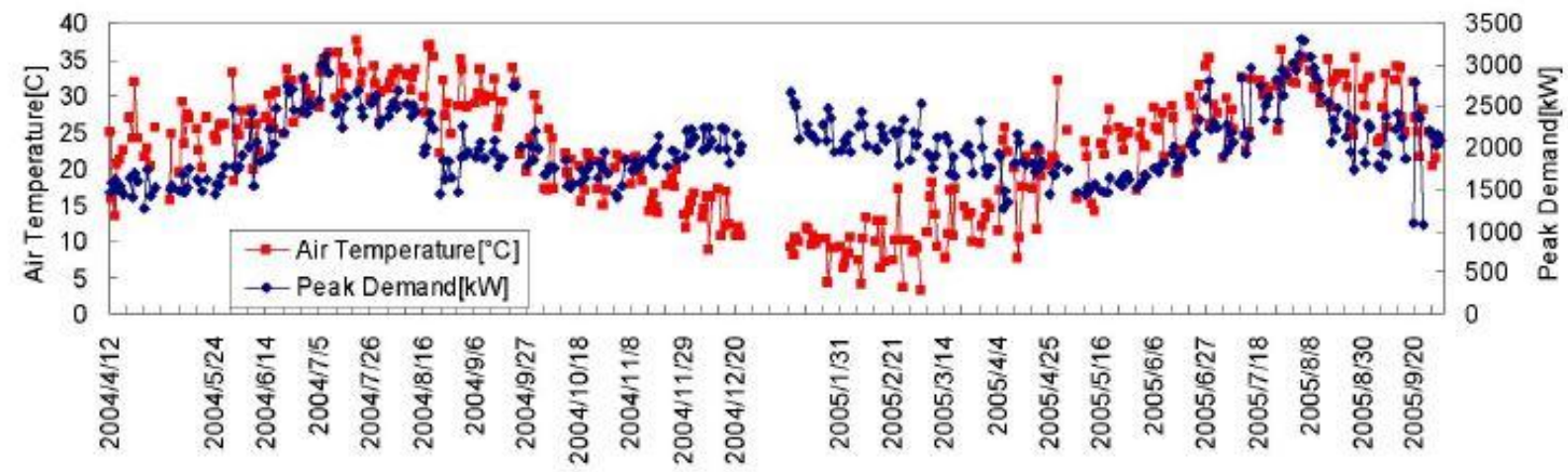

Figure 2.2.3: Meisei University Air Temp and Power Correlation.

Confirming that temperature influences the power demand on a given day, Dr. Iba includes temperature terms in his power-predicting formula. The entire formula, equations 2.2.2 and 2.3.3, and definitions of its parameters can be found below. 


$$
\begin{gathered}
\widetilde{P_{1, j}}=w_{1} S_{1, j}+w_{2} S_{2, j}+w_{3} S_{7, j}+g w_{4} S_{365, j} \\
S_{k, j}=P_{i-k, j}+\alpha\left(\widetilde{T}_{1}-T_{i-k}\right) \frac{P_{i-k, j}-P_{i-k, m i n}}{P_{i-k, p e a k}-P_{i-k, m i n}}
\end{gathered}
$$

$\mathrm{i}=$ Target date

$\mathrm{j}=$ Time number (1-48), 2 per hour

$\widetilde{\mathrm{P}_{1, \mathrm{j}}}=$ Forecasted load on date $\mathrm{i}$ at time $\mathrm{t}$ in Watts

$\widetilde{\mathrm{T}_{1}}=$ Forecasted mean temp on date $\mathrm{i}$ in Celsius

$\mathrm{T}_{\mathrm{i}-\mathrm{k}}=$ Past recorded mean temperature on date $\mathrm{i}-\mathrm{k}$ in Celsius

$\mathrm{w}_{\mathrm{p}}=$ Weight for each term in formula (unitless)

$\mathrm{S}_{\mathrm{k}, \mathrm{j}}=$ Past curve after temperature compensation ( $\mathrm{k}=1$ : yesterday) in Watts

$\mathrm{g}=$ Annual growth rate of load (unitless)

$\alpha=$ Sensitivity of mean temperature against peak load in one over Celsius

$\mathrm{i}$ is used to indicate the day for which we are predicting power, while $\mathrm{j}$ is a specific time during that day. Power is predicted in 30 minute intervals, so j ranges from 1-48. That means, each $S_{k}$ and $P_{i-k}$ curve consists of 48 points as well. Generally, it makes sense that power predictions should only be done one day in advance. The reasoning for this is that his formula predicts power based on the actual power demand of the day before the target date, two days before the target date, one week before the target date, and one year before the target date. Said actual power demand values on previous dates are represented in the formulas by $P_{i-k, j}$, where $\mathrm{k}$ is the number of days prior to the target date. For instance, if $\mathrm{k}=2, P_{i-2, j}$ is the power two days before day $\mathrm{i}$ at time $\mathrm{j}$. It is possible to predict power more than a day in advance, but that would require using predicted power in place of the actual power demand terms in equations 2.2.2 and 2.2.3. 
Based on statistical analysis conducted by Dr. Iba, each term in equation 2.2.2 should have a different weight associated with them. More specifically, he found that information from the day before the targeted date is most important, then two days before, then one year before, then one week before. The weights which minimized error between the predicted power demanded by the campus and the actual power demanded by the campus are shown in table 2.3.1.

\begin{tabular}{|c|c|c|c|}
\hline$w_{\mathbf{1}}$ & $w_{\mathbf{2}}$ & $w_{\mathbf{3}}$ & $\boldsymbol{w}_{\mathbf{4}}$ \\
\hline 0.63 & 0.24 & 0.05 & 0.08 \\
\hline
\end{tabular}

Table 2.2.1: Meisei University Weights for Equation 2.2.2.

The last term in formulas 2.3.2 and 2.3.3 that should be discussed is $\alpha$, the sensitivity of mean temperature against load. As Dr. Iba determined, there is a relationship between the power demanded by an entity and the ambient temperature. In his paper written in 2008 , he set out to find the coefficient that most accurately predicted power demand on Meisei's campus. From his statistical analysis, he found that there is no definite value of $\alpha$ during the spring and fall seasons. This can be seen in figure 2.2.4 where most fall (triangles) and spring (Xs) data points fall in the 10-20 degrees Celsius range. At those temperatures, there is no clear slope, while in both the high temperatures (summer points — squares) and low temperatures (winter points—diamonds), a positive and negative slope are found, respectively. 


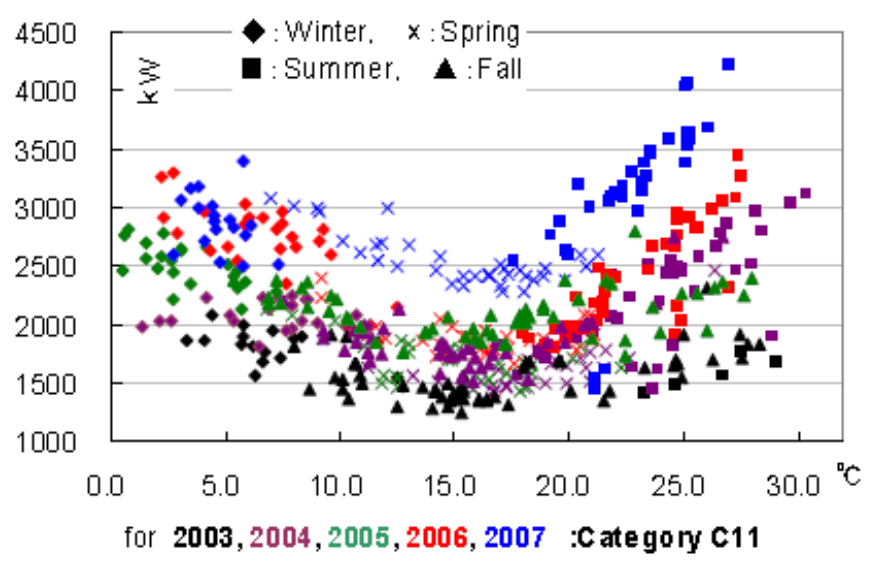

Figure 2.2.4: Meisei University Power Demand vs Temperature.

\begin{tabular}{|c|c|c|}
\hline \multirow{2}{*}{ Year } & \multicolumn{2}{|c|}{ Mean Temperature against Peak Demand } \\
\cline { 2 - 3 } & Slope & R2 \\
\hline $\mathbf{2 0 0 4}$ & 121.0 & 0.93 \\
\hline $\mathbf{2 0 0 5}$ & 90.0 & 0.83 \\
\hline $\mathbf{2 0 0 6}$ & 163.5 & 0.90 \\
\hline $\mathbf{2 0 0 7}$ & 159.1 & 0.74 \\
\hline
\end{tabular}

Table 2.2.2: Meisei University Temperature Coefficients.

Confident that the power predicting formula performed well enough to have the BESS follow the discharge curve determined by the predicted power for a given day, Dr. Iba laid out a flowchart describing how the actual algorithm works. Each of the variables included in the flowchart are described below. The algorithm begins by taking three preset variables, the timestep $\mathrm{t}$, the energy available in the battery $\mathrm{E}$, and the estimate for the nominal power that day $\mathrm{P}_{0}$. Immediately, the program checks if the timestep is a multiple of the time interval where the nominal power is to be recalculated. If so, the program follows the path to the right, summing over the power curves to yield an energy value, D. This value is then compared to E, 
to determine a mismatch between the two values. If $\mathrm{d}$, the mismatch, is large, we run into the possibility of the battery running out of energy before the day is over. As long as this mismatch is smaller than a previously specified tolerance, the program heads back to the left branch to check if it is supposed to run in default mode, or must run mode. If in must run mode, the discharge power in default mode $\mathrm{P}_{\text {must }}$ is followed. If not, the discharge power is set to equal the difference between the actual power demand in the local area at that time and the nominal power level $\mathrm{P}_{0}$, as long as this does not exceed the rated power of the battery. The energy remaining in the battery is recalculated based on the chosen discharge power. Lastly, the timestamp is updated and the loop can begin again.

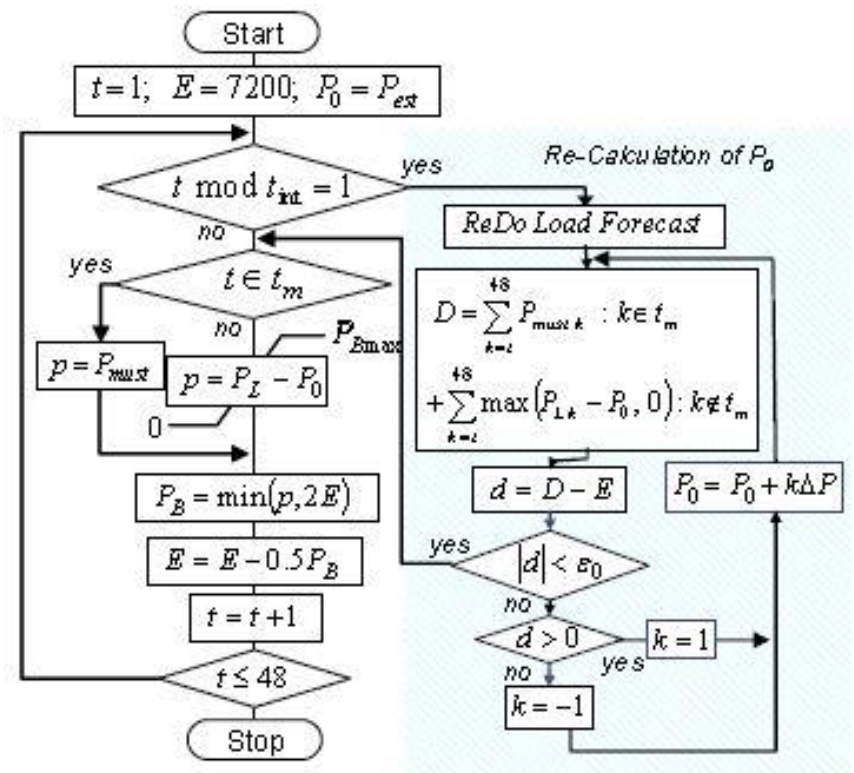

Figure 2.2.5: Meisei University Load Following Algorithm Flowchart.

$\mathrm{t}=$ timestep (1-48), 2 per hour

$\mathrm{E}=$ Energy in the battery at a given time $\mathrm{t}$. At the beginning of each day, $\mathrm{E}$ will be equal to the rated energy of the battery in kilojoules.

$\mathrm{P}_{0}=$ Target net receiving power value in kilowatts.

$\mathrm{T}_{\mathrm{int}}=$ Recalculation time interval of $\mathrm{P}_{0}$ in number of points. If $\mathrm{T}_{\mathrm{int}}=2$, the interval is 1 hour. 
$\mathrm{T}_{\mathrm{m}}=$ The time period where the battery must run at previously set constant values in point number. This is a default mode.

$\mathrm{P}_{\text {must }}=$ Power output during the default, or must run mode in kilowatts.

$P_{B \max }=$ Rated output power of the battery in kilowatts.

$\mathrm{P}_{\mathrm{L}}=$ Net power demand in the local area in kilowatts.

$\mathrm{P}_{\mathrm{B}}=$ Power output of the battery for a given timestep (30 minutes) in kilowatts.

$\mathrm{D}=$ Accumulated energy to be discharged from a given point in time until the end of the day in kilojoules. This value will converge to $\mathrm{E}$, the remainder of the battery energy.

$\Delta \mathrm{P}=$ Incremental change in $\mathrm{P}_{0}$ in kilowatts.

$\mathrm{d}=$ mismatch between $\mathrm{D}$ and $\mathrm{E}$ in kilojoules.

$\varepsilon_{0}=$ Tolerance level in kilojoules.

Figure 2.2.6 is a visual describing how well the power predicting formula 2.3.2 and algorithm performed when implemented in 2006. In the figure, multiple power curves are displayed, in addition to the error between the actual and predicted power. The actual power demanded by the campus on July $12^{\text {th }}, 2006$ is labeled "Ptrue," while the predicted power is labeled "Pforecast." The difference in power values between those two curves is labeled "error." The remaining four power curves represent actual power demanded one day, two days, one week and one year before July $12^{\text {th }}, 2006$. When power demanded by the campus is highest, the battery will need to discharge at a higher rate in order to bring the net power demanded back to the nominal level $\mathrm{P}_{0}$. Because this is when the most strain can be taken off of the grid, we want our power predicting formula to yield a small error at this time. Clearly, the smallest error between the predicted power demand and the actual power demand occurs at this time (points 14-17), which further promotes this formula as one to be implemented at NaS BESS sites. 


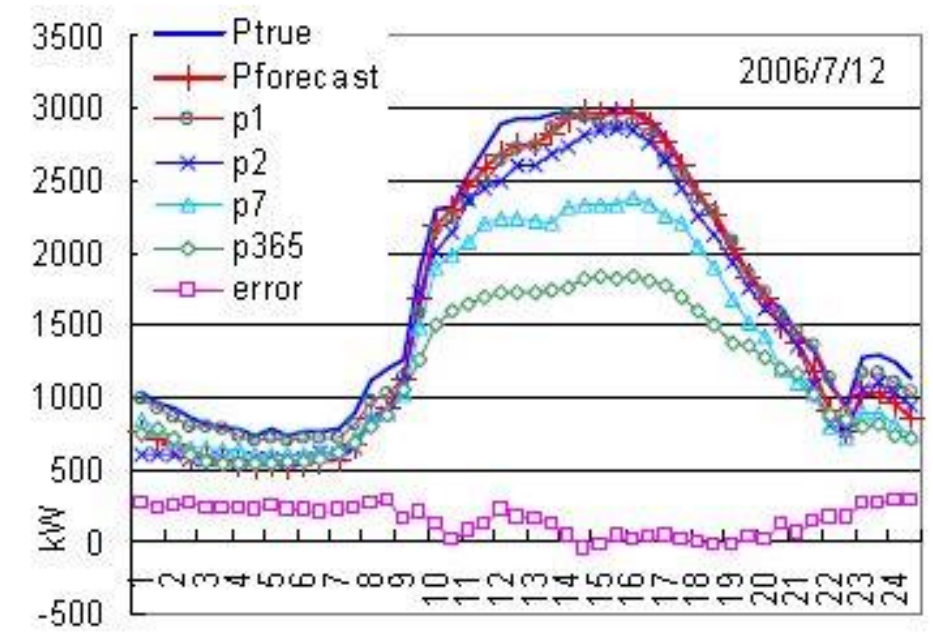

Figure 2.2.6: Meisei University Predicted Power and Error.

Above, we investigated what error was present when formula 2.3.2 was implemented as a power following algorithm. In addition to looking at magnitude of error, it is important to examine how the rated energy of the battery limits its usefulness in a grid-scale setting. Because the algorithm is meant to follow the predicted power curve, its primary concern is not the actual energy discharged into the grid. This means, when the peak power for a given day is higher and lasts longer than the average day, the amount of energy left in the battery will decay quicker because the battery will be discharging at maximum capability for a longer period of time. Figures 2.2.7 and 2.2.8 show the power of the battery over a day during a light load and a heavy load scenario. When the battery's power is below the horizontal, it is charging and when it is above the horizontal, it is discharging into the grid.

In the first case the actual load is light (compared to the average power demanded on campus) and the refresh time is set at two hours. The refresh time is set so that the nominal power level, $\mathrm{P}_{0}$, can be recalculated throughout the day. The more this value is recalculated, the more accurate the power prediction will be. In the figure, we see that the battery does not run out 
of energy to provide to the grid. This is evidenced by the fact that the received power by the campus, or the net power consumed (the red curve), does not spike during peak load hours. Peak load on campus ends around 6 pm or $7 \mathrm{pm}$, which would correspond to points 18 or 20. During daylight hours, when the most strain is present on the grid, the net power received by the campus maintains a fairly constant level, which is exactly what the algorithm was intended to do.

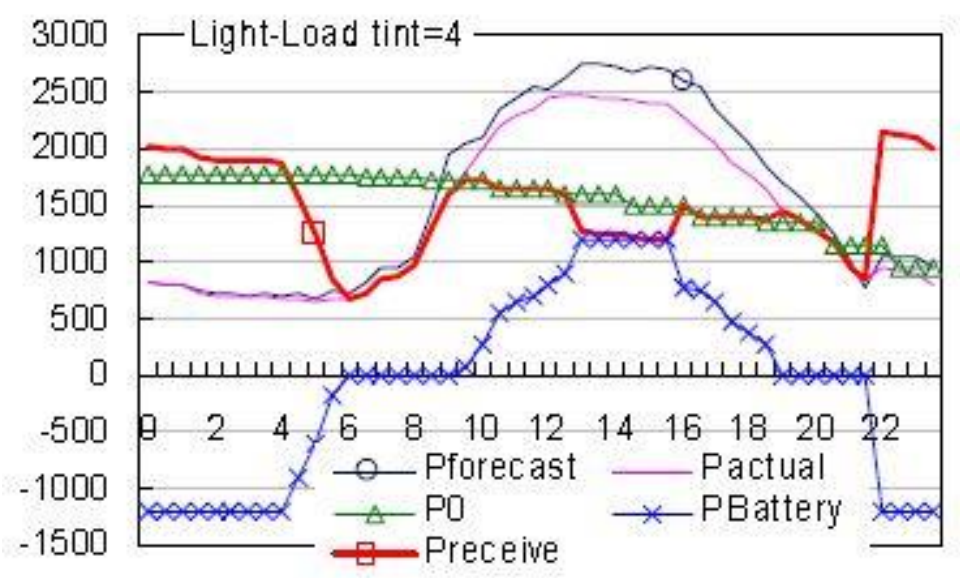

Figure 2.2.7: Meisei University Light Load Power Curves.

In the case where the power demand for a given day is heavier than on an average day, we see the net power received (the red curve) spike around 18:00 or $6 \mathrm{pm}$. Even with the refresh rate set at two, or every hour, the recalculation of the nominal power limit cannot prevent the battery from discharging to the point of zero stored energy. In this case, we see the battery discharge curve reach the horizontal before $6 \mathrm{pm}$, leaving the grid to ramp up its power supply to the campus. Placing this sort of strain on the grid is what we want to avoid, so editing of the algorithm must be done to make sure recalculation prevents the battery from becoming empty during peak hours. 


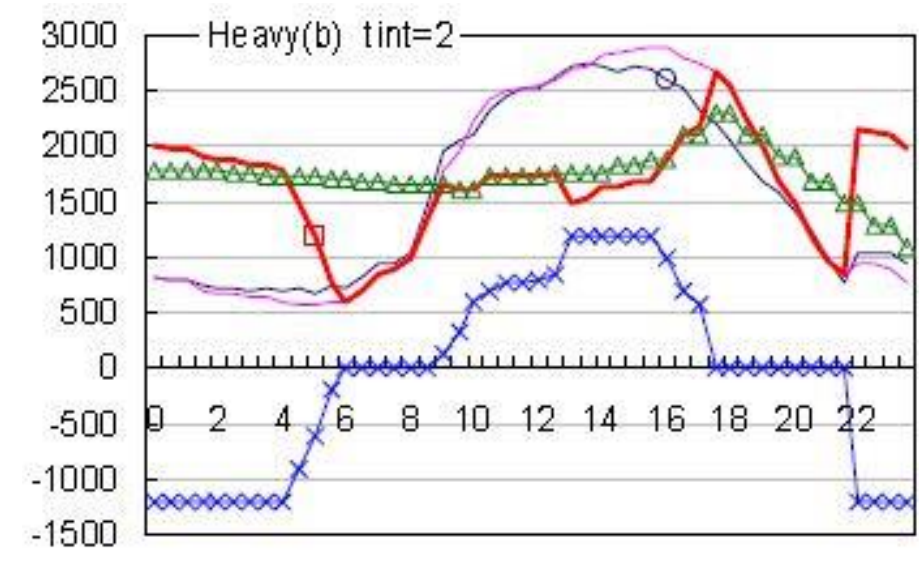

Figure 2.2.8: Meisei University Heavy Load Power Curves.

Figure 2.2.9 presents a numerical representation of how well the control algorithm performed. The author attempted to quantify the performance with three metrics. The first of those three metrics is with the standard deviation of $\mathrm{P}_{0}$. As mentioned previously, $\mathrm{P}_{0}$ is the nominal power level, or net power that we wish to be pulled from the grid. The sigma values for various days are shown in black on the plots below. The smaller the standard deviation, the better the formula performed, according to the author. The second metric used by Dr. Iba was what he calls the deficiency of battery energy, dubbed $E_{d e f}$. This value is calculated by summing the difference between the net received power and nominal power at each of the 48 points during the day and diving that by 2 , since there are 24 hours in the day and 48 points in total. In equation form, this is:

$$
E_{\text {def }}=\frac{1}{2} \sum_{j=1}^{48} P_{\text {received }, j}-P_{0, j}
$$

The third and final metric used to measure the control algorithm's performance was peak receiving power. Ideally, the peak receiving power would be equal to the nominal power $\mathrm{P}_{0}$. 
This metric is generally useful, because the closer the peak is to $\mathrm{P}_{0}$, the better the algorithm is performing. Though it holds some merit as a tool to measure performance, it cannot be the only measure of success due to the fact that the battery has discharge power and energy storage limitations. Because the peak power at any point in the year in not more than 3-5 times the rated power of the battery, the specifications of the battery are not terribly limiting. If the average peak power demanded in a day was closer to 10 times the rated power of the battery, the peak receiving power would be rather high on a daily basis. The resulting net received power curve would have nearly the same shape as the actual demanded power, rather than the flat line that we are looking to obtain.

Between the two plots within the figure below, the energy deficiency is generally lower in the second plot, though not all of the major spikes are eliminated. Interestingly enough, the refresh rate changing from two hours down to one hour does not really affect the other two metrics, standard deviation of the nominal power level and the maximum power received. 

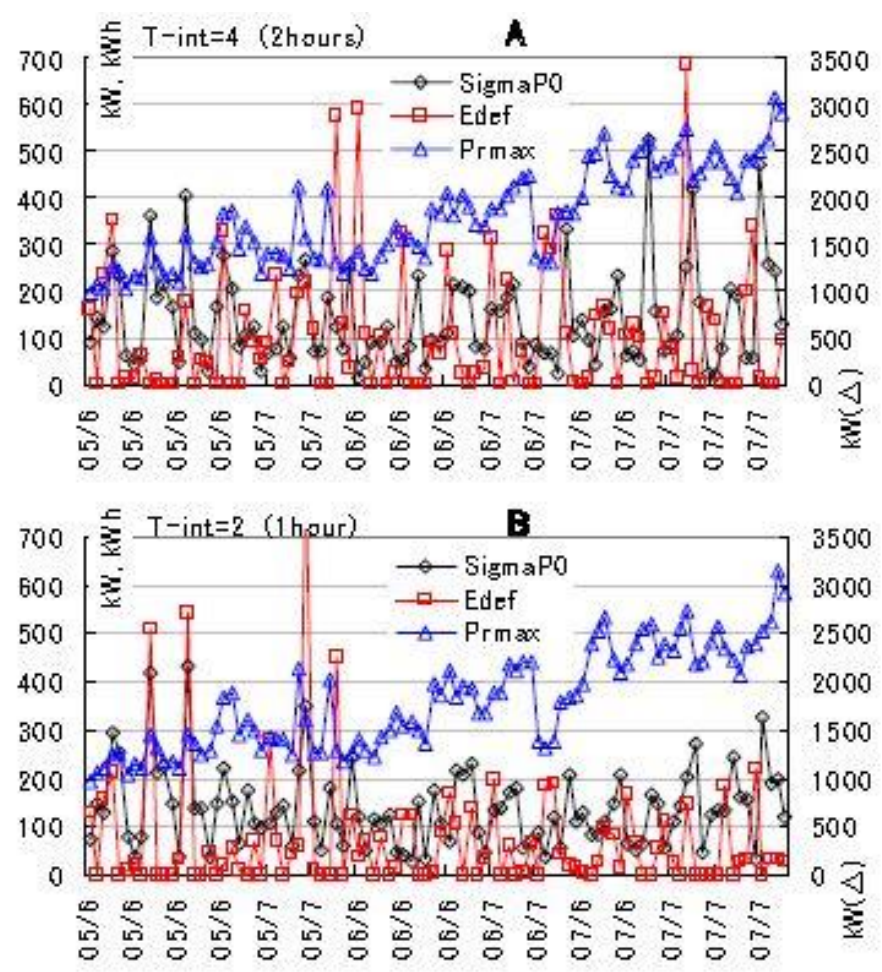

Figure 2.2.9: Meisei University Algorithm Performance. 


\section{Chapter 3 -- Simulation and Implementation of Charging and Discharging Algorithm}

Dr. Kenji Iba’s NaS Battery Energy Storage System control algorithm yielded promising results in terms of load following. Implementing such an algorithm would certainly assist utility companies in leveling load, reducing strain on electrical equipment and use of peaker power plant providers. As mentioned in previous sections, the programmer of the battery control must be very aware of the rated energy of the battery and be sure to avoid reaching the minimum state of charge during peak local usage. Failing to do so will result in a large net received power spike during a period of time when the grid is already under stress from surrounding loads. In the algorithm developed for the PG\&E NaS batteries, this will be at the forefront of concerns.

Because load leveling was only one of the services that can be provided by the grid-scale battery at the Yerba Buena site, the algorithm will need to incorporate voltage support, frequency support and pricing data. To successfully provide all of these services, a layered program will be created which uses a list of priorities to determine how the battery should charge and discharge.

\section{Section 3.1: Initial Algorithm Development}

The first step in developing a custom algorithm for the BESS should be to determine the priority of each service we would like the system to provide. One might believe there are two different points of view to be addressed, that of the private owner of the battery and that of the utility company. Ultimately, if private owners are to receive payments for their grid-scale system providing services, they will be paid by the utility. Therefore, it is in the private owner's best interest to create an algorithm that matches the priorities of the utility companies. If a utility owns a grid-scale storage system, their priorities are to reduce cost, provide reliable service to customers, and reduce risk of damaging equipment. Dr. Iba's algorithm will assist the grid in supplying power to local load. This addresses marginal cost reduction, since less power must be 
purchased from a wholesaler, or worse, a peaker plant. There are several methods to address the protection of equipment. When large loads are present, line voltage can drop. When voltage sags below a certain point, equipment can be severely harmed, so current transformers, relays, and circuit breakers are used to open connections before this point. Ideally, utilities would prefer the algorithm to sense voltage levels, understand when voltage needs to be boosted, and communicate with its DC/AC converter to adjust reactive power output. Raising reactive power output from the battery will provide voltage support, restoring line levels to their nominal values, while maintaining service to customers. Maintaining service means continuing to sell energy, therefore reducing theoretical losses that would have been incurred had the battery not helped restore nominal line voltage and breakers had tripped. Similarly, to supply reliable service and protection of equipment, the line frequency must also be kept within a certain range. Loosely, this range is between 59 and $61 \mathrm{~Hz}$. Under heavy load conditions, frequency drops, and under light load conditions, frequency rises. Response to a change in frequency can be done mechanically with generators, but it is much quicker to regulate frequency electronically, say with a battery. Clearly, as with voltage levels, utilities would want the algorithm to monitor line frequency and increase or decrease power output accordingly to reduce or raise frequency back to $60 \mathrm{~Hz}$. Knowing how expensive grid equipment is, it seems the gains from keeping this equipment safe outweigh the gains of load leveling. This allows us to declare the priorities of the algorithm as:

\section{Voltage Support}

2. Frequency Support

3. Energy Arbitrage

4. Load- Leveling 
i. Based on Dr. Iba's formula

\section{Section 3.2: Data and Analysis of First Algorithm}

To develop the algorithm, a few pieces of information are needed. As discussed above, the load-leveling layer of the program will be directly from formulas 2.3 .2 and 2.3.3. These formulas require past power and weather data. Load data from the Hitachi office in San Jose, California (where the battery is located) for March 2009 to March 2010 was provided by PG\&E and fed through the load-following portion of the algorithm. The weather data was pulled from Wunderground.com, a website that stores ambient information collected at airports around the country. Equally, a TMY3 file could have been pulled from the National Renewable Energy Laboratory's website, as they possess similar, if not the same airport weather data.

Though the load-leveling portion of the program is based on Dr. Iba's formula, changes needed to be made in order to fit the collected data and environment of the battery. The first thing to note is that data provided by PG\&E was 15 minute data. This means a data point was collected every 15 minutes rather than the 30 minutes presented in Dr. Iba's paper written in 2008. As a result, there are 96 data points per day, which should increase the accuracy of the predicted power values, given the same constants. Next, those constants, such as the temperature sensitivities provided in the Meisei University study, need to be adjusted such that they fit weather relationships in the Bay Area, California. Because the Bay Area has a very temperate climate, the minimum average temp for a given day in our data set was nearly 50 degrees Fahrenheit, or 10 degrees Celsius, compared to a minimum average temperature between 0 and 7 degrees Celsius. The amount of heating required to keep warm is smaller in this part of California, so the slope of the temperature sensitivity has a smaller magnitude. Similarly, the maximum average temperature in the Bay Area in the data set was 84 degrees Fahrenheit, or 
about 28.9 degrees Celsius, compared to a maximum average temperature of 30 degrees Celsius in Japan. Because this part of California has slightly cooler temperatures in the summer, the temperature sensitivity has a smaller magnitude. To account for this difference, temperature sensitivities for San Jose, California were calculated. Figure 3.2.1 shows all of the data points for the summer and winter seasons and the regression lines calculated by Microsoft Excel. Points in red represent data recorded in summer, while points in blue represent data recorded in winter. The temperature coefficient seen in formula 2.3.2 is different for each of the seasons and equal to the slope of the best fit line. In other words, the $\alpha$ value for summer and winter should be 0.0338 and 0.0271 , respectively. Below each of the best fit line equations is the measure of how well the line fits the data points. The closer to 1 the $\mathrm{R}^{2}$ value is, the better the fit. The summer $R^{2}$ value was calculated as 0.1065 , while the winter $R^{2}$ value was calculated as 0.0636 . Clearly, these numbers are not approaching 1 , where the regression line perfectly fits the data. For this reason, the temperature coefficient for summer and winter found here should not be used.

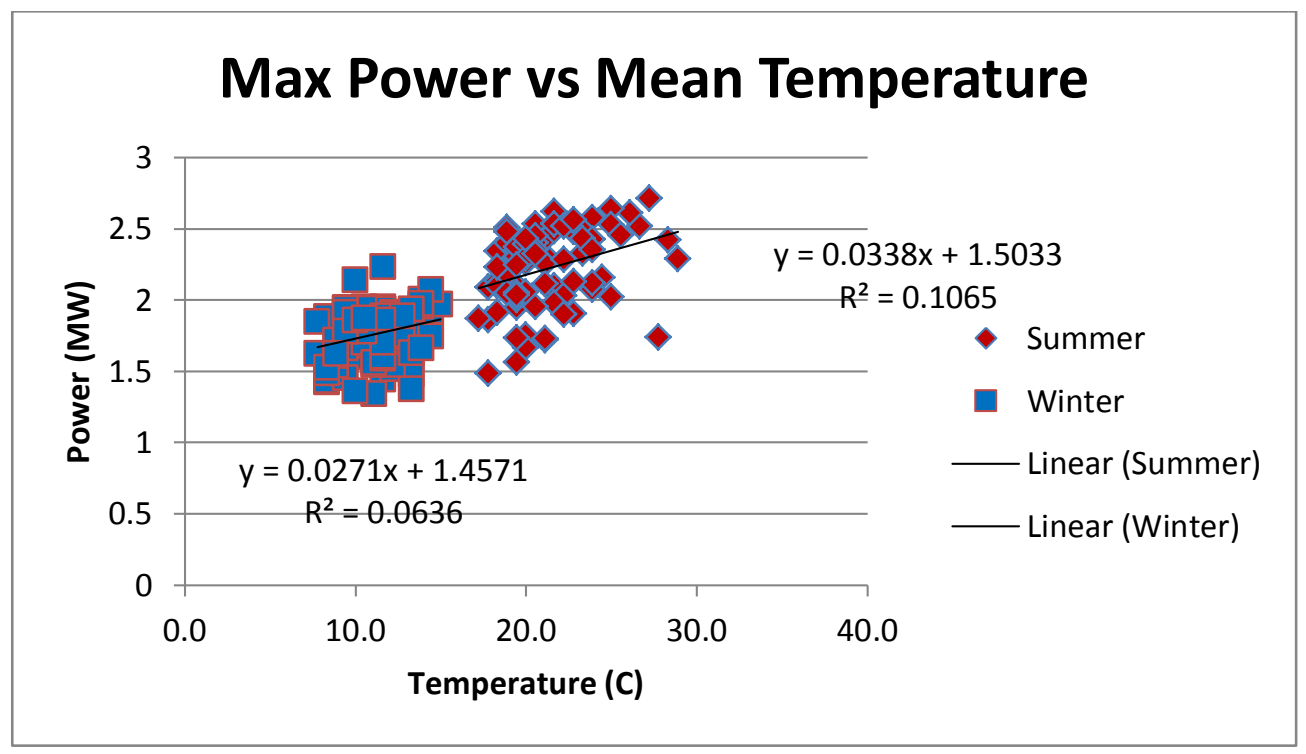

Figure 3.2.1: Finding Temperature Sensitivity for San Jose, CA. 
The second method used to determine the appropriate temperature coefficients for summer and winter was to use the data from both seasons and run a single regression. Figure 3.2.2 shows the combined data set and single regression. The slope calculated for the best fit line was 0.0435 . The $\mathrm{R}^{2}$ value calculated for this linear relationship was 0.5382 . Unlike the case shown above, the fit of this line was much closer to 1 . This slope was used as the temperature coefficient, $\alpha$ for both summer and winter, while spring and fall had values of 0 , in the algorithm developed for PG\&E's NaS batteries. These values are summarized in Table 3.2.1.

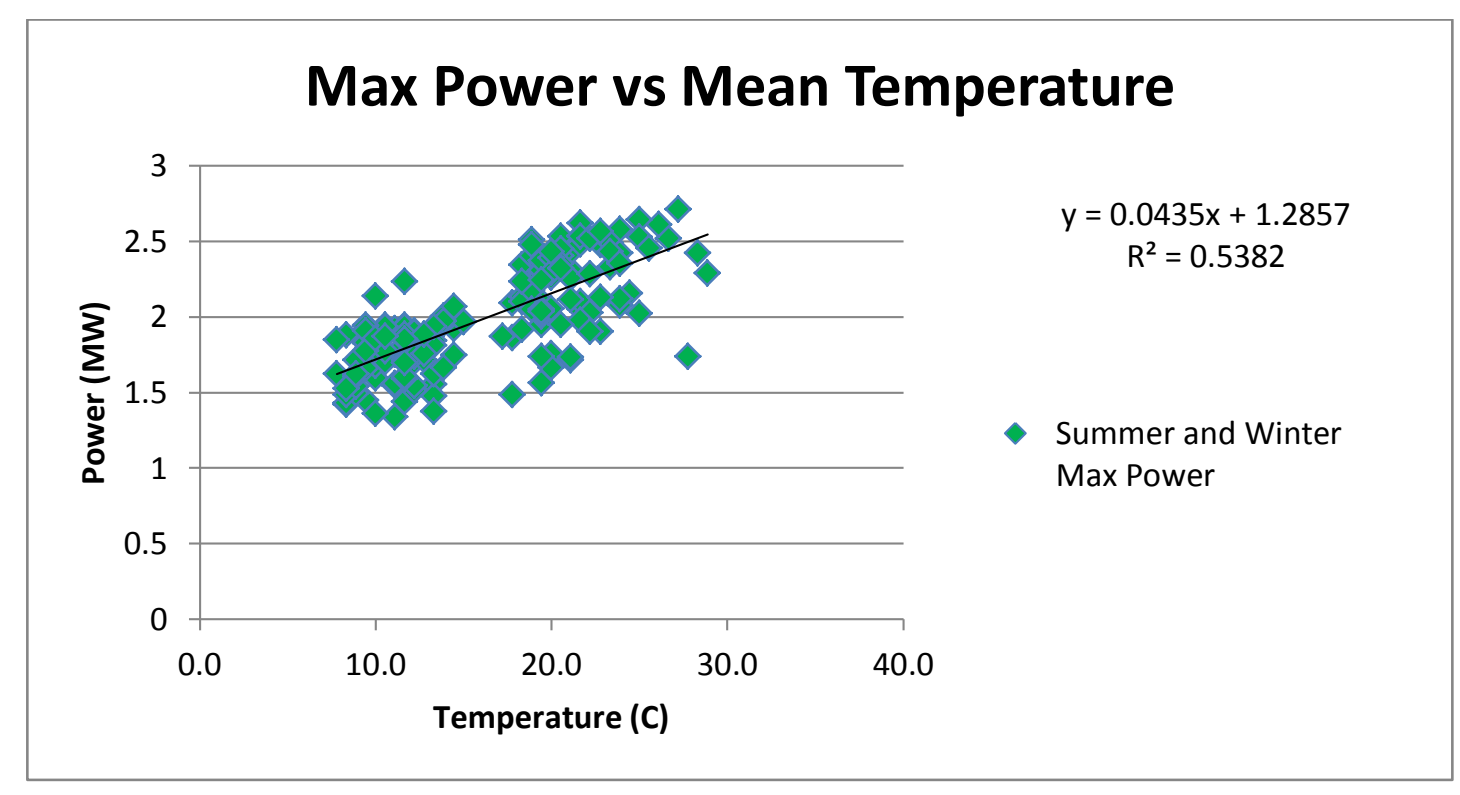

Figure 3.2.2: Temperature Sensitivity for San Jose, CA

\begin{tabular}{|l|r|r|r|}
\hline \multicolumn{2}{|c|}{ Season Dates (Start - End) } & Coefficient \\
\hline Spring & $3 / 15 / 2009$ & $6 / 19 / 2009$ & 0 \\
\hline Summer & $6 / 20 / 2009$ & $9 / 19 / 2009$ & 0.0435 \\
\hline Fall & $9 / 20 / 2009$ & $12 / 19 / 2009$ & 0 \\
\hline Winter & $12 / 20 / 2009$ & $3 / 19 / 2010$ & 0.0435 \\
\hline
\end{tabular}

Table 3.2.1: Season Dates and Temperature Sesitivities.

The last edit to make in order to apply formulas 2.3.2 and 2.3.3 to the system at hand is to the weight coefficients in formula 2.3.2. The four terms in the equation, adjusted power from one 
day before, two days before, one week before, and one year before, work together to predict the power demanded for a target day. The data set provided by PG\&E was for the dates of March 15, 2009 to March 14, 2010. Since this is one year of data, it is not possible to include the fourth term in formula 2.3.2. Because Dr. Iba's algorithm yielded positive results, keeping similar weight coefficients seemed reasonable, so when eliminating the fourth term (assigning a weight of 0 to it), the weights of the other terms should not be far off from those presented in Table 2.2.1. The weights shown in Table 3.2.2 are the values used in the proposed control algorithm for the NaS BESS.

\begin{tabular}{|c|c|c|}
\hline $\begin{array}{l}\text { Weight } \\
\text { Term }\end{array}$ & Description & $\begin{array}{l}\text { Magnitude Used in Proposed } \\
\text { Algorithm }\end{array}$ \\
\hline w1 & $\begin{array}{l}\text { Coefficient of adjusted power from } 1 \text { day before target } \\
\text { date }\end{array}$ & 0.66 \\
\hline w2 & $\begin{array}{l}\text { Coefficient of adjusted power from } 2 \text { days before } \\
\text { target date }\end{array}$ & 0.25 \\
\hline w3 & $\begin{array}{l}\text { Coefficient of adjusted power from } 7 \text { days before } \\
\text { target date }\end{array}$ & 0.09 \\
\hline w4 & $\begin{array}{l}\text { Coefficient of adjusted power from } 365 \text { days before } \\
\text { target date }\end{array}$ & 0 \\
\hline
\end{tabular}

Table 3.2.2: Weight Coefficients Used in Algorithm.

With the changes presented in this section, our load predicting equations became:

$$
\begin{gathered}
\widetilde{\mathrm{P}_{1, j}}=0.66 \mathrm{~S}_{1, j}+0.25 \mathrm{~S}_{2, \mathrm{j}}+0.09 \mathrm{~S}_{7, \mathrm{j}} \\
\mathrm{S}_{\mathrm{k}, \mathrm{j}}=\mathrm{P}_{\mathrm{i}-\mathrm{k}, \mathrm{j}}+\alpha\left(\widetilde{\mathrm{T}}_{1}-\mathrm{T}_{\mathrm{i}-\mathrm{k}}\right) \frac{\mathrm{P}_{\mathrm{i}-\mathrm{k}, \mathrm{j}}-\mathrm{P}_{\mathrm{i}-\mathrm{k}, \mathrm{min}}}{\mathrm{P}_{\mathrm{i}-\mathrm{k}, \text { peak }}-\mathrm{P}_{\mathrm{i}-\mathrm{k}, \mathrm{min}}}
\end{gathered}
$$

where $\alpha$ is dependent on the season of year and given in Table 3.2.1. 
In order to understand how well the power predicting portion of the algorithm performs once all the changes to Dr. Iba's formula have been applied, the square error for each day was calculated. Square error is this project is given by:

$$
\text { Square Error }=\frac{1}{96} \sum_{j=1}^{96}\left(P_{i, j}-P_{0}\right)^{2}
$$

where $P_{i, j}$ is the power on target date $i$ and time $j$, and $P_{0}$ is the target net power received by the local load. A power prediction formula that perfectly predicts the power demanded at every data point during the day will yield a square error of zero. To get a visual idea of what a certain square error looks like, a few days were chosen at random to analyze. Figures 3.2.3 and 3.2.4, shown below, are plots of predicted power demanded (red) in MW and actual power demanded (blue) in MW versus Point Number of the day. Data for June $25^{\text {th }}, 2009$ is presented first, with a square error for the day of 0.0183 . Having a small error between predicted and actual power demand at each point of the day is ideal, but it is most important that error is minimized during peak use hours, such that the load-leveling to reduce strain on the grid is most effective. Peak usage, in terms of point number for this date is from 50 to 70 , or 12:30 pm to 5:30 pm. During this time, the red curve, though not overlapping the blue curve, is following it pretty well. 


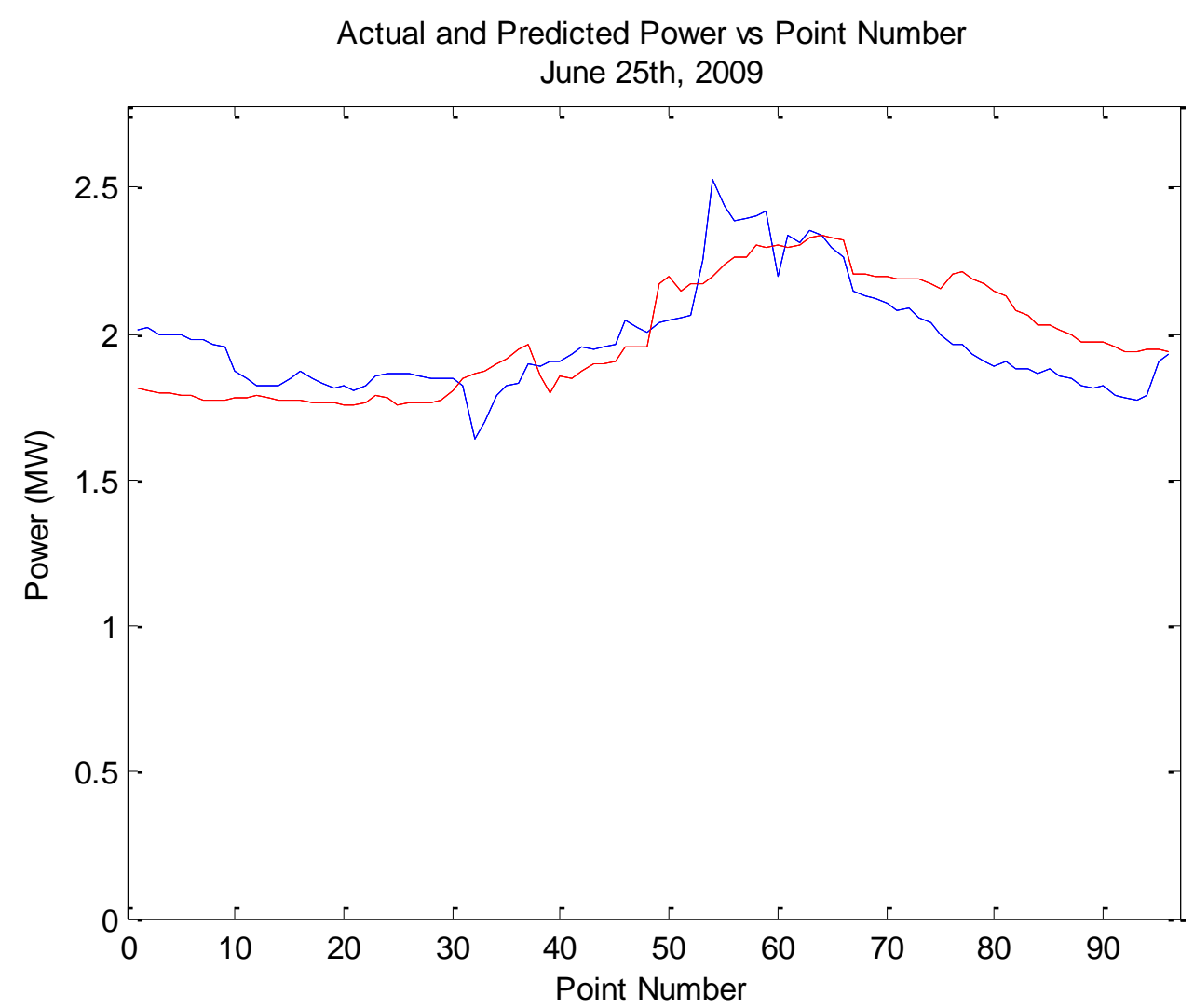

Figure 3.2.3: Square Error (6/25/2009).

Figure 3.2.4 shows predicted power and actual power data from June $27^{\text {th }}, 2009$ with a square error of 0.17 , nearly 10 times higher than on June $25^{\text {th }}$. Clearly, the predicted power has a similar shape as that of the actual power demand, but there is always a power gap between the two curves, rather than an overlapping. From these two plots, we can now picture what a given square error value to correlate to in terms of matching the predicted power to the actual power. 


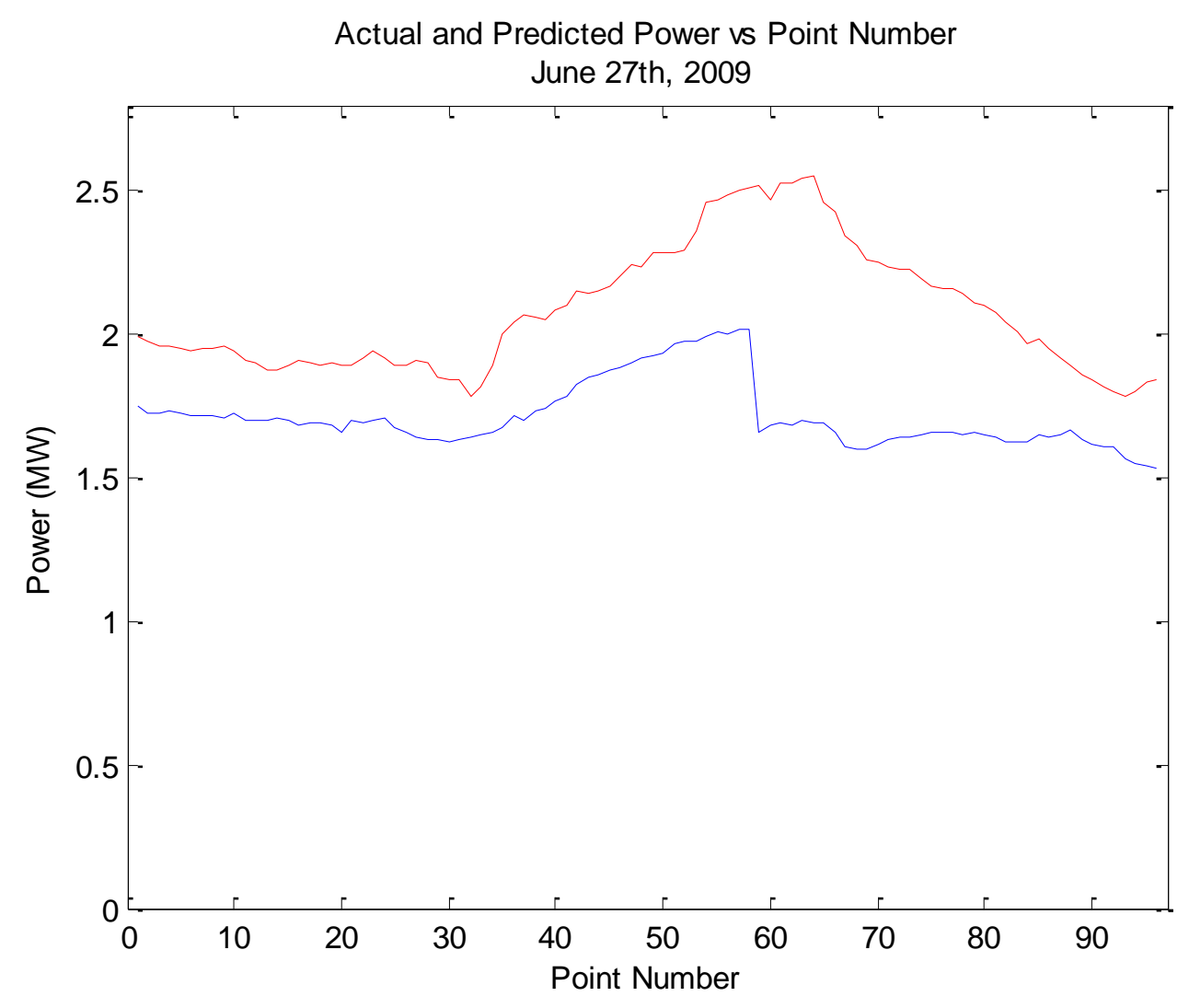

Figure 3.2.4: Square Error (6/27/2009).

As mentioned previously, the complete algorithm has three services it provides, but accounts for energy prices as well, totaling to four different portions. Figure 3.2.5 shows the flowchart for the proposed control scheme of the NaS battery system. The program begins creating a dummy variable that is then compared to the actual line voltage, vLine. If the line voltage is less than the nominal minus a predetermined tolerance, the battery systems can aid in restoring line voltage to its nominal value by sending reactive power to the grid. This is done by altering the output $\mathrm{AC}$ voltage from the battery system's power electronics such that it is higher than the line voltage. Once this has been done, the program loops back around to check if the line voltage is still less than the nominal value minus some tolerance. If so, it simply executes as it did before. If the line voltage is not less than the nominal line voltage minus some tolerance, 
the program checks if the actual line voltage is higher than the nominal value plus that same tolerance. If so, the battery begins (or continues) to charge, increasing the load seen by the grid. Increasing the load seen by the grid should result in a voltage sag, if the rated power of the battery is comparable to the total transformer load which the system is connected to. Once the battery has begun charging, the program loops back around to check if the actual line voltage is too low or too high. Assuming the line voltage is where it is supposed to be, somewhere between $\pm 5 \%$ of the nominal voltage, the program moves on to the frequency regulation phase.

Just as with the voltage regulation section, the program creates a dummy variable to check if the frequency of the line is less than $60 \mathrm{~Hz}$ (the nominal line frequency is the US) minus some tolerance. If the line frequency is low, the battery begins (or continues) discharging energy into the grid. This reduces the load as seen by the grid, hopefully restoring the frequency to 60 Hz. Once this portion of the program has been executed, it loops back around to the beginning of the frequency phase to check if the line frequency is still less than the nominal frequency minus some tolerance. If not, the program checks if the frequency is higher than the nominal line frequency plus some tolerance. If so, the battery begins (or continues) charging to increase the load as seen by the grid, hopefully restoring the frequency to $60 \mathrm{~Hz}$. To double check that the frequency is within an appropriate range, the code loops back to the beginning of the frequency phase to check if the line frequency is within its allowed range. If this is true, the algorithm moves to the price portion.

In this section, real time price information is assumed to be available. Thresholds for charging and discharging are created with the intent to discharge the battery when the actual price is higher than a specified threshold and charge the battery when the actual price is lower than a specified threshold. The discharge threshold is given by the average price to purchase 
energy during that season plus some tolerance, while the charge threshold is the average price to purchase energy during that season minus some tolerance. The magnitude of power sent to or pulled from the grid will be determined by how much the actual price exceeds the discharge price threshold or lags below the charge price threshold. For example, if line voltage and frequency are at acceptable levels and the price of energy is $\$ 100$ per MWh more than the discharge price threshold, the battery should discharge at a higher rate than if the price is only $\$ 10$ per MWh more than the threshold. If either of the thresholds is broken, the program changes the battery power appropriately and loops back around to see if the real time price is has changed. If neither of the thresholds is broken, the program moves to the final phase of the algorithm, the load-leveling phase.

The goal of the load-leveling phase is to reduce the amount of power the grid supplies to a given load. The load could be a distribution transformer or a single customer. In the case of the Yerba Buena BESS, Hitachi is the closest client and some of their load data will be analyzed. Because a flat load represents the smallest strain on the grid, the load-leveling phase aims to create a constant (or close to) net load seen by the grid. To do this, a target power, p0, is set as the goal for net received power from the grid. This target value is recalculated at a user specified interval to ensure that the battery has enough energy stored in it to feed the grid. The algorithm immediately checks if it is time to recalculate this target value. If so, the energy required by the battery to meet the target for the rest of the day, $\mathrm{D}$ is calculated. This is done by summing over the remaining projected power points minus the target power value and multiplying them by 0.25 since four points are taken every hour, and we are looking for energy in terms of Megawatt Hours. If there is a user specified time for charge or discharge, D is simply altered by finding the energy stored or used in that time and then summing over the non "must run" times. The 
algorithm then evaluates whether the energy needed for the rest of the day is greater than the energy left in the battery. If so, the target power level is raised, reducing the energy needed from the battery. Once $\mathrm{p} 0$ has been adjusted appropriately, the battery power for the next 15 minutes (assuming no voltage, frequency, or price interruptions occur) is decided. The battery discharge level cannot exceed the maximum or minimum set by the manufacturer and is either the predicted power minus the target power, or the total energy left in the battery divided by the remaining time in the day. Whichever of these quantities is smaller is the one that is actually set as the battery's output. If a negative output is calculated, that means the battery is charging, as negative output is, in fact, input to the device. The remaining energy in the battery after this 15 minute interval then found by subtracting the battery power multiplied by 0.25 and subtracting it from e, the battery's available energy. If the battery is charging (negative $\mathrm{pB}$ ), e will increase. If pNum (point number, 1 through 96) is greater than 96, the current day is updated otherwise, the current point number of the day is incremented to pNum plus 1 and the program restarts at the voltage correction phase.

It is important to note, just as in the last portion of the proposed control algorithm, though not shown in the flowchart due to space limitations, the energy of the battery is recalculated at the end of each phase. The new energy the battery has available for discharge after a time interval is:

$$
\mathrm{e}=\mathrm{e}-\mathrm{t} * \mathrm{pB}
$$

where e is the available energy (megajoules) in the battery and $\mathrm{pB}$ is the battery power (megawatts) for $t$ minutes. Contrary to the energy equation in the load-leveling phase, the 
energy recalculation for the other three phases uses a place holder $t$ for the time. This is because the battery output will not last for a full 15 minutes, necessarily. When correcting voltage or frequency to nominal levels or selling/buying power from the grid, the battery only need be on for a few seconds in some instances. For this reason, an internal clock must be used to monitor the time passed until the sequence has been completed. Whatever elapsed time the system records is inserted into t's place in equation 3.2.4.

\section{Proposed NaS BESS Control Algorithm}

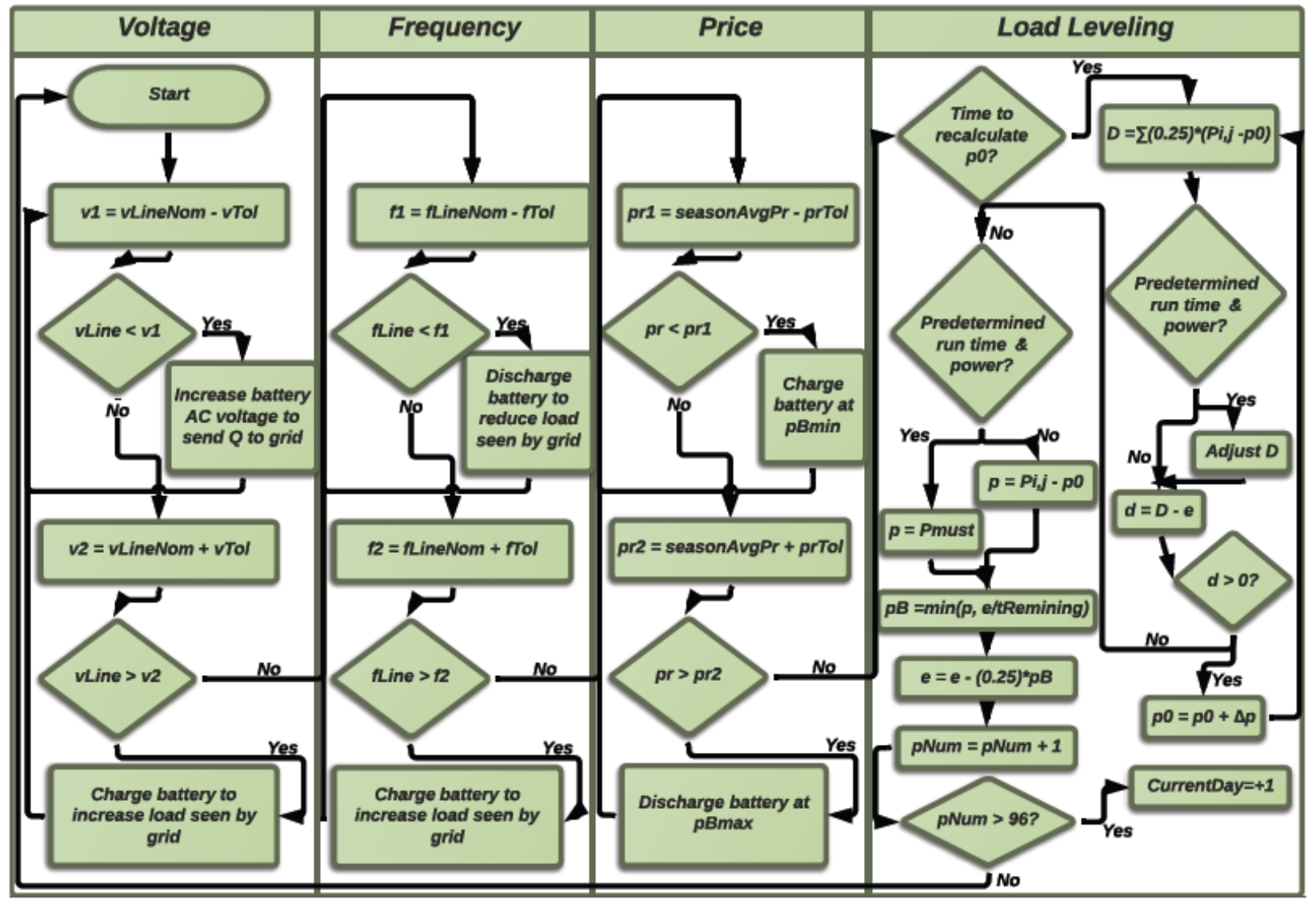

Figure 3.2.5: Proposed Control Algorithm Flowchart. 
vLine = Actual line to line AC voltage connected to NaS BESS at a given moment

vLineNom $=$ Nominal line to line AC voltage connected to NaS BESS (21kV at Yerba Buena)

vTol $=$ User decided limit for how far from nominal line voltage is acceptable

fLine $=$ Actual line frequency connected to NaS BESS at a given moment

fLineNom $=$ Nominal line frequency connected to NaS BESS $(60 \mathrm{~Hz}$ in the United States $)$

$\mathrm{fTol}=$ User decided limit for how far from nominal frequency is acceptable

$\mathrm{pr}=$ Actual price per $\mathrm{kWh}$ in the region where the BESS is located at a given moment

seasonAvgPr = Average price per $\mathrm{kWh}$ for the current season of the year

prTol $=$ User decided limit for how far from average price is acceptable

\section{Section 3.3: Assessing Performance of First Algorithm}

Having presented the proposed control algorithm, it may be beneficial to compare the complex battery power curve to that of much simpler cases. The simplest of cases would be exactly as done in the Vacaville-Dixon PG\&E report, where the battery is charged to $100 \%$ state of charge and then discharged at a single rate down to $10 \%$ state of charge (per the manufacturer's recommendation). Figure 3.3.1 shows the battery system charging at the rated power for the Yerba Buena plant, $4 \mathrm{MW}$. Power values during charging times will always appear as negative values since the BESS is a source of power. The system is assumed to be at $10 \%$ state of charge and then charged all the way up to $100 \%$ state of charge. After sitting idle for a few hours, the battery is discharged from $100 \%$ down to $10 \%$ at $4 \mathrm{MW}$ during peak usage hours. 


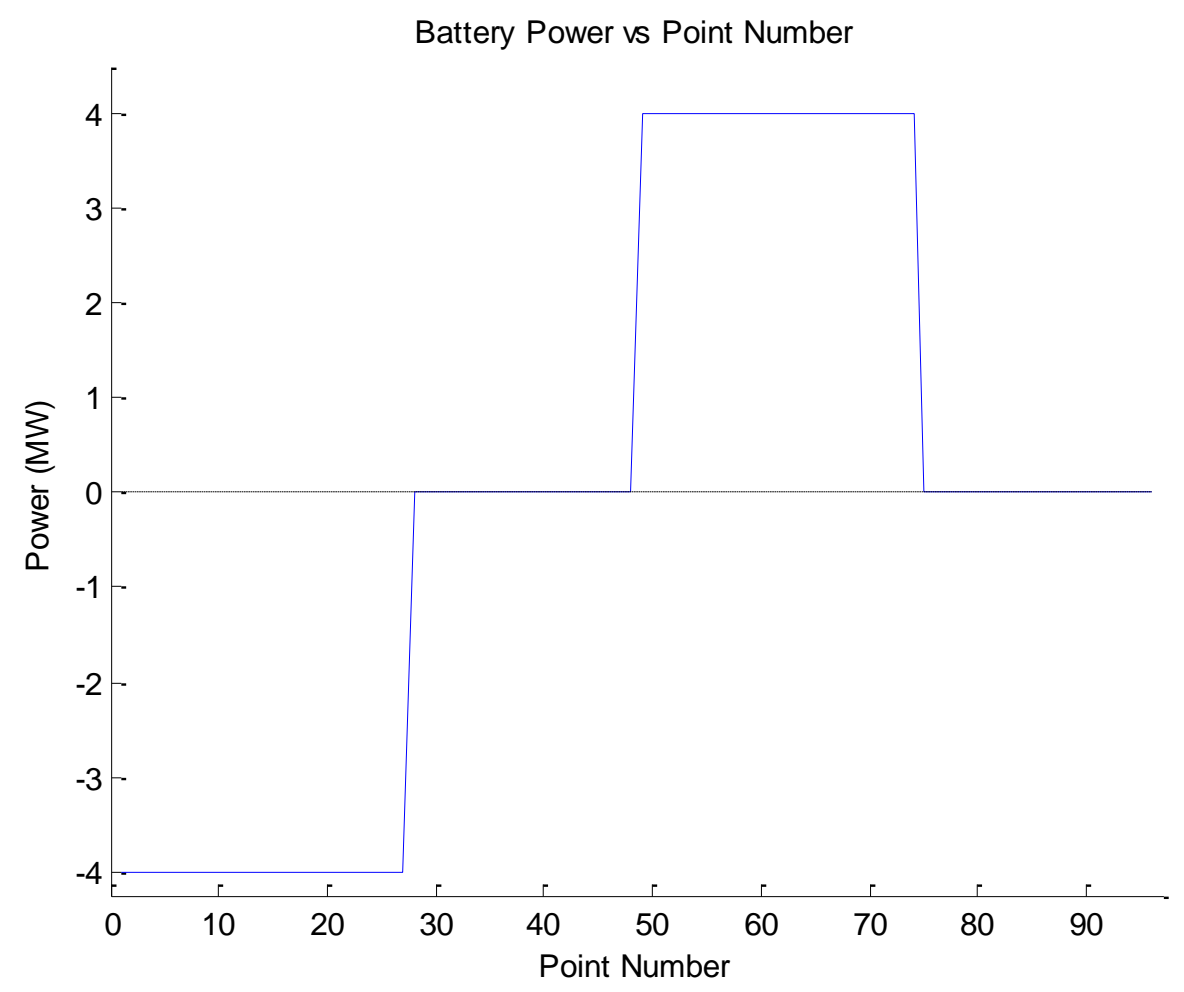

Figure 3.3.1: Simple 7 Hour Discharge Profile.

Because economics are a huge factor in this project, we need to know the energy that is stored or delivered in each of those periods. If the battery is being used to its full potential, which it is here, the net change in energy in the battery for a given day will be zero. This does not mean that the battery will have neither lost nor made the user any money. Energy prices are most expensive during peak hours, so theoretically, there are gains to be calculated from the energy arbitrage committed in this example. The net amount of money gained by the system's performance is:

$$
\text { Profit } \left.=0.25 \text { hours } * \sum_{j=1}^{96} \text { Price }_{\text {per } k W h}\left(\mathrm{P}_{\text {Out }_{j}}-\mathrm{P}_{\text {In }_{j}}\right) \text { [Dollars }\right]
$$


In words, the profit made from the battery is equal to the net power out multiplied the price at that time, multiplied by the time the battery discharged at that rate, summed over all points of the day. Because power multiplied by the time the system discharges at that certain rate yields energy, it makes sense to discuss energy in a visual manner, as well. Figure 3.3.2 shows the same power curve as in the figure above, with the addition of indicating the energy stored and sent to the grid during charging and discharging, respectively. Because the state of charge at the beginning and end of the day is assumed to be the same, the net energy gained by the battery is zero.

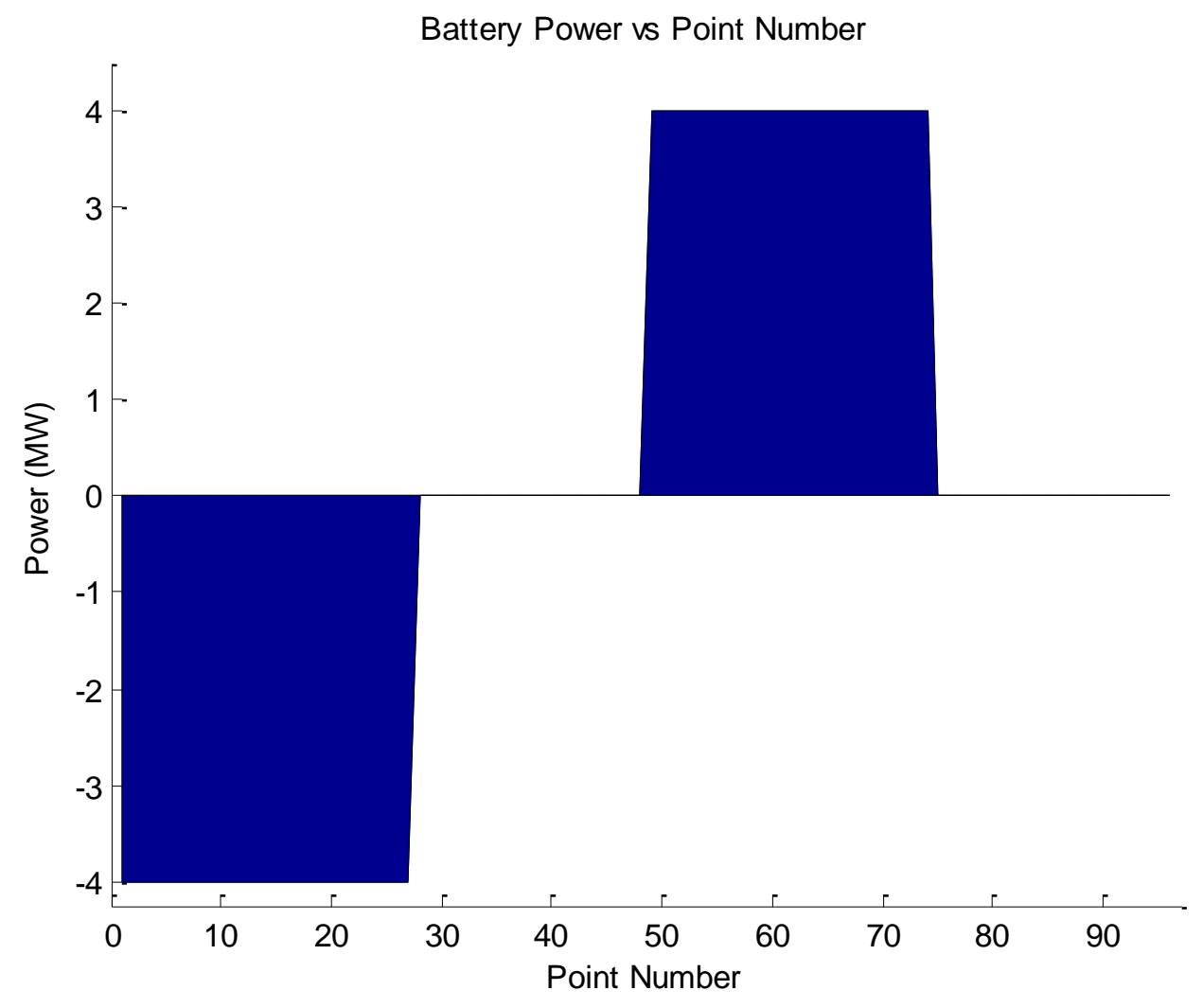

Figure 3.3.2: Simple 7 Hour Discharge Profile with Area. 
Another very simple discharge profile is shown below in Figure 3.3.3, where, this time, the charging rate and duration is the same as presented above, but the discharge rate is half as large and the duration is twice as long. In total, this battery could be discharged at half of its rated power, $2 \mathrm{MW}$, for nearly 14 hours in a given day. If the local load is typically around this size, power from the grid would not even be required. Just as Figure 3.3.2 indicates the energy stored and sent to the grid for the profile in Figure 3.3.1, Figure 3.3.4 shows the energy stored and sent to the grid for the profile in Figure 3.3.3. Though the shapes of these areas are quite different, the net energy stored in the battery is still zero. Similar to first profile, the profit yielded by this discharge curve is given by equation 3.2.1. Using pricing data, we can determine how much profit can be made from the two simple cases and compare that to the profit made in the case where our load following algorithm is implemented.

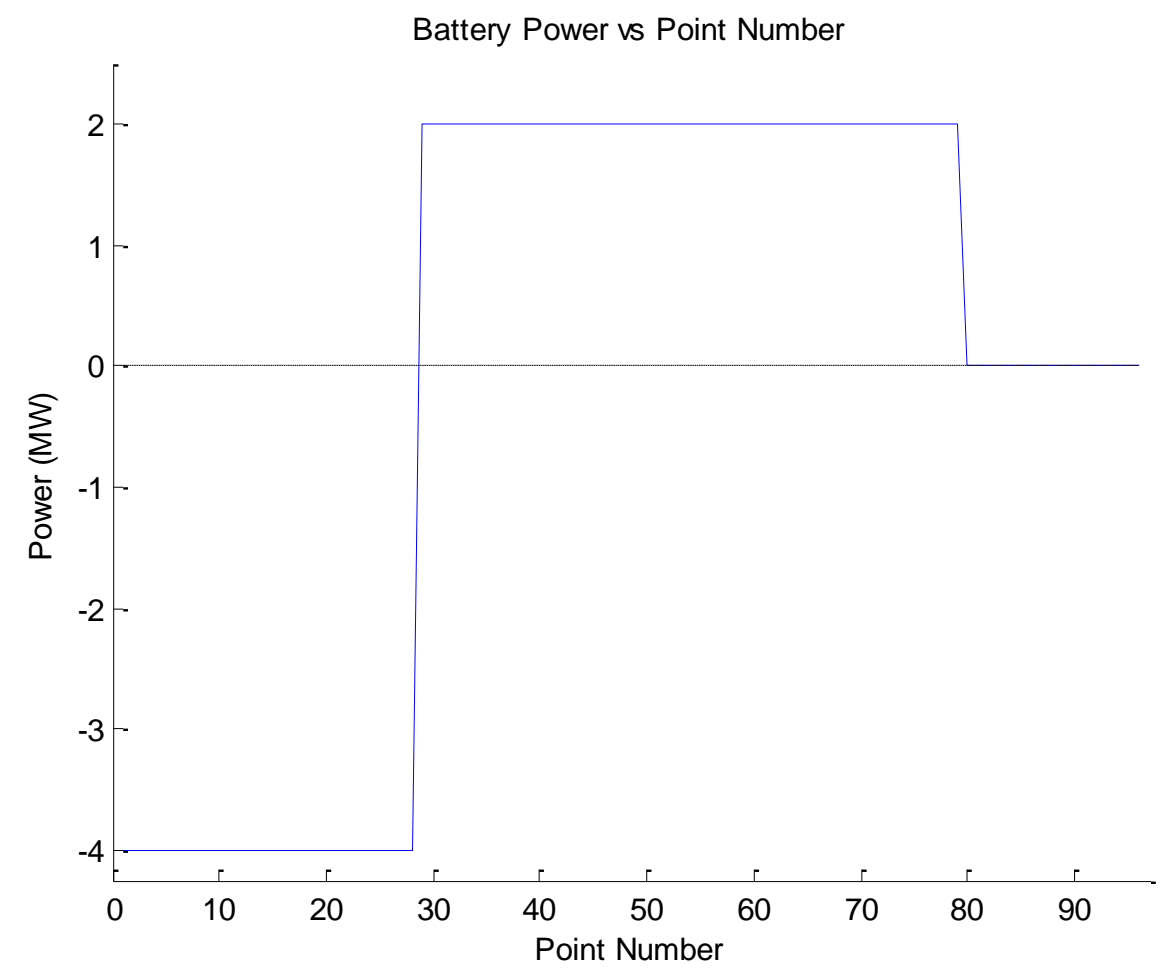

Figure 3.3.3: Simple 14 Hour Discharge Profile. 




Figure 3.3.4: Simple 14 Hour Discharge Profile with Area.

When determining which battery discharge curve yields greatest profits, pricing data from 1/23/2013 was used, while power data from 1/23/2010 was used. This was done due to a lack of data availability. This same data was used for each of the three cases, 7 hour discharge at $4 \mathrm{MW}, 14$ hour discharge at $2 \mathrm{MW}$, and load-following based on equations 3.2.1 and 3.2.2.

Figure 3.3.5 shows the first case, a 7 hour charge, idle period, 7 hour discharge, and then final idle period to end the day. The battery's profile is shown as the green curve in the figure. Included in the figures below are the predicted demand, the actual demand, the battery power, the net demand, and the target power, p0. The first curve to look at in this plot should be the net demand (magenta), as leveling the load is the priority for this portion of the algorithm. 
Unfortunately, it is only flat during the times which the battery is idle. When the battery is charging, the net load is increased to nearly $6 \mathrm{MW}$, when it is discharging the load is decreased to less than -2 MW. The goal was for the net demand to be equal to $\mathrm{p} 0$ for as much of the day as possible, but clearly, this profile fails at doing just that. Though the profile performs poorly, in terms of leveling load, the profit generated using said price data turned out to be 1,373 dollars. If an $\mathrm{NaS}$ system ran this profile every day and earned the same profit throughout the expected lifetime of about 10 years, the profit would amount to just over 5 million dollars. It is important to note that estimate comes as a back of the envelope calculation, disregarding inflation rate, discount rate, and maintenance needed for the system.

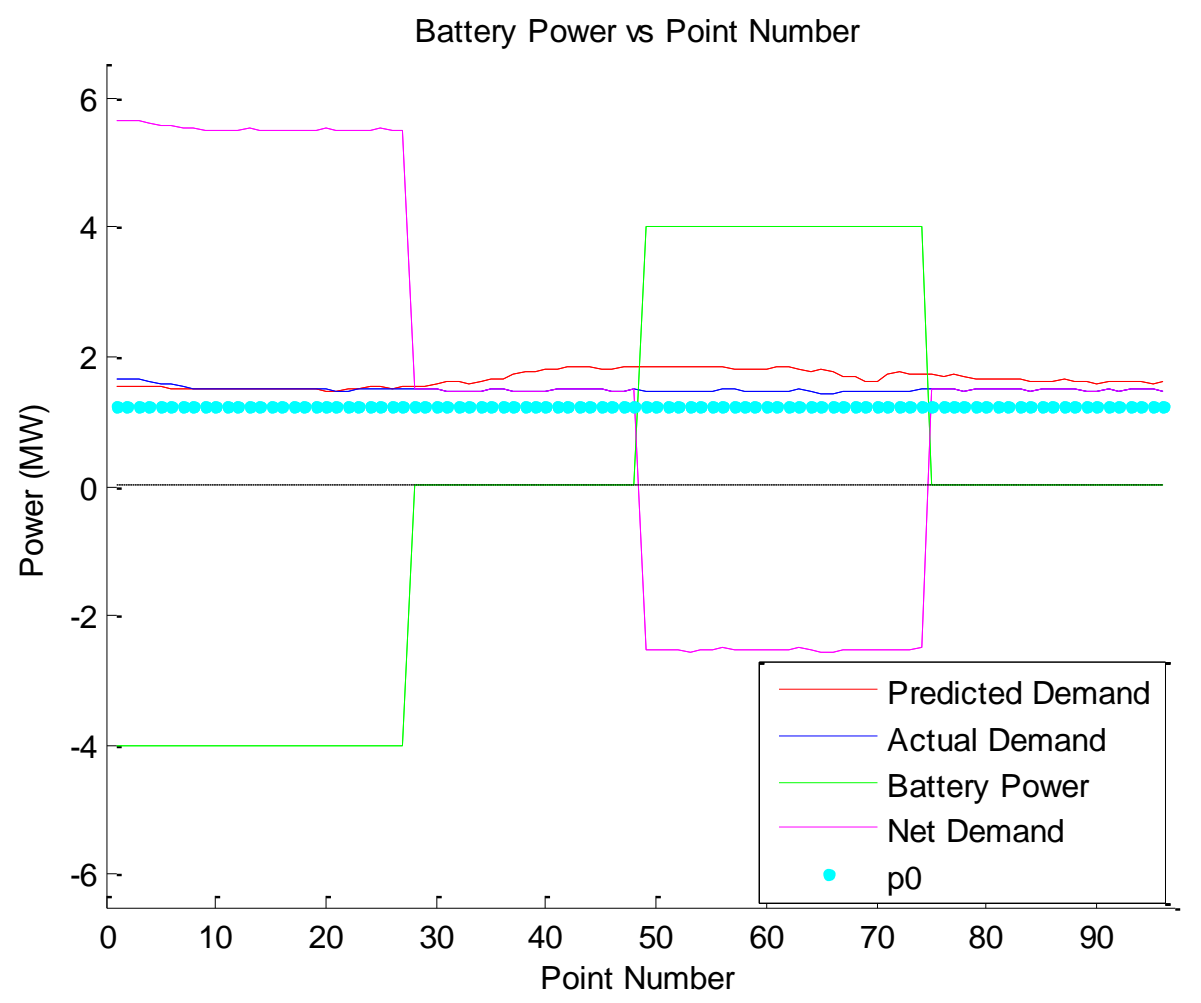

Figure 3.3.5: Simple 7 Hour Discharge Profile (1/23/2010). 
Figure 3.3.6 shows the second case, a 7 hour charge, 14 hour discharge profile. Similar to the first case, the net demand curve is rarely flat throughout the whole day. In fact, the only time that it is close to $\mathrm{p} 0$ is once the battery has reached its minimum energy and is awaiting the start of a new day to recharge. Unlike the first case, the minimum net power is just less than $0 \mathrm{MW}$, about 2 MW more than the 7 hour discharge profile. Knowing this profile does not accomplish load-leveling very well either, the profit that it yields should be discovered. Using the same profit equation found above, this profile brings in 715.3 dollars, nearly half that of the first case.

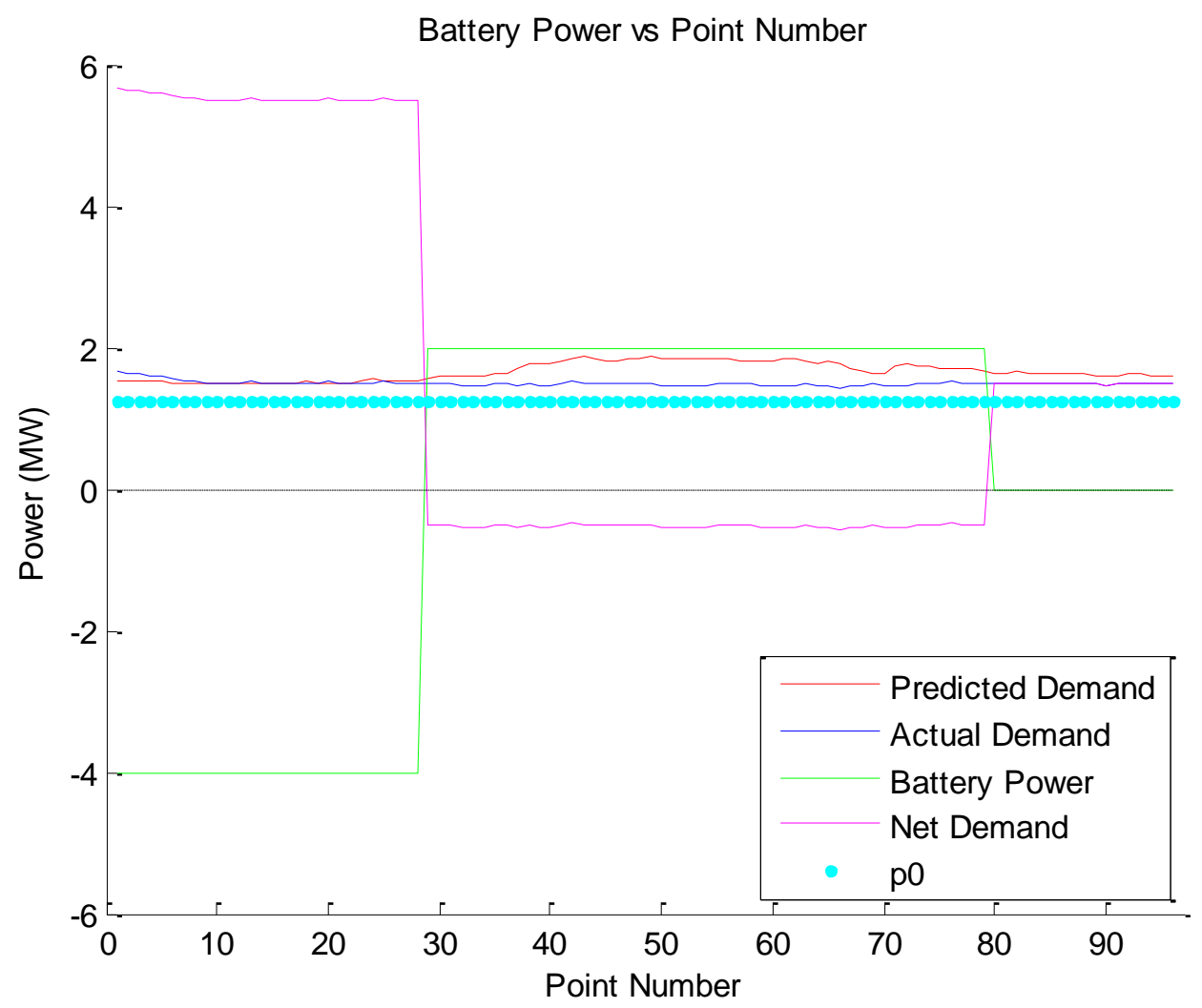

Figure 3.3.6: Simple 14 Hour Discharge Profile (1/23/2010).

The third and last case to observe is the profile utilizing the load-leveling scheme presented in Figure 3.2.5. As with the first two cases, the battery starts out at $10 \%$ state of 
charge and draws power at $4 \mathrm{MW}$ for nearly 7 hours. Once the battery is full, the loadfollowing, which uses predicted power points, kicks in. What we find is because the Hitachi load is so small compared to the rated power of the battery and the target net demand is close to the predicted demand, the battery outputs little energy into the grid. The highest battery output power is just about $0.5 \mathrm{MW}$. The resulting net power demand curve is very close to flat for all peak hours and is not far from our target power value. This means that the load-leveling algorithm successfully reduces strain on the grid after the morning charge. If the program is truly going to provide a service so that the net load is flat all day long, the battery must charge at a slower rate with this data. Unfortunately, the battery also ends the day with unused energy, meaning that a profit loss can be expected. The calculated profit for this case was found to be 818.82 dollars. This scenario's one redemption, financially, is that being close to full at the end of one day means not having to charge the next day. Not needing to charge the next day means the profit will be positive (the next day) as long as the battery discharges during a time when the price of energy is higher than it was when the battery was first charged. Though this is a positive, the fact that it took two days to yield a positive or zero profit is still disappointing. One goal of developing a control scheme for $\mathrm{NaS}$ battery systems was to make them profitable to the point that the private sector would begin wide-scale implementation to compliment renewables. Yielding a negative to little profit by utilizing an algorithm is no way to catch an investor's eye (not in a good way, anyway). Table 3.3.1 summarizes the profits calculated for each of the three cases, using power data from 1/23/2010 and price data from 1/23/2013. 


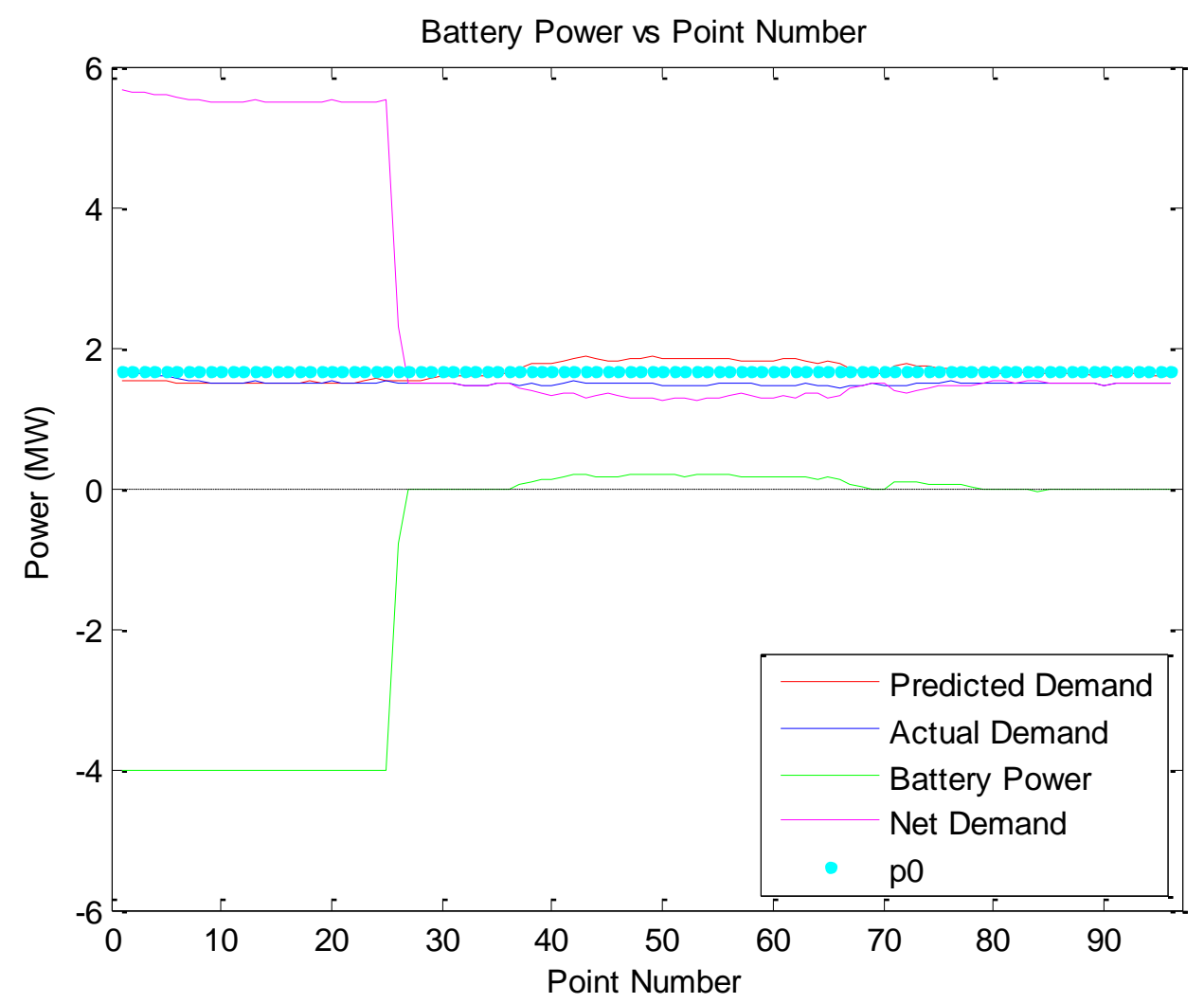

Figure 3.3.7: Load Following Profile (1/23/2010) Hitachi.

\begin{tabular}{|l|c|}
\hline \multicolumn{1}{|c|}{ Discharge Profile } & Profit for $\mathbf{1 / 2 3 / 2 0 1 0}(\mathbf{\$})$ \\
\hline 7 Hour Discharge & 1,373 \\
\hline 14 Hour Discharge & 715.3 \\
\hline Load Following & -818.82 \\
\hline
\end{tabular}

Table 3.3.1: Simple and Load-Following Discharge Profile Profits

The load-following cases was unprofitable due to the battery's net charge gained being greater than zero. Of course, this was a result of Hitachi generating a demand that was smaller than the battery's power and energy ratings. Therefore, should the load at hand be a transformer rather than an individual consumer, the load-following case should produce very different results. To demonstrate this, transformer data from June $14^{\text {th }}, 2014$ in San Jose, Califonia was 
used. As with the cases above, the pricing data was from 1/23/2013. Figure 3.3.8 illustrates the higher the load the battery is helping the grid to reduce, the more involved the battery must be. In other words, loads with larger peaks require greater discharge from the battery if $\mathrm{p} 0$ is to be maintained, which results in a smaller amount of energy stored in the battery at the end of the day. When the systems discharge more energy into the grid during peak hours, the more profitable the system becomes. For the data shown in the figure below, the profit was calculated to be -100.77 dollars. This scenario yields 700 dollars more than the previous load-following case with only a small visible increase in battery power, based on Figure 3.3.8. If the load were closer to $10 \mathrm{MW}$ peak, this algorithm could produce positive profits comparable to those in the simple discharge profiles.

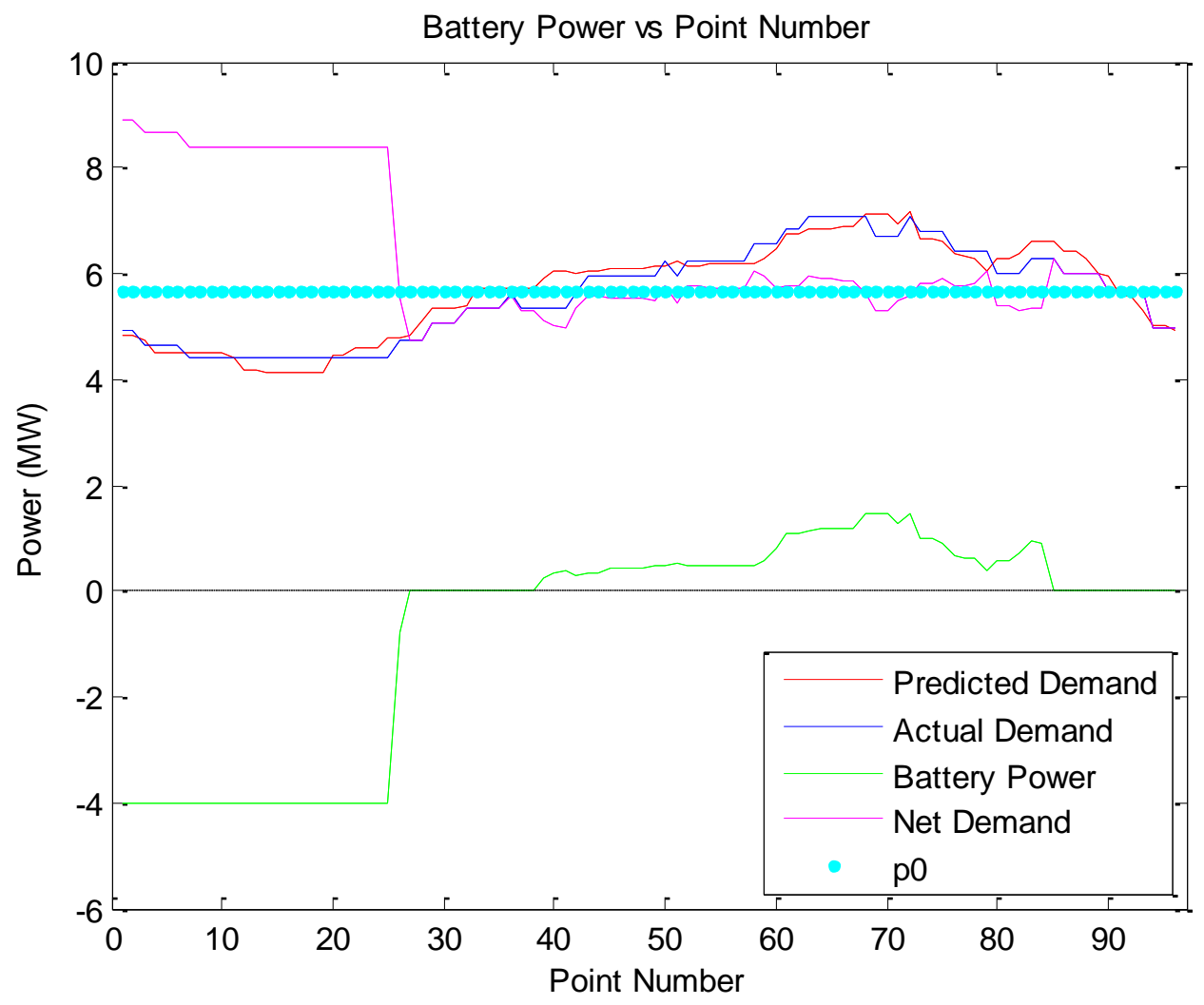

Figure 3.3.8: Load Following Profile (6/24/2014) Transformer. 
Another factor to analyze when determining profit from discharge profiles is heater power. The batteries, because of their composition, must be kept near 300 degrees Celsius. During discharge, the cells are naturally heated, but during charge and idle time, the battery needs to be kept warm with an electric heater. This heater has a rated power of $150 \mathrm{~kW}$ or 0.150 MW. Especially in cases where the load is comparable to the power rating of the battery system, this draw just to keep the battery operational nearly wipes out profits. When the load is much greater than the rating of the battery, the system will be discharging at higher rates for longer times, keeping the cells warm and reducing time the heater spends on.

Ideally, we would want to completely judge the success of the full four-tiered algorithm by determining the profit generated by the battery's profile over lengths of time, but due to data limitations, that analysis is not conducted here. It is important to note though, even if the proposed four-tiered control scheme yields less profit than the other profiles, the services that it provides may have greater intrinsic value. When determining what control your NaS BESS should employ, this must be taken into consideration.

\section{Section 3.4: Suggestions for an Improved Algorithm}

As mentioned in Section 3.4, Dr. Iba's power predicting formulas had to be edited to fit the data provided by PG\&E. On one hand, this could possibly throw off the accuracy of the prediction, but it raises the question, what other alterations can be made to further improve that same formula's accuracy. Terms included in the original equation make use of data from one day ago, two days ago, one week ago, and one year ago. Each of these has a different weight, with the more heavily weighted terms being the ones that occurred most recently. A next step for improving the load-following portion of this proposed algorithm would be to analyze the 
effect of adding a term to include the very last data point before the target data point. To better illustrate this concept, the new power prediction formula would appear as:

$$
\widetilde{P_{1, j}}=w_{1} S_{0, j-1}+w_{2} S_{1, j}+w_{3} S_{2, j}+w_{4} S_{7, j}+g w_{5} S_{365, j}
$$

Each term in this equation is exactly as explained in the Literature Review portion of this paper (see equation 2.2.3) with the exception of $S_{0, j-1}$, which represents the temperature and power adjusted data point taken last. Since the data being used in this analysis is 15 minute data, that term looks at the power demanded 15 minutes ago. Knowing the point you are trying to predict and the point taken 15 minutes ago have the same mean temperature for the day, there is no correction that needs to be done to the previous point, meaning:

$$
S_{0, j-1}=\mathrm{P}_{\mathrm{i},-1 \mathrm{j}}
$$

The next change that could be implemented to the power predicting formula would be to completely remove the term with the smallest coefficient, according to Dr. Iba's research. Though we do not know for certain that the weight of the newest term added to the power predicting formula, $S_{0, j-1}$ would be larger than that of the adjusted power from 7 days ago, it certainly seems reasonable that something happening moments ago would better correlate to what is about to happen rather than what happened one week ago. Making this change would alter equation 3.4.1 such that it would become:

$$
\widetilde{P_{1, j}}=w_{1} S_{0, j-1}+w_{2} S_{1, j}+w_{3} S_{2, j}+g w_{5} S_{365, j}
$$


where the first $\mathrm{S}$ term is described by equation 3.3.2 and the rest of the terms are defined in equation 2.2.3.

The next change that should be considered when developing a control algorithm for a battery system should be how the temperature coefficient is determined. Dr. Iba describes his process in his 2008 paper about his system, indicating the sensitivity should be seasonal. From the results in attempting to find coefficients relevant to San Jose, California, it seems there is room for improvement. My suggestion is to create different sensitivities based on temperature range rather than season. For example, if the mean temperature in a given area ranges from 0 to 40 degrees Celsius, the range should be divided into two groups. With these two groups, from 0 to 20 degrees Celsius and 21 to 40 degrees Celsius, two regressions can be done and the measure of fit can be found. Next, the same range, 0 to 40 degrees Celsius, should be broken into three groups, running three regressions and analyzing the measures of fit. This process should be repeated (up to, perhaps, 6 different groupings) and the results with the best overall measures of fit should be used. 


\section{Chapter 4 -- Rate Structure}

At this point in time, in the energy sector, grid-scale storage systems do not have their own pricing structure. This is easy to understand, as comparatively, not many of these systems are in place. As more and more are integrated into the grid, increased energy arbitrage leading to less stable net demand curves may necessitate the creation of a new rate structure. To clarify, the goal of this paper is to develop an algorithm which provides valuable services to utilities with storage owners being compensated for their services. One of the main outcomes of the implementation of energy storage systems should be a level net demand. In the two simple charge and discharge profiles presented in Section 3.4, operators generated the most profit by buying cheap energy and selling during peak hours, but they actually created a more erratic net power demand for the utility to provide. Ultimately, grid-scale storage systems should reduce peak power needed from the grid, reducing dependence on dirty coal-fired and gas power and peaker plants. Raising net power demand or making it less level ups the strain on the grid and additional carbon emissions to our environment. To combat this, a rate structure must be developed to promote the assisting of utilities in powering loads with level net demand while owners still profit for their efforts.

\section{Section 4.1: Rate Structures for Commercial Clients}

The greatest boom in implementation of grid-scale energy storage is likely to come in the renewable sector. It is well-known that reducing the power variability associated with these technologies will make them more profitable. In cases where storage systems are added to renewable systems, it makes sense not to alter rate structure for consumers wildly, but to make them more profitable overall. When the implementation of a technology is desired on a grand scale, it is typically done in one of two ways. The first would be through legal action. For 
example, mandating that $33 \%$ of California's energy be generated by a renewable resource has driven activity in that sector to record highs. The second method of inspiring further installation of energy storage systems is to make them more profitable. If the government requires utilities to purchase a certain percentage of power from green energy suppliers, that alone encourages suppliers and utilities to take advantage of storage to make the $33 \%$ goal more attainable, but increasing payouts to those utilizing the technology will get consumers and developers who are looking to make an entrance into the sector more involved as well.

In the case of commercial renewable energy providers, they are solely providers. This means net metering is not involved and any power produced falls into a time of production or tiered structure directly. The question is which of the two better suits both the utilities and the energy storage owners. To get a better idea, the effect of adding an energy storage system to a renewable power plant (solar in this case) should be considered. Figure 4.1.1 shows the total available power output via MPPT for a sample day, the clipped power output, and the proposed system output with a storage system, such as a sodium sulfur battery, integrated with the panels. Clipping is the process of changing operating point along a group of solar panel's IV curve. This is done to prevent the available power from exceeding the limits of the inverter. When this is done, energy, represented by shading below the blue curve and above the red curve, is lost (more accurately, never created). Rather than lose megawatt hours due to inverter size constraints, this energy could be diverted to the storage unit. In addition, since utilities desire power production that is constant and predictable, energy produced during the early hours in a day can also be fed into storage for later use. During peak hours, the solar and battery facility has the ability to send constant power to the grid, as shown by the black curve in the figure below. 


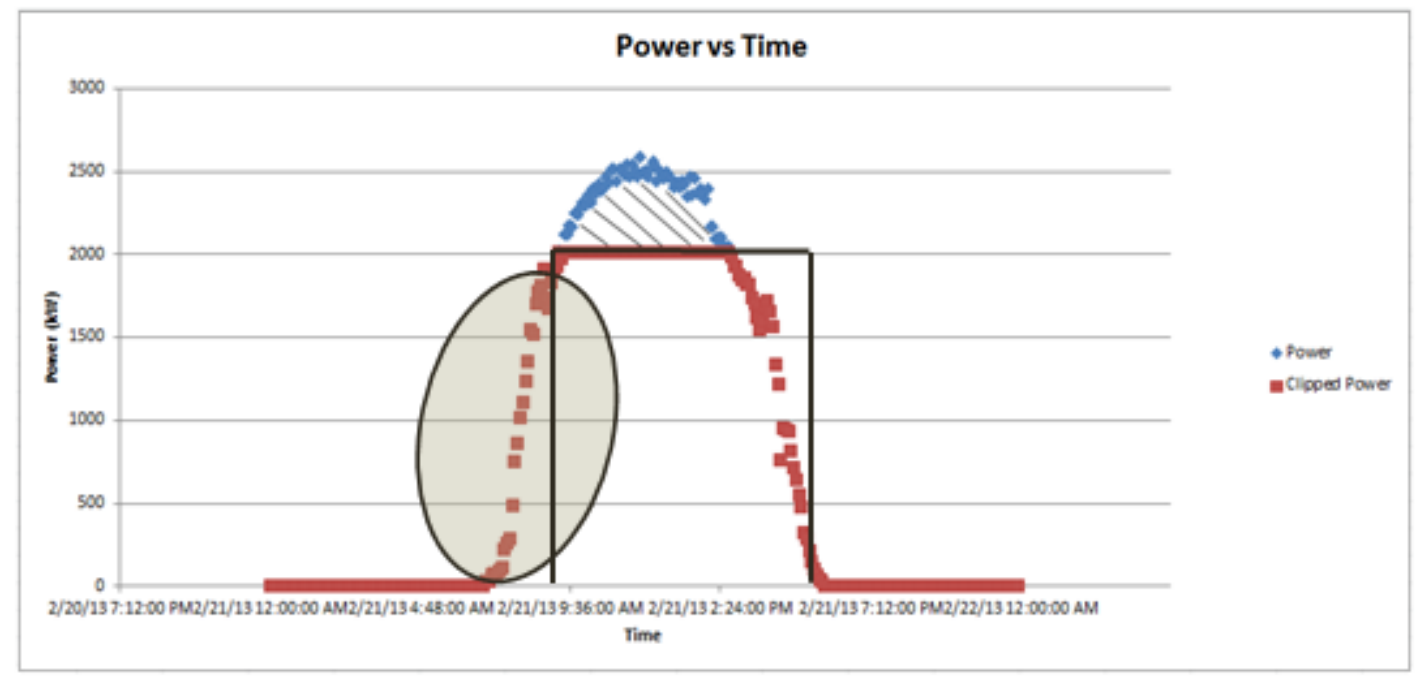

Figure 4.1.1: Solar Power Integrated with Battery Storage Technology.

This power output is more valuable and the Power Purchasing Agreement (PPA) between the provider and utility should reflect that. The reason for this power holding more value is because it is predictable, constant, and is generated by renewables, meaning it has no negative effect on load-leveling, as we saw in Section 3.4. The simplest suggested rate structure for commercial renewable power plants with energy storage should be based on a time of production schedule, so that commercial owners are properly incentivized to integrate storage solutions. An example of a time of production rate structure before and after adding energy storage to a renewable energy facility would be:

\begin{tabular}{|l|c|c|c|c|}
\cline { 2 - 5 } \multicolumn{1}{c|}{} & Summer & Winter & Summer & Winter \\
\hline $\begin{array}{l}\text { Time of } \\
\text { Production }\end{array}$ & May 1 - October 31 & November 1 - April 30 & May 1 - October 31 & November 1 - April 30 \\
\hline Peak & $\$ 200$ & $\$ 175$ & $\$ 300$ & $\$ 250$ \\
\hline Off-Peak & $\$ 120$ & $\$ 80$ & $\$ 150$ & $\$ 120$ \\
\hline \multicolumn{2}{r|}{ Before Adding Storage } & \multicolumn{2}{c|}{ After Adding Storage } \\
\cline { 2 - 5 }
\end{tabular}

Table 4.1.1: Commercial Time of Production Schedule. 
Another possible rate structure for facilities producer power with renewable and storage technology would be a tier system that counts the number of megawatt hours pushed onto the grid during peak and off-peak times. Table 4.1.2 illustrates this concept further. If peak hours are defined as $12 \mathrm{pm}-8 \mathrm{pm}$, the power provider stands to make even more money with an integrated renewable and storage facility because the energy that is normally produced during off-peak hours can be stored and then discharged during peak hours. Essentially, this becomes commercial renewable energy arbitrage, which benefits the producer because they profit, the utility company because they get reliable and constant power, and the environment because the energy produced to support the grid is from renewables.

\begin{tabular}{|l|c|c|c|c|c|c|}
\cline { 2 - 7 } \multicolumn{1}{c|}{} & \multicolumn{2}{c|}{$\begin{array}{c}\text { Energy Range } \\
\text { (MWh) }\end{array}$} & $\begin{array}{c}\text { Price per MWh } \\
\text { (\$) }\end{array}$ & \multicolumn{2}{c|}{$\begin{array}{c}\text { Energy Range } \\
\text { (MWh) }\end{array}$} & $\begin{array}{c}\text { Price per MWh } \\
\text { (\$) }\end{array}$ \\
\hline Tier 1 & 0 & 100 & 150 & 0 & 100 & 125 \\
\hline Tier 2 & 101 & 200 & 300 & 101 & 200 & 250 \\
\hline Tier 3 & 201 & Above & 400 & 201 & Above & 350 \\
\hline
\end{tabular}

Table 4.1.2: Commercial Tier Rate Structure.

\section{Section 4.2: Rate Structures for Residential Clients}

Residential renewable energy providers should have a different rate structure because they are consumers in addition to being providers. Many homes with solar panels are on one of two rate structures, a time of use schedule or a tier structure, both of which do fall under net metering. An example of a time of use schedule is the following:

\begin{tabular}{|l|c|c|}
\multicolumn{1}{c|}{} & Summer & Winter \\
\hline Time of Use & May 1 - October 31 & November 1 - April 30 \\
\hline Peak & $\$ 0.25$ & $\$ 0.20$ \\
\hline Off-Peak & $\$ 0.10$ & $\$ 0.08$ \\
\hline
\end{tabular}

Table 4.2.1: Residential Time of Use Schedule. 
For every kilowatt hour that is used during peak hours from May $1^{\text {st }}$ to October $31^{\text {st }}$, the consumer pays 25 cents. From Novermber1st to April $30^{\text {th }}$, that same kilowatt used during peak time costs the consumer 20 cents. During off-peak times in the summer, the consumer pays 10 cents for every kilowatt hour used, while in the winter during the same hours of the say, it costs 8 cents. In this rate structure there are four defined time periods when the consumer can use energy. Similarly, the exact same four time periods exist for when the consumer can send energy back to the grid via their solar panels. When energy is sent back to the grid, the net number of kilowatt hours used decreases. At the end of every month, the net number of kilowatt hours is calculated, multiplied by the time period's price, and summed together. Clearly, you will not have winter and summer energy use in the same billing cycle, based on the season definitions in Table 4.2.1, so really, only two time periods in which you can use (or generate) energy exist. See equation 4.2.1 for clarification.

$$
\text { Cost }=\left(E_{\text {netPeak }}\right)\left(\text { Price }_{\text {Peak per kWh }}\right)+\left(E_{\text {netoff-Peak }}\right)\left(\text { Price }_{\text {Off-Peak per kWh }}\right)[\text { Dollars }]
$$

Table 4.2.2 illustrates how a tier structure would work for homes utilizing both solar and energy storage technology. Rather than deal with what time of day the energy was used or generated, all that matters is the total used at the end of the month. The user "climbs the ladder" in this rate structure, paying a cost equal to the number of kilowatt hours consumed in each tier multiplied the price per kilowatt hour for that tier, summed together. For example, if a customer consumes $1100 \mathrm{kWh}$ in a month, based on the data in Table 4.1.4, their monthly cost would be: 


$$
\text { Monthly Cost }=(500)(0.10)+(499)(0.20)+(99)(0.40)=\$ 189.4
$$

\begin{tabular}{|l|c|c|c|}
\cline { 2 - 4 } \multicolumn{1}{c|}{} & \multicolumn{2}{c|}{ Energy Range (kWh) } & Price per kWh (\$) \\
\hline Tier $\mathbf{1}$ & 0 & 500 & 0.10 \\
\hline Tier $\mathbf{2}$ & 501 & 1000 & 0.20 \\
\hline Tier 3 & 1001 & Above & 0.40 \\
\hline
\end{tabular}

Table 4.2.2: Residential Tier Rate Structure.

When a home has solar panels and is a part of the net energy metering system, the number of kilowatt hours put back onto the grid helps the consumer "climb back down the ladder." If the same customer generates $600 \mathrm{kWh}$ in the same month they use $1100 \mathrm{kWh}$, the net usage is 500 $\mathrm{kWh}$, meaning the new monthly total is:

$$
\text { Monthly Cost }=(500)(0.10)=\$ 50
$$

In this structure, there is no additional benefit to employing battery storage, as energy arbitrage cannot be committed. To incentivize residential consumers, one of two things must happen. A time of use schedule must be employed, as that inherently incentivizes consumers, or a tier structure where all energy coming from solar or battery is paid for at the highest tier's price.

Rates for those with storage but without any renewable production should not receive the same benefits as those who are grouping their storage with renewables, necessarily. As seen in Section 3.4 , profit can be made simply by charging a battery during off-peak hours and discharging during peak hours. One method of preventing this would be by implementing a tier system. Ultimately, the goal of developing new rate structure is not to prevent customers from committing energy arbitrage, but to receive a service, such as load-leveling. When an 
interconnection request is put in for a storage system without an accompanying solar or wind component, there should be a legal agreement that energy arbitrage is allowed as long as the net power demand at the local transformer is within a certain tolerance at all times. For example, Figures 3.3.5 and 3.3.6 enlightened us to the effect of charging at a power level similar to that of the load. In each of those cases, the net power demand by the load increased far above the target level, p0. Should the system be charging and the net power demand does not exceed p0 by, say $5 \%$, the consumer is allowed to charge at a low cost. The same condition would apply during peak hours for discharge. Discharging a storage system, such as a battery, only helps reduce strain on the grid if the net power demand is leveled, so as long as the net power demand is within a certain percentage of p0, discharge should be allowed. Such a rate structure would benefit both parties, the consumer and the utility. 


\section{Chapter 5 -- Conclusion}

This paper began by discussing how the electric system works on a high level; how energy is generated, transmitted and supplied to customers. Shortcomings of the system were raised and grid-scale energy storage was mentioned as a solution to some of those issues. The various types of energy storage technologies that are mature enough to be implemented on a grid-scale were laid out. From there, the benefits and drawbacks of each system were presented. Some of the most valuable benefits of storage technologies are the ability to store massive amounts of energy, the ability to store energy for a long period of time, high energy and power density, long lifetime and cyclability, and low marginal and capital cost. The possible services to be provided by storage systems were then classified as either power or energy applications. Knowing where Sodium Sulfur batteries fit into the realm of energy storage, the task of determining how to use a 4 MW, 28 MWh battery owned by PG\&E was introduced. The services that seemed most useful to a utility company, voltage support, frequency support and load-leveling were selected. Voltage support is frequently needed on distribution lines as voltage sags when a heavy load is present and rises above nominal level during light load situations. In the case of a heavy load and a sagging voltage, sending reactive power to the line will boost the voltage back to nominal level. Generally, this is done with capacitor banks. The downfall of capacitor banks are they provide a fixed amount of reactive power, whereas a battery facility can employ power electronics to provide a variable amount of reactive power to correct voltage levels. Correcting voltage levels prevents the damage of equipment and loss of service to numerous consumers. Line frequency has even stricter limits in terms of percentage variation that is allowed before damage is done to very expensive machinery, making regulation of it a high priority as well. Load shifting is most likely the best way to remove expensive peaker plants from a utility company's payroll. In addition, it allows for less strain on equipment, 
potentially increasing lifetime. Having targeted these services as ones to provide from the $\mathrm{NaS}$ battery, a literature review was conducted to determine where to begin when developing a control algorithm.

The Yerba Buena battery that was the focus of this thesis has a similar system installed about 100 miles north-east of it that is also owned by PG\&E. Data from this battery told us that the best 24 Hour AC Round-Trip efficiency was recorded when the battery discharged at rated power. In addition, higher efficiencies were measured when there was an idle time before recharging the battery at the end of the day. Both pieces of information were integrated into the control algorithm that was developed for the Yerba Buena battery. A control algorithm from a professor in Japan with a similar NaS system on the university's campus was then investigated. As its intention was to level load, which aligned with my goals for the PG\&E battery, the algorithm was adopted once temperature and term coefficients were adjusted. In chapter 3 , the full control scheme was developed and the load-following portion of it was tested on sample data. The load-leveling result was compared against simple profiles like those from the PG\&E Vacaville-Dixon report and the simple profiles turned out to be more profitable, though they did not level load well. It was found that the load-leveling algorithm produces greater profit when the load in question is about two times greater than the rated power of the storage system. Realizing that simple profiles were profitable without actually leveling load prompted a discussion on rate structure.

For both the owner and the utility company to be pleased with the operation of the battery, the utility must have had a service conducted for it (voltage support, frequency support, load-leveling) and the owner must yield a profit (or credit to their account if they are a residential consumer). Rate structures that provided such a result include either a time of production 
schedule or tier and time of production combination for commercial producers who integrate renewables and storage, a time of use schedule for residential customers with renewables and storage, and a partial time of use schedule for residential customers with only an energy storage system.

In order for renewable energy to surpass dirtier energy production methods, energy storage will play a large role. With further investigation into rate structure and quantifying benefits of receiving voltage support and frequency, more light will be shed on actual revenue brought in by systems and payoff schedules. Further research in this area should aim to improve control algorithm with proposed rate structures to learn how to optimize profit. The better the algorithm, the more money the system is responsible for making, the more commercial and residential customers will include the system in their future power plant and home improvement designs. 


\section{References}

[1] Basic Structure of the Electric System. Digital image. The Minute Man. N.p., 29 June 2011. Web. 5 Nov. 2013.

Cummings, Robert W., William Herbsleb, and Sydney Niemeyer. Generator

[2] Governor and Information Settings. Rep. North American Electric Reliability Corporation, 30 Sept. 2010. Web. 29 Nov. 2013.

[3] Kirby, Bredan J. Frequency Regulation Basics and Trends. Rep. Oak Ridge National Laboratory, 2004. Web. 29 Nov. 2013.

[4] Koritarov, V. (2013, September 3). Grid-Scale Energy Storage. PSERC Webinar.

Hoshino, and Wada. "Sodium-sulfur Battery. - HITACHI LTD." Free Patents Online. N.p., n.d. Web. 17 Oct. 2013.

Rastler, D. Electricity Energy Storage Technology Options A White Paper Primer

[6] on Applications, Costs, and Benefits. Tech. Electric Power Research Institue, Dec. 2010. Web. 17 Oct. 2013.

Steeley, William, and Robert Schainker. "Vaca-Dixon Sodium-Sulfur Battery Energy Storage System." Dec. 2013.

Iba, K.; Ideta, R.; Suzuki, K., "Analysis and Operational Records of NAS Battery,"

[8] Universities Power Engineering Conference, 2006. UPEC '06. Proceedings of the 41st International, vol.2, no., pp.491,495, 6-8 Sept. 2006

Iba, Kenji, Kouji Tanaka, and Kuniaki Yabe. Operation and Control of NaS

[9] Batteries on a University Campus. Tech. Tokyo Electric Power Co., July 2008. Web. 22 Oct. 2013. 


\section{Appendix A}

\section{Load-following code in Matlab}

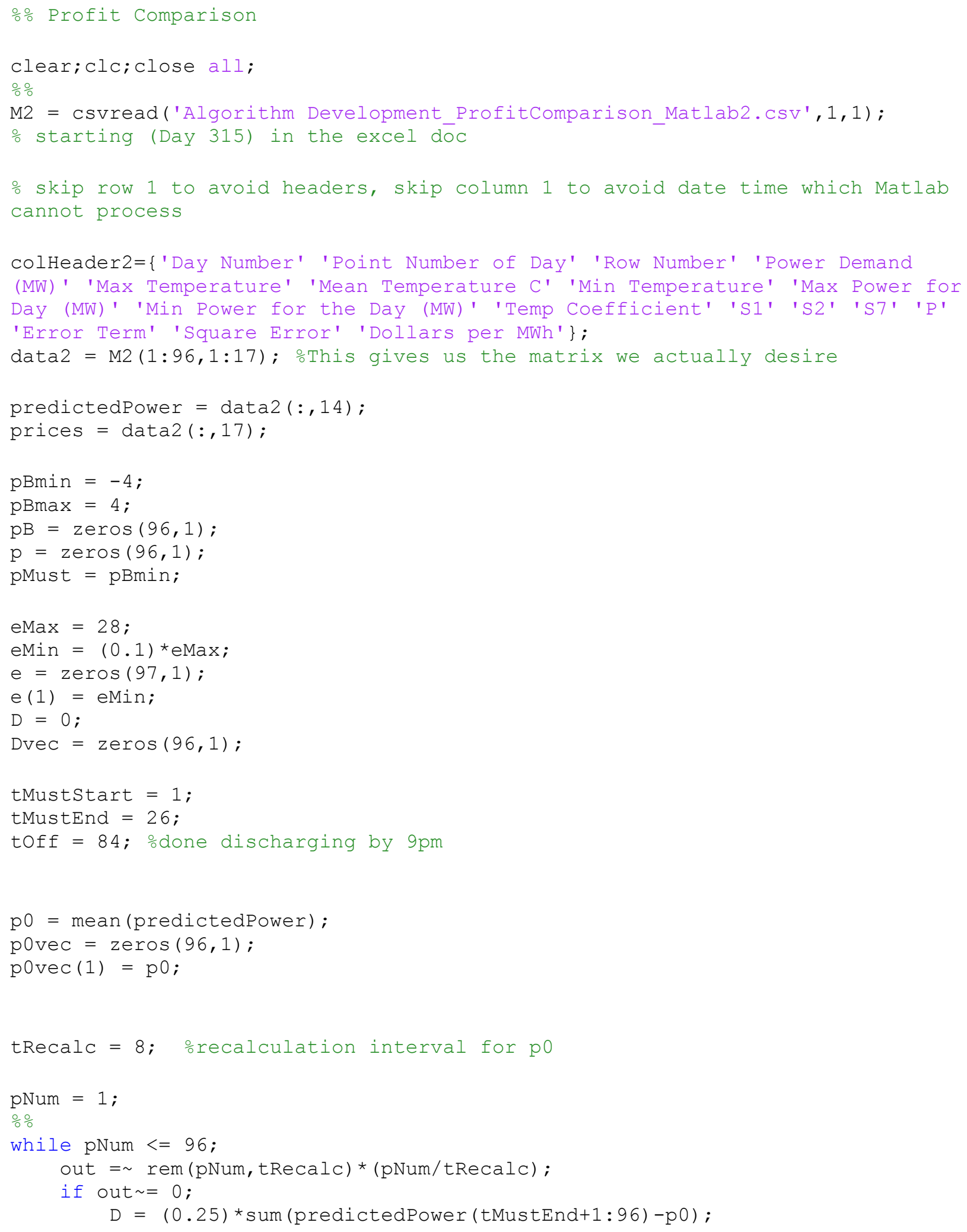




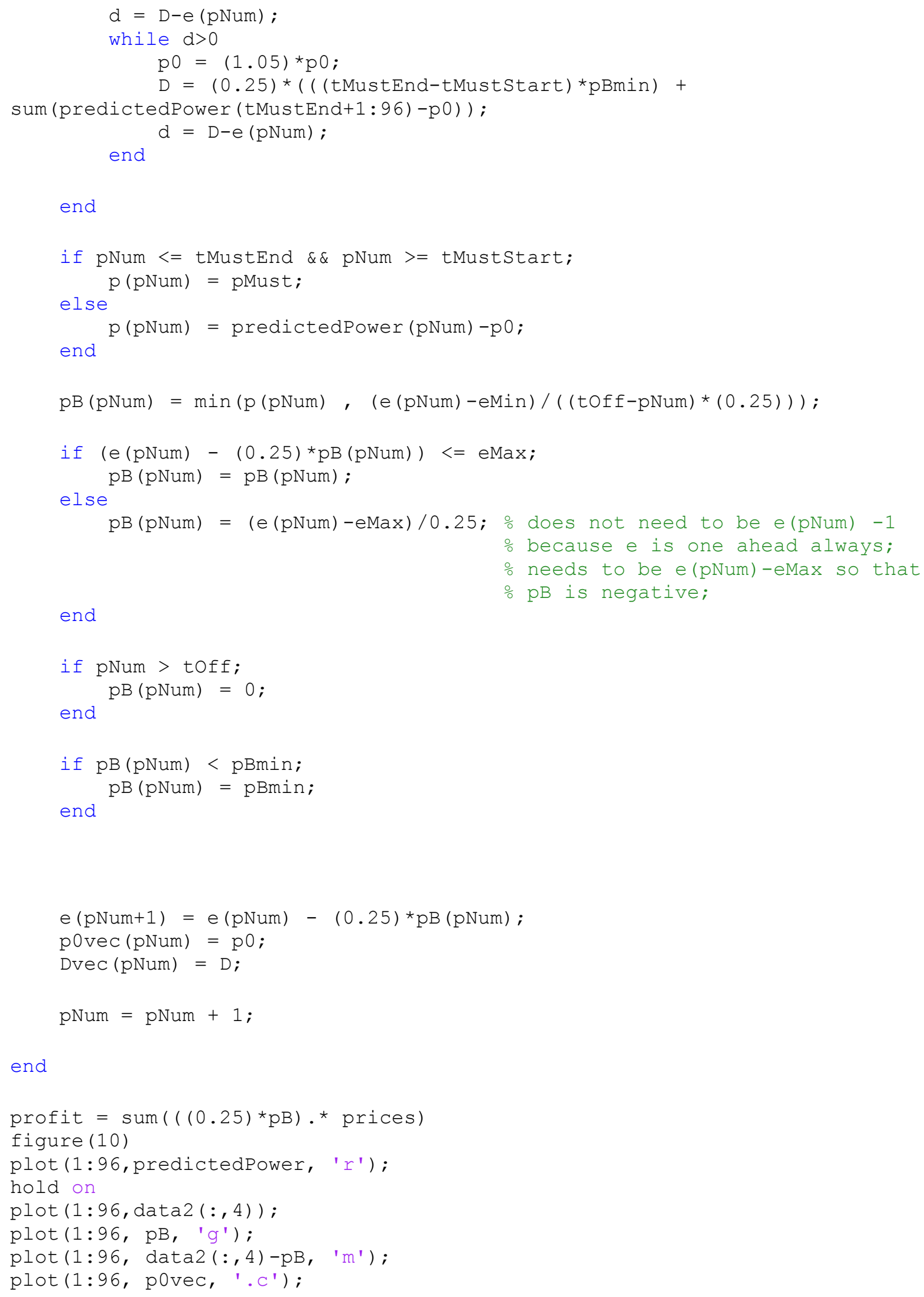




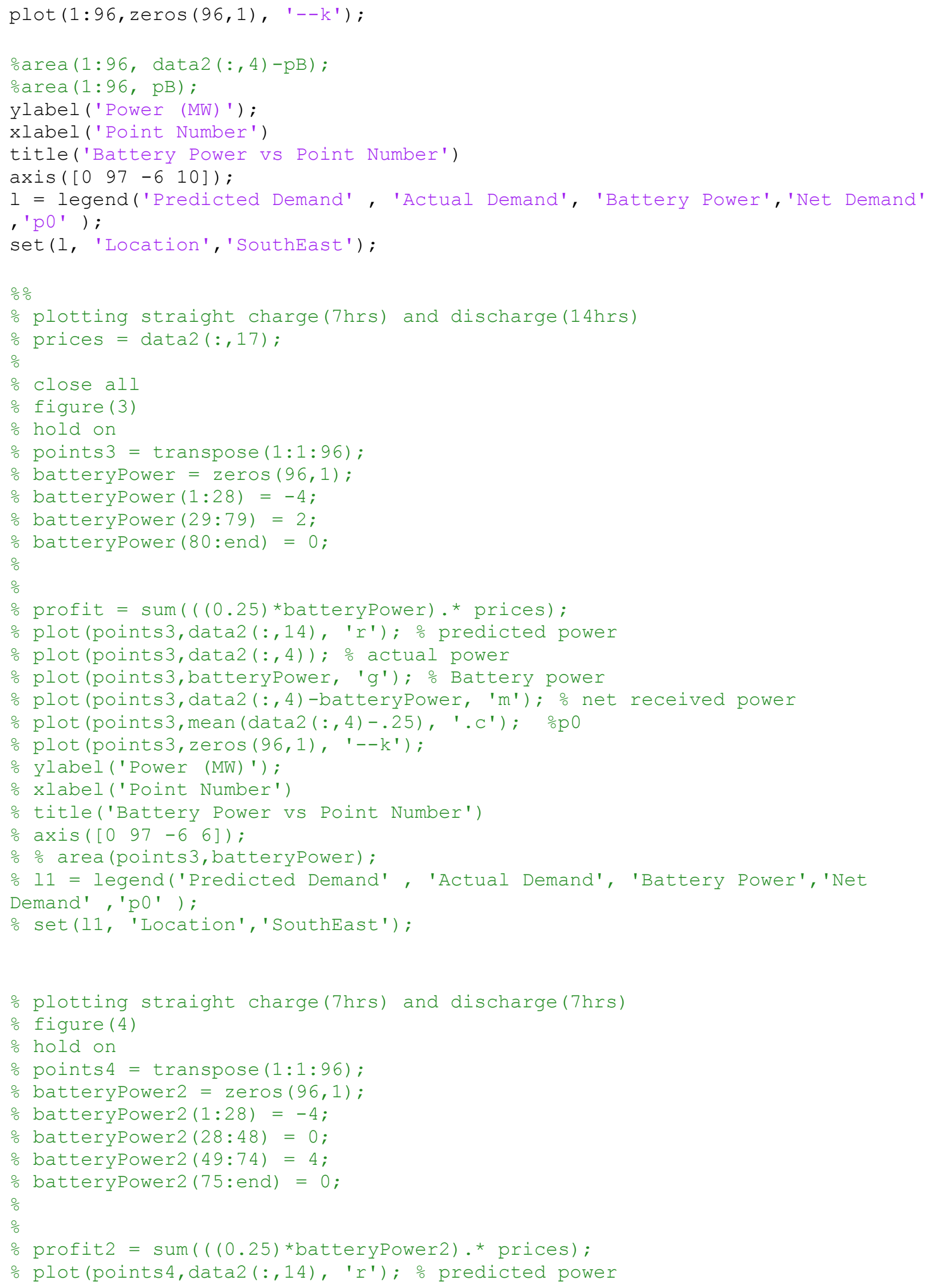




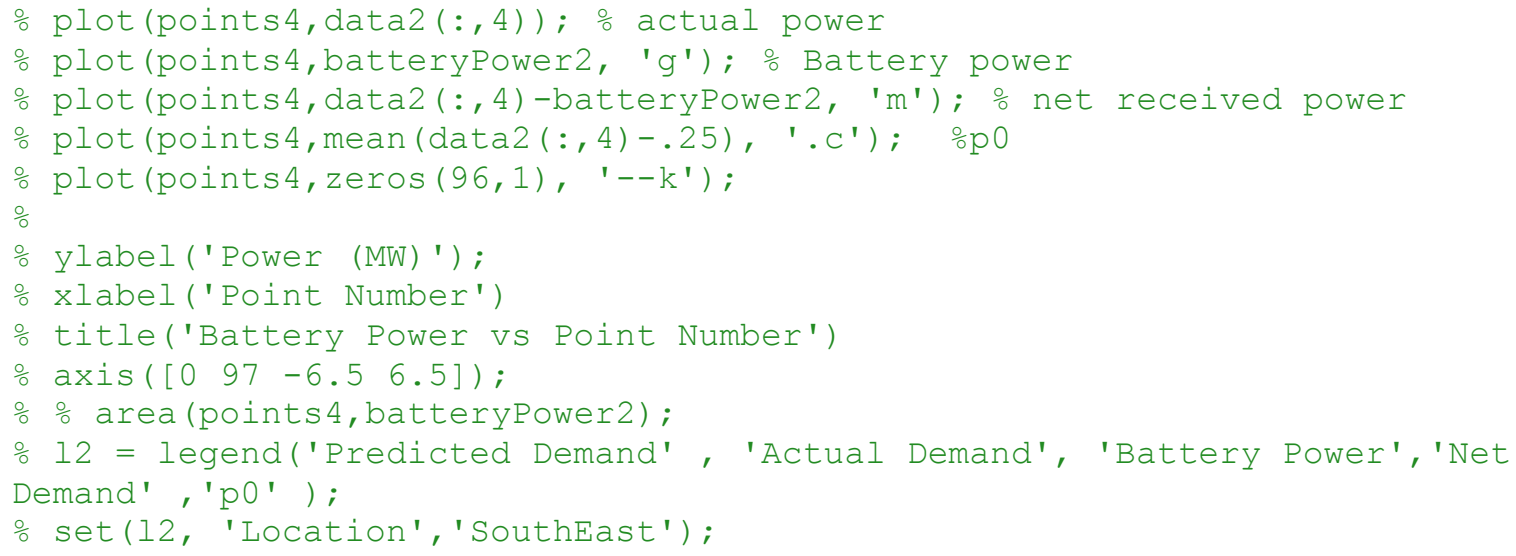

